Aus der Abteilung Gastroenteropathologie

(Prof. Dr. med. L. Füzesi)

im Zentrum Pathologie

der Medizinischen Fakultät der Universität Göttingen

\title{
Unterschiedliche Aktivierung von Signalwegen zur Zellproliferation in mesenchymalen Tumoren des Gastrointestinaltrakts
}

\author{
INAUGURAL-DISSERTATION \\ zur Erlangung des Doktorgrades
}

für Zahnheilkunde

der Medizinischen Fakultät

der Georg-August-Universität zu Göttingen

vorgelegt von

Kristin Köhler

aus

Göttingen

Göttingen 2010 
Dekan: $\quad$ Prof. Dr. med. C. Frömmel

1. Berichterstatter: PD Dr. med. F. Haller

2. Berichterstatter: Prof. Dr. med. D. Doenecke

Tag der mündlichen Prüfung: 14.06.2010 


\section{Inhaltsverzeichnis}

\section{Abkürzungsverzeichnis}

1

1.1

1.1.1

1.1.2

1.1.2.1

1.1.2.2

1.1.3

1.1.4

1.2

1.2.1

1.2.2

1.3

1.4

1.5

2

2.1

2.2

2.3

2.4

2.5

3

3.1

3.2

3.2.1

3.2 .2

3.2 .3

3.2.4

3.2 .5

3.3

3.3.1

Einleitung.

\section{1}

Mesenchymale Tumoren des Gastrointestintrakts. 1

Gastrointestinale Stromatumoren (GIST)........................................ 3

Leiomyogene Tumoren.................................................... 5

Leiomyom......................................................... 6

Leiomyosarkom.................................................................... $\quad 7$

Neurogene Tumoren..................................................................... 8

Fibroblastische Tumoren.................................................................. 9

Typ-III-Rezeptor-Tyrosin-Kinasen........................................... 11

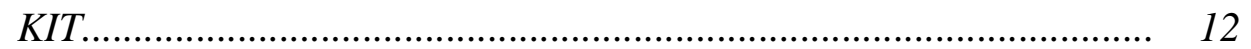

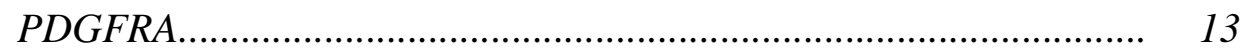

Intrazelluläre Signaltransduktion................................................... 14

Regulation des Zellzyklus.......................................... 16

Fragestellung.................................................... 18

Material und Methoden.......................................................................... 19

Untersuchungsmaterial................................................................... 19

Manueller Tissue Micro Arrayer (TMA)............................................ 19

Immunhistochemie..................................................................... 22

Quantitative Auswertung der immunhistochemischen Färbungen...... 26

Statistik................................................................................. 27

Ergebnisse............................................................................................................ 29

Darstellung des untersuchten Tumorkollektivs................................ 29

Klinisch-pathologische Parameter.................................................... 29

Geschlechterverhältnis................................................................... 29

Altersverteilung der Patienten.......................................................... 30

Tumorgröße............................................................................ 31

Anatomische Lokalisation............................................................ 31

Mitosenanzahl........................................................................... $\quad 34$

Expression der Rezeptor-Tyrosin-Kinasen........................... 35

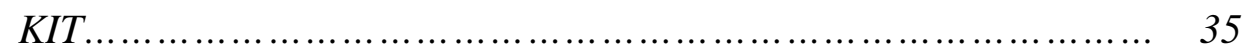


3.3.2

3.4 .

3.4 .1

3.4 .2

3.4 .3

3.5

3.5.1

3.5.2

3.5.3

3.5.4

4

4.1

4.2

4.3

4.4

5

6

7
PDGFRA. . 36

Expression der Signaltransduktions-Proteine 38

SRC. 38

AKT1 38

ERK2 39

Expression der Zellzyklus-Proteine. 41

Cyclin-D1 41

E2F1 42

Cyclin-B1 42

Mib1-Antigen 43

\section{Diskussion.} 46

Vergleich der klinisch-pathologischen Parameter. . 46 Vergleich der KIT- und PDGFRA-Expression.... 49 Vergleich der Expression ausgewählter Signaltransduktions- 51 Proteine.

Vergleich der Expression ausgewählter Zellzyklus-Proteine. 53

Zusammenfassung.. 57

Abbildungs- und Tabellenverzeichnis. 59

Literaturverzeichnis. 


\section{Abkürzungsverzeichnis}

AKT

ALK

AP

CCND1

CDC2

CDK

DNA

E2F1

ERK

EZD

G0-Phase

G1-Phase

G2-Phase

GIST

Grb2

HPFs

IFP

IHC

IMT

JMD v-akt murine thymoma viral oncogene homolog

anaplastic lymphoma kinase

Alkaline Phosphatase

Cyclin-D1

Cyclin-dependent kinase (= CDK1)

cyclin-dependent kinase

Desoxyribonukleinsäure

transcription factor 1

extracellular signal-regulated kinase

extrazelluläre Domäne

Ruhephase des Zellzyklus

$\mathrm{G}$ = gap, 1. Interphase des Zellzyklus

$\mathrm{G}=$ gap, 2. Interphase des Zellzyklus

gastrointestinaler Stromatumor

growth factor receptor-bound protein 2

high-power fields

inflammatorischer fibroider Polyp

Immunhistochemie

inflammatorischer myofibroblastärer Tumor

juxtamembranäre Domäne 
KI

Ki-67

KIT

LM

LMS

LSAB

Mib1

M-Phase

MPNST

mRNA

MYC

PDGF

PDGFR $\beta$

PDGFRA $(\alpha)$

PDGFR-A, -B, -C, -D Isoformen (A, B, C, D) von Ligand PDGF

PI3- Kinase

$\mathrm{RB}$

S100

SCF

SFKs

SFT

Kinase-Insert c-kit, = CD117

Leiomyom

Leiomyosarkom

Labelled (Strept-)Avidin-Biotin-Methode

Mitosephase des Zellzyklus

maligner peripherer Nervenscheidentumor

platelet-derived-growth-factor

phosphatidylinositol-3-OH-Kinase

Retinoblastoma neutral $\mathrm{pH}$ )

Stammzellfaktor

SRC family kinases

solitärer fibröser Tumor antigen identified by monoclonal antibody Ki-67, = Mib1

v-kit Hardy-Zuckerman 4 feline sarcoma viral oncogene homolog, =

Mindbomb homolog 1 (Antikörper gegen Ki-67)

messenger-Ribonukleinsäure (Boten-RNA)

v-myc myelocytomatosis viral oncogene homolog

platelet-derived-growth-factor receptor beta

platelet-derived-growth-factor receptor alpha

“neurologischer” Marker (100 \% soluble in ammonium sulfate at 
S-Phase

SRC

TK1D

TK2D

TMA

TMD

WT-GIST

ZM
Synthesephase des Zellzyklus

cellular homolog of the transforming protein of Rous sarcoma virus

Tyrosin-Kinase-Domäne 1

Tyrosin-Kinase-Domäne 2

Manueller Tissue Micro Arrayer

transmembranäre Domäne

Wildtyp-gastrointestinaler Stromatumor

Zellmembran 


\section{Einleitung}

\subsection{Mesenchymale Tumoren des Gastrointestinaltrakts}

$\mathrm{Zu}$ den mesenchymalen Tumoren des Gastrointestinaltrakts gehören die gastrointestinalen Stromatumoren (GIST) sowie die Tumoren leiomyogenen, neurogenen und fibroblastischen Ursprungs (Tabelle 1.1/1.).

Während bis Ende der 70er Jahre grundsätzlich eine überwiegend leiomyogene Herkunft der mesenchymalen Tumoren des Gastrointestinaltrakts angenommen wurde, zeigte sich durch Verwendung ultrastruktureller und zunehmend immunhistochemischer Untersuchungsmethoden in den 1980er-Jahren, dass viele der gastrointestinalen mesenchymalen Tumoren keine echte myogene Differenzierung besitzen.

Heute ist es möglich, die unterschiedlichen Entitäten des Gastrointestinaltraktes aufgrund histomorphologischer, immunhistochemischer, klinischer und teils molekulargenetischer Charakteristika diagnostisch besser aufzutrennen. Diese Differenzierung hat große prognostische und therapeutische Bedeutung, da die Tumoren kein uniformes biologisches Verhalten aufweisen und teilweise eine differente therapeutische Behandlung erfordern.

Im Folgenden werden zunächst alle mesenchymalen Tumoren des Gastrointestinaltrakts beschrieben und voneinander abgegrenzt. Dabei wird auf die drei Tumorentitäten GIST, Leiomyom und Leiomyosarkom detaillierter eingegangen, da diese in der vorliegenden Dissertation weiter charakterisiert werden sollen. 
Tabelle 1.1/1: Charakteristika mesenchymaler Tumoren des GI-Trakts * zusätzlich molekulargenetische Veränderungen

Tabelle teilweise übernommen aus (Haller 2008), zusammengestellt aus (Miettinen et al. 2000a, Fletcher et al. 2002, Mechtersheimer et al. 2003, Yamaguchi et al. 2004, Rossi et al. 2005, Miettinen und Lasota 2006, Peterson et al. 2006, Schildhaus et al. 2008, Lasota et al. 2009)

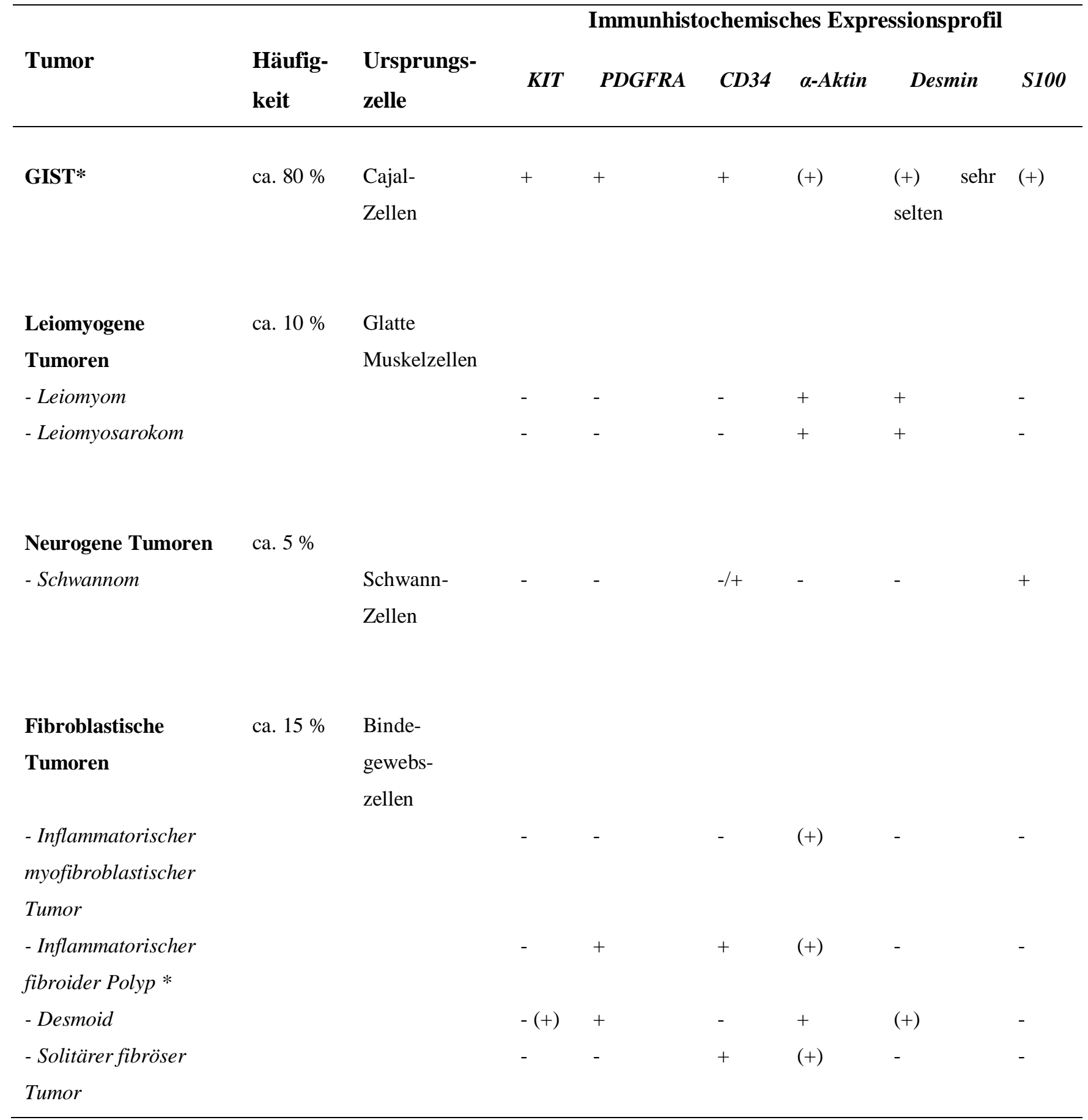




\subsubsection{Gastrointestinale Stromatumoren (GIST)}

GIST sind mit ca. 80 \% die häufigsten mesenchymalen Tumoren des Gastrointestinaltrakts (Hirota et al. 2003). Erst seit wenigen Jahren sind GIST als eigenständige Entität definiert, davor wurden sie aufgrund morphologischer Ähnlichkeiten und der örtlichen Nähe zur glatten Muskulatur als leiomyogen interpretiert und den Leiomyomen, Leiomyosarkomen oder Leiomyoblastomen zugeordnet (Appelman 1986, Dei Tos 2003, Chandu de Silva und Reid 2003).

Man betrachtet inzwischen die KIT-exprimierenden interstitiellen Cajal-Zellen als mögliche Ursprungszellen von GIST, was die Koexpression von einigen neurogenen und myogenen Merkmalen bei GIST erklären würde (Miettinen und Lasota 2001).

Histologisch zeichnen sich GIST durch eine spindelzellige oder epitheloidzellige Morphologie aus, wobei auch Mischtypen auftreten können (Abbildung 1.1.1/1). In einigen Fällen lassen sich auch Entzündungszellen (hauptsächlich Lymphozyten und Plasmazellen) und Nekrosen finden (Graadt van Roggen et al. 2001). GIST können eine fehlende bis hin zu einer sehr hohen mitotischen Aktivität aufweisen.

Immunhistochemisch zeigen GIST in 95 \% eine Expression von KIT und in 60-70 \% eine Expression von CD34. Sie sind äußerst selten und dann nur fokal Desmin-positiv (1 - 2 \%), können jedoch positiv füra -Aktin (30 - 40 \%) und S100 (ca. 5 \%) sein (Monihan et al. 1994, Fletcher et al. 2002, Miettinen und Lasota 2006).

Auf molekulargenetischer Ebene besitzen ca. 60 - 70 \% der GIST aktivierende Mutationen des v-kit Hardy-Zuckerman 4 feline sarcoma viral oncogene homolog (KIT)-Gens, sowie ca. $10 \%$ aktivierende Mutationen des platelet-derived-growth-factor receptor alpha (PDGFRA)Gens (Kindblom et al. 1998, Heinrich et al. 2003 a, b). GIST ohne nachweisbare Mutationen dieser beiden Gene werden als Wildtyp-GIST (WT-GIST) bezeichnet und machen etwa 10 15 \% der Fälle aus (Hirota et al 1998, Rubin et al. 2001, Heinrich et al. 2003 a, b). Zurzeit geht man davon aus, dass WT-GIST im Gegensatz zu KIT- und PDGFRA-mutierten GIST einen alternativen Entstehungsmechanismus besitzen (Heinrich et al. 2003a, Debiec-Rychter et al. 2004). In einigen KIT-/PDGFRA-WT-GIST konnten aktivierende Mutationen des V-raf murine sarcoma viral oncogene homolog B1 (BRAF-) Gens gefunden werden (Agaimy et al. 2009). Die KIT- bzw. PDGFRA-Mutationen führen zu einer Liganden-unabhängigen 
Autoaktivierung des Rezeptors, was wiederum eine unkontrollierte intrazelluläre Signalweitergabe und schließlich übermäßige Zellproliferation zur Folge hat (Hirota et al. 1998). PDGFRA-mutierte GIST zeigen im Vergleich zu KIT-mutierten GIST öfter eine epitheloide Morphologie und sind vorwiegend im Magen lokalisiert, während KIT-mutierte GIST häufiger spindelzellig sind und zu 2/3 im Magen, und zu 1/3 im Darm auftreten (Wardelmann et al. 2004, Penzel et al. 2005, Haller et al. 2007).

PDGFRA kann als Marker ebenfalls hilfreich sein. Mithilfe von PDGFRA ist es nach Ansicht einiger Autoren auf immunhistochemischer Ebene möglich, KIT-negative GIST differentialdiagnostisch von anderen mesenchymalen Tumoren des Gastrointestinaltrakts zu trennen (Rossi et al. 2005). Eine PDGFRA-Expression kann sowohl in PDGFRA-mutierten, als auch in KIT-mutierten und WT-GIST nachweisbar sein (Pauls et al. 2005). Jedoch zeigen die molekulargenetischen Untergruppen von GIST quantitative Unterschiede hinsichtlich der PDGFRA-Expression. GIST mit PDGFRA-Mutation haben eine höhere PDGFRA-Expression als GIST mit KIT-Mutation (Haller et al. 2007). Die Möglichkeit, KIT-negative GIST von anderen mesenchymalen Tumoren bzw. KIT- und PDGFRA-mutierte GIST immunhistochemisch trennen zu können, hat prognostische Bedeutung. Hinsichtlich des biologischen Verhaltens bestehen sowohl zwischen GIST und „Nicht-GIST“ als auch zwischen KIT- und PDGFRA-mutierten GIST Unterschiede (Lasota et al. 2004, Haller et al. 2007).

GIST treten meist bei Erwachsenen mit einem mittleren Alter von 55 - 60 Jahren auf. Sie können als kleine bis relativ große $(2-30 \mathrm{~cm})$ Tumoren im gesamten Gastrointestinaltrakt auftreten (Corless et al. 2004), kommen jedoch am häufigsten im Magen (60 - 70\%) und Dünndarm (20 - 25\%) vor (Miettinen und Lasota 2006). Weitere Lokalisationen sind Kolon und Rektum (5\%) sowie Ösophagus (<5\%) und selten extra-intestinal (Mesenterium, Retroperitoneum) (Miettinen und Lasota 2001).

Es existiert für GIST keine eindeutige Dignitätseinteilung. Das klinisch-pathologische Spektrum der GIST erstreckt sich von benignen, zufällig entdeckten Knötchen bis hin zu malignen Tumoren mit schlechter Prognose (Miettinen und Lasota 2001). Bis zu 30 \% der GIST können zum Lokalrezidiv führen oder metastasieren (Miettinen et al. 2002). Es gibt keine sicheren histo- bzw. zytomorphologischen Merkmale der Malignität, um eine eindeutige Einteilung des biologischen Verhaltens vornehmen zu können. Zur Abschätzung des 
„Malignitätspotentials“ werden daher prognostisch relevante Parameter herangezogen, mit deren Hilfe Risiko-Gruppen formuliert werden können. Es bestehen aktuell zwei RisikoKlassifikationen für GIST, die auf den Parametern Tumorgröße und Mitoserate (Fletcher et al. 2002) bzw. Tumorgröße, Mitoserate und Lokalisation des Tumors (Miettinen et al. 2002, Miettinen und Lasota 2006) basieren.

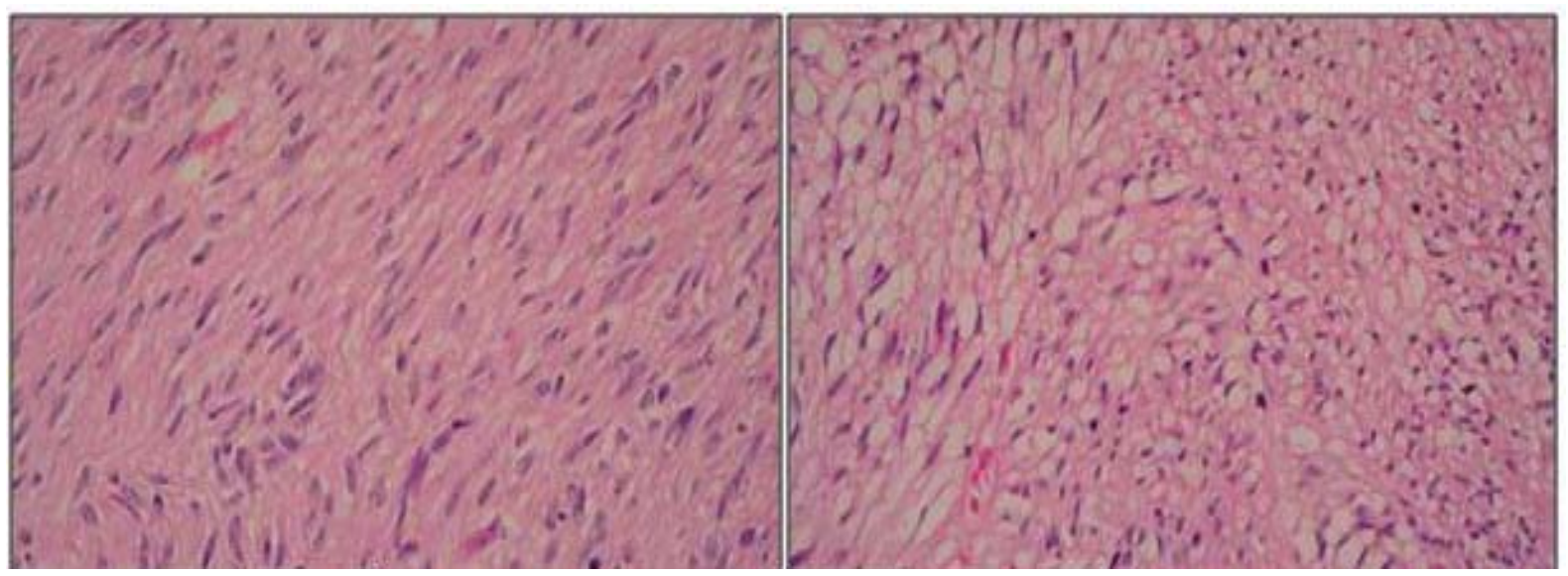

Abb. 1.1.1/1: Histomorphologische Bilder eines GIST (linkes Bild: spindelzellige Morphologie, rechtes Bild: epitheloidzellige Morphologie, H\&E, × 100)

\subsubsection{Leiomyogene Tumoren}

Die im Vergleich zu GIST relativ seltenen leiomyogenen Neoplasien lassen sich in benigne (Leiomyome) und maligne (Leiomyosarkome) Tumoren unterteilen. Sie sind nach GIST die zweithäufigsten mesenchymalen Neoplasien des Gastrointestinaltrakts, kommen jedoch beispielsweise im Dünndarm nur mit 4 \% der Häufigkeit von GIST vor (Miettinen et al. 2009a). Sie gehen aus Zellen der glatten Muskulatur hervor und bilden polypoide oder intramurale Läsionen (Agaimy und Wünsch 2007). Sie besitzen eine im Vergleich zu GIST differente Zytomorphologie. Die Tumorzellen zeigen feingeweblich charakteristische Befunde glatter Muskelzellen mit fein-fibrillär-eosinophilem Zytoplasma. In einem Leiomyosarkom finden sich im Gegensatz zu einem Leiomyom deutliche nukleäre Atypien und zahlreiche Mitosen (Abbildung 1.1.2.1/1 bzw. Abbildung 1.1.2.2/1, Miettinen et al. 2009a). Die leiomyogenen Tumoren sind immunhistologisch positiv für $\alpha$-Aktin und Desmin, bei fehlender Expression von KIT, CD34 und S100 (Miettinen et al. 2000a). Für leiomyogene 
Tumoren des Gastrointestinaltrakts sind derzeit keine definitiven tumorinitiierenden molekulargenetischen Veränderungen bekannt.

\subsubsection{Leiomyom}

$\mathrm{Zu}$ den Leiomyomen zählen das intramurale ösophageale Leiomyom, das polypoide Leiomyom der Muscularis mucosae, und das Leiomyom vom uterinen Typ. Sie sind in den verschiedenen Hohlorganen des Gastrointestinaltrakts unterschiedlich häufig lokalisiert und besitzen vereinzelt spezifische Merkmale.

Die immunhistochemischen Profile der meisten Leiomyome zeigen ein typisches leiomyogenes Bild. Sie sind $\alpha$-Aktin- und Desmin-positiv und im Allgemeinen negativ für KIT und CD34 (Miettinen et al. 2000a). Die KIT-Positivität der Mastzellen von ösophagealen Leiomyomen oder die KIT-Positivität der interstitiellen Cajal-Zellen weniger Leiomyome muss dabei von „echter“ KIT-Positivität getrennt werden (Miettinen et al. 2000b).

Für das Leiomyom vom uterinen Typ ist der zusätzliche immunhistochemische Nachweis von Hormonrezeptor-Expression (Östrogen und Progesteron) von besonderer differentialdiagnostischer Bedeutung (Miettinen et al. 2000a).

Leiomyome bleiben in der Regel sehr klein. Während Leiomyome der Muscularis mucosae meist eine Größe von unter $1 \mathrm{~cm}$ aufweisen, können die normalerweise 1 - $3 \mathrm{~cm}$ großen ösophagealen Leiomyome jedoch bisweilen über $10 \mathrm{~cm}$ groß werden (Miettinen et al. 2000b, Seremetis et al. 1976). Allgemein sind Leiomyome hauptsächlich im Ösophagus, selten im Magen und so gut wie nie im Dünndarm lokalisiert (Miettinen und Lasota 2006).

Das intramurale (ösophageale) Leiomyom hebt sich speziell von GIST durch die häufige Lokalisation im Ösophagus ab. Sie sind im Magen und Dünndarm selten, im Kolon etwas häufiger und treten meist bei jüngeren Patienten (mittleres Alter: 30 - 35 Jahre) auf. Das Leiomyom der Muscularis mucosae hingegen bildet kleine intraluminale Polypen und findet sich meist im Kolon und Rektum älterer Patienten (Miettinen und Fetsch 2006). Das Leiomyom vom uterinen Typ ist typischerweise um den Dünndarm oder im Retroperitoneum vor allem bei Frauen lokalisiert (Miettinen et al. 2000a).

Das Geschlechterverhältnis von Frauen zu Männern der Patienten mit einem Leiomyom beträgt ca. 1:2 (Miettinen und Lasota 2001, Miettinen et al. 2001a). 
Mitotische Aktivität fehlt den Leiomyomen im Grunde generell (Miettinen und Fetsch 2006).

Es finden sich jedoch auch vereinzelt Leiomyome mit schwach ausgeprägter mitotischer Aktivität (< 1 - 3 Mitosen/50 HPFs) (Miettinen et al. 2009a); bei einer höheren mitotischen Aktivität liegt ein Leiomyosarkom vor.

Leiomyome sind benigne leiomyogene Tumoren und weisen somit grundsätzlich eine gute Prognose auf. Ungeachtet der möglichen immensen Größe der ösophagealen Leiomyome zeigen alle Untergruppen der Leiomyome übereinstimmend ein benignes biologisches Verhalten (Abraham 2007).

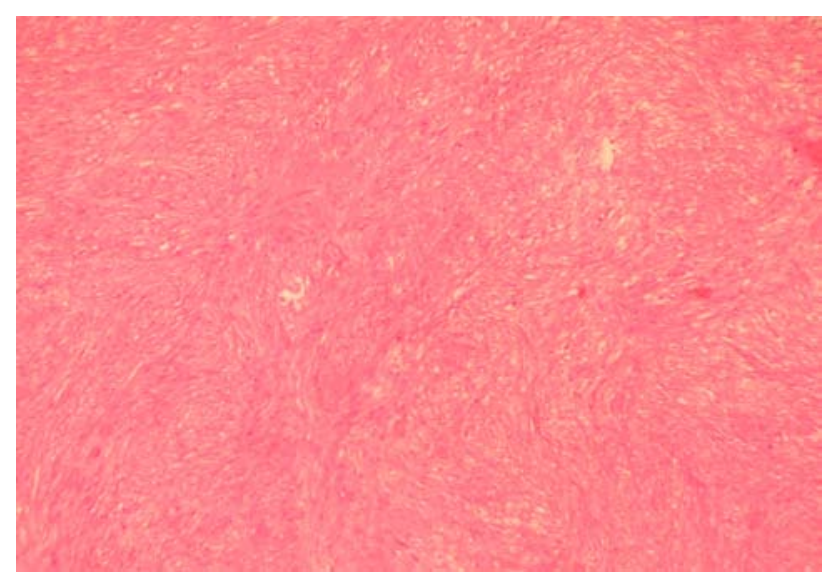

Abb. 1.1.2.1/1: Histomorphologisches Bild eines Leiomyoms (H\&E, × 100)

\subsubsection{Leiomyosarkom}

Leiomyosarkome sind mit $0,1 \quad$ - $10 \%$ aller mesenchymalen Tumoren des Gastrointestinaltrakts sehr rar. Sie zeigen immunhistochemisch allgemein Positivitätafür Aktin und Desmin. Auch wenn sich die Färbung gelegentlich nur fokal darstellt, sind sie durchweg $\alpha$-Aktin-positiv. Die Positivität für Desmin hingegen ist weniger konsistent (Abraham 2007). Einzelne Leiomyosarkome können KIT-Expression zeigen, dann jedoch nur sehr fokal und in einzelnen neoplastischen Zellen. Typischerweise sind sie jedoch KITnegativ (Miettinen et al. 2000a). CD34-Positivität findet sich dagegen häufiger (30 - 40 \%), dann jedoch vorzugsweise in retroperitonealen Leiomyosarkomen (Rizeq et al. 1994, Miettinen et al. 2000a). 
Leiomyosarkome können trotz ihrer Seltenheit in allen Teilen des Gastrointestinaltrakts lokalisiert sein. Sie kommen jedoch am häufigsten im Kolorektum und am seltensten im Magen vor (Miettinen und Fetsch 2006). Leiomyosarkome treten häufiger bei älteren Menschen auf und können sowohl als kleine intraluminale polypoide oder sehr große transmurale Tumoren auftreten (Miettinen et al. 2003). Duodenale Leiomyosarkome sind zwischen 10 und $19 \mathrm{~cm}$ groß und meist transmurale Tumoren, während Leiomyosarkome des Kolons eine Größe von 3 bis $8 \mathrm{~cm}$ aufweisen und polypoide intraluminale Tumoren darstellen (Miettinen et al. 2000c). Leiomyosarkome zeigen allesamt stark ausgeprägte mitotische Aktivität mit meist >50 Mitosen/ 50 HPFs (Miettinen und Fetsch 2006).

Leiomyosarkome des Gastrointestinaltrakts sind leiomyogene Tumoren mit variablem biologischen Verhalten, die jedoch grundsätzlich typische Merkmale hoher Malignität wie Lokalrezidive oder Metastasierung mit entsprechend schlechter Prognose aufweisen (Miettinen et al. 2009a).

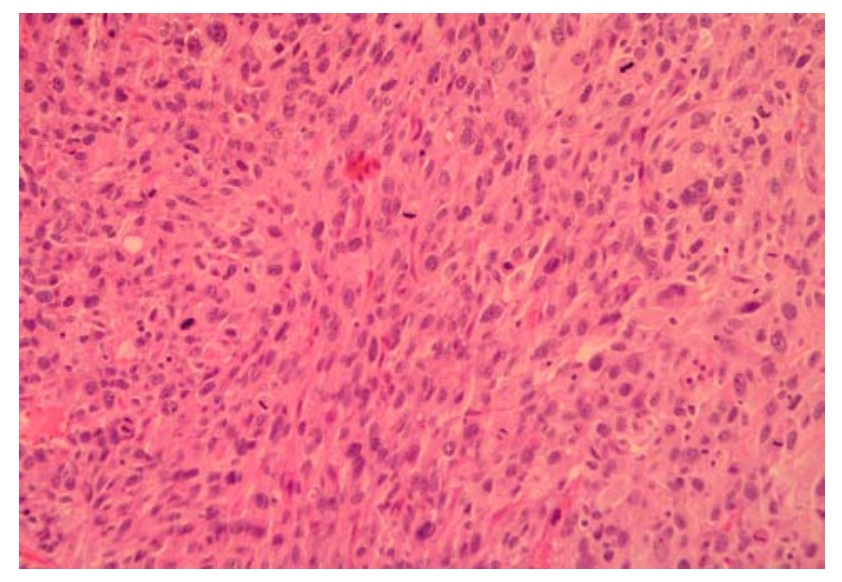

Abb. 1.1.2.2/1: Histomorphologisches Bild eines Leiomyosarkoms (H\&E, $\times 100)$

\subsubsection{Neurogene Tumoren}

$\mathrm{Zu}$ den mesenchymalen Tumoren des Gastrointestinaltrakts von neurogenem Ursprung gehören die wahrscheinlich aus den Schwann-Zellen entstehenden $\underline{\text { Schwannome }}$ (Neurinome). 
Feingeweblich zeigen sie ein spindelzelliges oder epitheloides Bild mit einer charakteristischen, manschettenartigen Häufung von Lymphozyten (peritumorales „Cuff“). Schwannome weisen keine Nekrosen auf und ihre mitotische Aktivität ist sehr gering (meist $\leq$ 1 Mitose/ 50 HPFs, selten bis 5 Mitosen/ 50 HPFs) (Miettinen et al. 2001b, Prevot et al. 1999).

Immunhistochemisch sind sie typischerweise stark S100-positiv, aber negativ für KIT-, CD34- und die leiomyogenen Marker (Miettinen et al. 2001b, Abraham 2007).

Schwannome sind benigne Tumoren, die in 60 - 70 \% der Fälle im Magen bzw. in 20 - 30 \% im Kolon zu finden sind. Sie treten fast nur im höheren Lebensalter auf, bleiben relativ klein $(<5 \mathrm{~cm})$ und haben eine günstige Prognose (Miettinen und Lasota 2006). Vom gutartigen Schwannom abzugrenzen ist die im Gastrointestinaltrakt sehr selten auftretende maligne Form eines neurogenen Tumors, der maligne periphere Nervenscheidentumor (MPNST, Lewis und Brennan 1996, Yamaguchi et al. 2003).

\subsubsection{Fibroblastische Tumoren}

Die fibroblastischen Tumoren entstehen wahrscheinlich aus Bindegewebszellen, zu ihnen gehören der inflammatorische myofibroblastäre Tumor, der inflammatorische fibroide Polyp, der Desmoid-Tumor und der solitäre fibröse Tumor.

Der inflammatorische myofibroblastäre Tumor (IMT) ist histologisch durch myofibroblastische Spindelzellen und ein inflammatorisches Infiltrat von Lymphozyten und Plasmazellen gekennzeichnet (Lawrence et al. 2000). Dieser Tumor ist immunhistochemisch typischerweise anaplastic lymphoma kinase- (ALK-) positiv und kann $\alpha$-Aktin-positiv sein, ist dabei jedoch KIT- und CD34-negativ (Griffin et al. 1999). Der IMT kommt typischerweise bei Kindern und jungen Erwachsenen vor (Miettinen und Lasota 2006). Die häufigste Lokalisation ist das Abdomen, wo der IMT auf dem Peritoneum vorkommt und den MagenDarm-Trakt involvieren kann (Miettinen et al. 2000a). Obwohl die meisten IMT benignen Charakter besitzen, treten bei einem kleinen Teil der Fälle lokale Rezidive und sehr selten Metastasen auf (Cook et al. 2001). 
Der inflammatorische fibroide Polyp (IFP) zeigt feingeweblich ein spindelzelliges Bild, welches durch ein an eosinophilen Granulozyten reiches entzündliches Infiltrat und eine starke Vaskularisierung gekennzeichnet ist (Abraham 2007). Die Spindelzellen sind als charakteristisches Merkmal meist in konzentrischen, zwiebelschalartigen Formationen um die Blutgefäße angeordnet. Insgesamt relativ selten im Gastrointestinaltrakt, kommt der IFP häufig im Magen, seltener im Dünndarm, Kolon und Ösophagus älterer Patienten vor. Er verursacht häufig ulzerierende intraluminale Polypen (Pantanowitz et al. 2004). Einige IFP, besonders wenn sie im Magen lokalisiert sind, können CD34-positiv sein, sind jedoch im Gegensatz zu GIST KIT-negativ (Miettinen und Lasota 2001, Miettinen und Lasota 2006). Obwohl in der Vergangenheit häufig als reaktiv bezeichnet, wird dem IFP aufgrund des kürzlich beschriebenen Nachweises von aktivierenden Mutationen des PDGFRA-Gens eher eine neoplastische Natur zugesprochen. PDGFRA-Expression und Mutationen dieses Rezeptors wurden sowohl bei IFP des Magens als auch kürzlich bei kleinen intestinalen IFP gefunden. Im Gegensatz zu GIST zeigen IFP jedoch auch aufgrund fehlender Metastasierung eine günstigere Prognose und sollten als benigne PDGFRA-gesteuerte Neoplasien betrachtet werden (Schildhaus et al. 2008, Lasota et al. 2009).

Die aggressive Fibromatose oder auch Desmoid-Tumor ist ein seltener, durch klonale Proliferation von Myofibroblasten entstehender Tumor. Histologisch zeigt er sich spindelzellig, reich an Kollagen und leicht erweiterten, prominenten Gefäßen. Die Mitoserate ist normalerweise niedrig (2 - 4 Mitosen/ 50 HPFs), kann jedoch bis zu 11 Mitosen/ 50 HPFs erreichen (Rodriguez et al. 2004, Yantiss et al. 2000). Der Desmoid-Tumor ist Aktin- und Desmin-positiv und negativ für CD34 und S100. In der Vergangenheit bestanden kontroverse Angaben über eine bestehende KIT-Positivität (Yantiss et al. 2000, Hanau und Miettinen 1995). Unter Vermeidung von starken Vorbehandlungen bei der immunhistochemischen Färbung konnte jedoch in einer jüngeren Untersuchung keine KIT-Expression gefunden werden (Rubin et al. 2005). Der Tumor zeigt außerdem PDGFRA-Expression (Liegl et al. 2006, Leithner et al. 2005). Die immunhistochemische Positivität für nukleäres beta-Catenin kann diagnostisch hilfreich sein (Lazar et al. 2008), ist jedoch kein bestimmendes Merkmal (Carlson, Fletcher 2007). Der Desmoid-Tumor entsteht meist im Mesenterium oder Retroperitoneum, kann jedoch aufgrund seines infiltrierenden Wachstums den Gastrointestinaltrakt involvieren (Abraham 2007). Er tritt häufiger bei Frauen auf und zeigt keine Metastasierung, besitzt jedoch die Tendenz zu Rezidiven (Leithner et al. 2005). 
Der solitäre fibröse Tumor (SFT) ist eine spindelzellige Neoplasie, die am häufigsten in der Pleura und äußerst selten im Gastrointestinaltrakt $\mathrm{zu}$ finden ist. Histologisch ist eine unterschiedliche Anzahl an hyalinisierten Kollagenfasern charakteristisch. Er kann ähnlich wie GIST CD34- und $\alpha$-Aktin-Positivität aufweisen (Shidham et al. 2002), ist jedoch KIT-, Desmin- und S100-negativ (Miettinen et al. 2000a). Der SFT ist meist einige Zentimeter groß, kann jedoch eine Größe von mehr als 20 cm erreichen (Mentzel et al. 1997). Hinsichtlich seines biologischen Verhaltens existieren unterschiedliche Kriterien, jedoch sind maligne Fälle außerhalb der Pleura allgemein sehr selten (Fukunaga et al. 1996, Hanau und Miettinen 1995). Anzeichen von Malignität können nukleärer Pleomorphismus, > 4 Mitosen/ 10 HPFs und Hämorrhagie oder Nekrosen sein (De Parot et al. 1999).

\subsection{Typ-III-Rezeptor-Tyrosin-Kinasen}

Rezeptor-Tyrosin-Kinasen unterstützen die Signal-Übermittlung von extra- nach intrazellulär. Der KIT- und der PDGF-Rezeptor $\alpha$ gehören zu der Familie der Typ-III-Rezeptor-TyrosinKinasen, welche eine extrazelluläre (EZD), eine transmembranäre (TMD), eine intrazelluläre (juxtamembranäre, JMD) Domäne und zwei durch einen Kinase-Insert (KI) getrennte Tyrosin-Kinase-Domänen (TK1D und TK2D) besitzen. An die extrazelluläre Komponente bindet der entsprechende Ligand, während die juxtamembranäre Domäne autoinhibitorische Funktion besitzt (Abbildung 1.2/1, Lasota und Miettinen 2008).

Der Aufbau dieser Rezeptoren ist ferner durch das Vorhandensein von fünf extrazellulär befindlichen immunglobulinähnlichen Schleifen charakterisiert, die der Regulation von Ligandenbindung, Dimerisierung und Proteolyse des Rezeptorproteins dienen (Pawson 2002, Roskoski 2005b). 


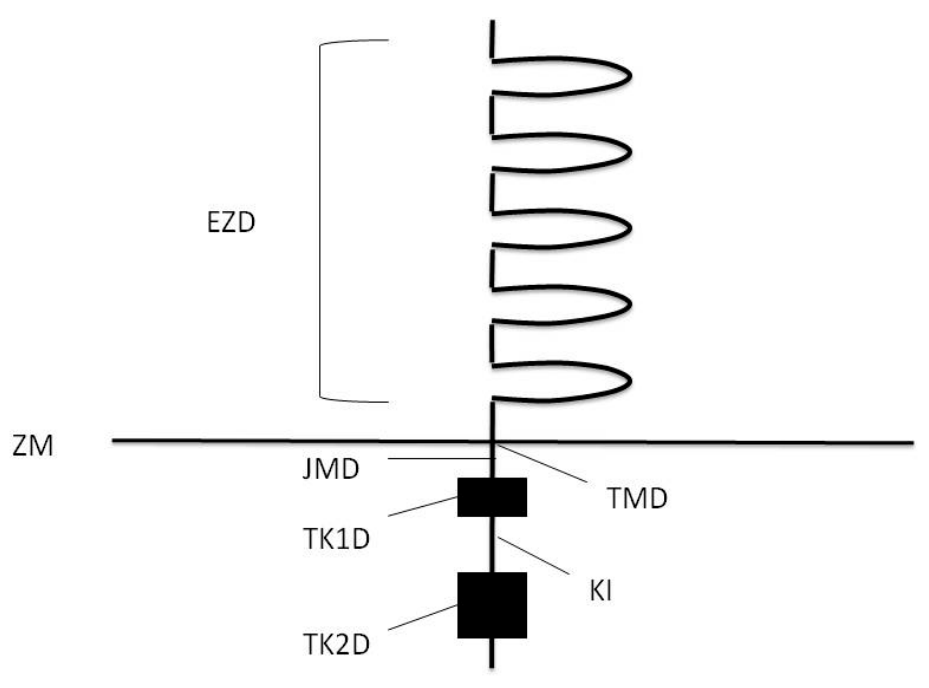

Abb. 1.2/1: Aufbau einer Rezeptor-Tyrosin-Kinase (EZD: extrazelluläre Domäne, ZM: Zellmembran, TMD: Transmembranäre Domäne, JMD: juxtamembranäre Domäne, TK1D: Tyrosin-Kinase-Domäne 1, KI: KinaseInsert, TK2D: Tyrosin-Kinase-Domäne 2)

\subsubsection{KIT}

Der KIT-Rezeptor und sein physiologischer Ligand Stammzellfaktor (SCF) sind entscheidend für Zelldifferenzierung, -proliferation und -überleben bei einigen Zelltypen (Roskoski 2005a). Die Aktivierung zur Signalübertragung erfolgt unter physiologischen Umständen durch den Stammzellfaktor (SCF, Williams et al. 1990). Die Signaltransduktion durch KIT spielt in Erythro- und Lymphopoese, sowie der Mastzellentwicklung und -funktion eine Rolle (Rönnstrand 2004). Die Expression von KIT findet auf hämatopoetischen Zellen, dendritischen Zellen, Mastzellen, Spermatozyten und interstitiellen Cajal-Zellen statt (Lyman und Jacobsen 1998). 


\subsubsection{PDGFRA}

Der PDGF-Rezeptor $\alpha$ geb̈rt ebenso wie der KIT -Rezeptor zu der Familie der Typ-IIIRezeptor-Tyrosin-Kinasen und wird unter physiologischen Umständen von seinem Liganden PDGF aktiviert. Nach heutigem Kenntnisstand existieren hiervon vier Isoformen. PDGFR-A und PDGFR-B können sowohl Homo- als auch Heterodimere bilden; PDGFR-C und PDGFRD bilden ausschließlich Homodimere (Fredriksson et al. 2004). Aus diesen Kombinationsmöglichkeiten ergeben sich sieben verschiedene Liganden. Bis auf PDGFR-DD können alle Liganden den PDGF-Rezeptor $\alpha$ aktivieren. Das Rezeptorprotein selbst dimerisiert nach Ligandenbindung, wobei auch Heterodimere mit dem PDGF-Rezeptor $\beta$ möglich sind. Der PDGF-Rezeptor a kommt auf erythropoetischen und myeloischen Vorläuferzellen im Knochenmark sowie auch auf Monozyten, Megakaryozyten, Fibroblasten, Endothelzellen, Osteoblasten und Gliazellen vor (Soriano 1997). PDGFRA ist während der Embryogenese essenziell für die Ausbildung des Mesenchyms und postnatal für Zellwachstum, Hemmung bzw. Stimulierung der Chemotaxis und Hemmung der Apoptose (Eriksson et al. 1992). 


\subsection{Intrazelluläre Signaltransduktion}

Die in der vorliegenden Dissertation untersuchten Signaltransduktions- bzw. ZellzyklusProteine im Kontext der einzelnen Zellzyklus-Abschnitte sind in Abbildung 1.2/2 dargestellt.

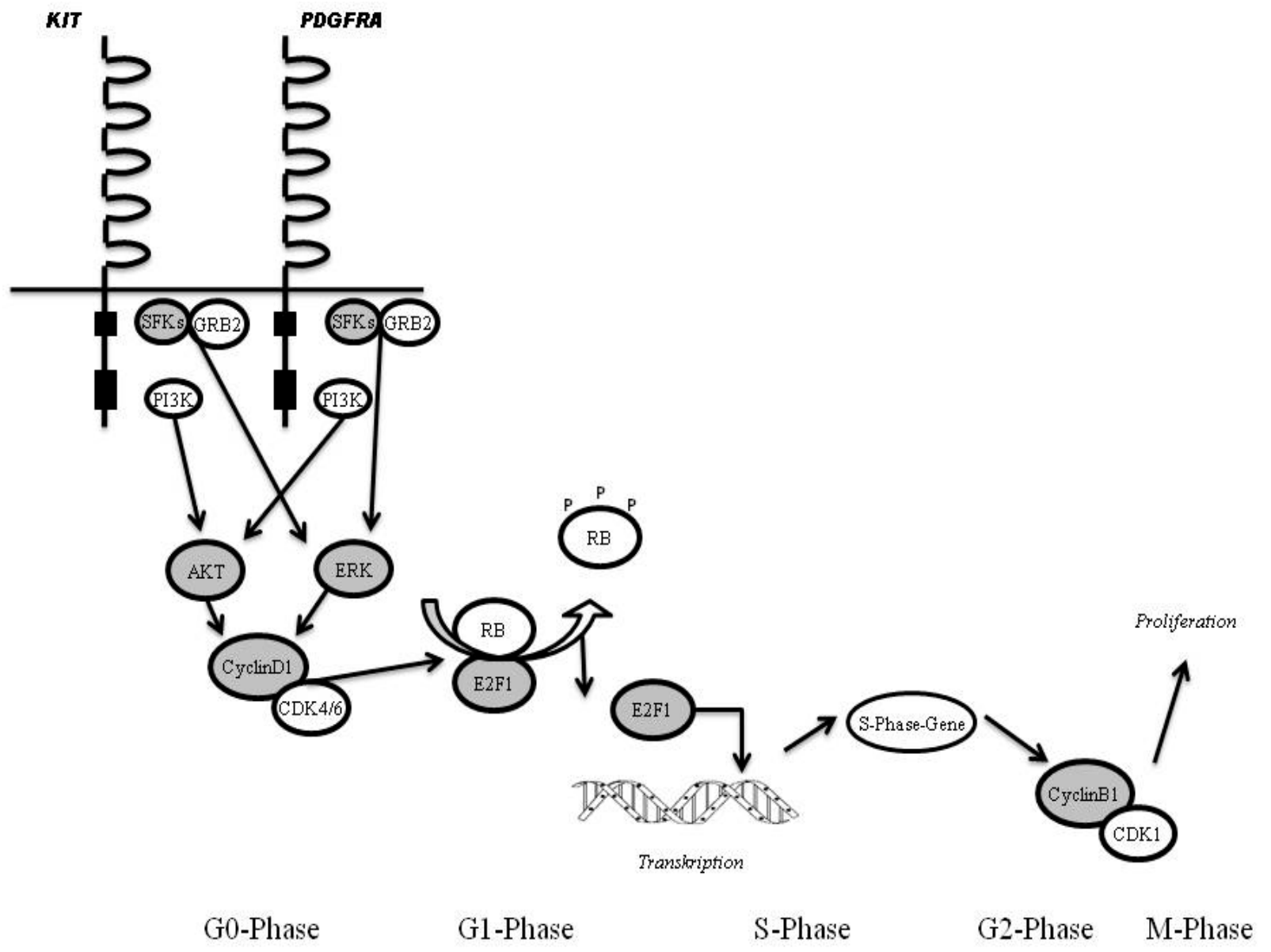

Abb. 1.2/2: Signaltransduktions- bzw. Zellzyklus-Proteine (grau unterlegte Felder = die in der vorliegenden Dissertation untersuchten Signaltransduktions- und Zellzyklus-Proteine) 
Ausgangspunkt für die physiologische Signalübertragung bei Rezeptor-Proteinkinasen wie KIT und PDGFRA ist die Bindung eines spezifischen Proteins (Liganden) an den extrazellulären Teil des Rezeptors. Die Aktivierung von Signalkaskaden von KIT und PDGFRA erfolgt prinzipiell gleich. Die weitere Beschreibung der Rezeptor-Aktivierung erfolgt exemplarisch am Beispiel der Rezeptor-Tyrosin-Kinase KIT.

Unter physiologischen Bedingungen beginnt die Signalübertragung mit der Bindung des spezifischen Liganden SCF an den KIT-Rezeptor. Dies führt zu einer Konformationsänderung des Rezeptors mit anschließender Dimerisierung von zwei KIT-Molekülen und einer gegenseitigen Phosphorylierung der Tyrosinreste beider Rezeptoren (Blume-Jensen et al. 1991). An die phosphorylierten Tyrosinreste können intrazellulär wiederum verschiedene Adapterproteine binden, die ihrerseits Phosphorylierung und somit Aktivierung bzw. Inaktivierung erfahren (Roskoski 2005b). Es folgen verschiedene Signalkaskaden, die intrazellulär für die Weiterleitung des Signals sorgen und entweder Differenzierung oder Proliferation vermitteln (Roskoski 2005a). Im einzelnen kommt es durch die Rezeptoren u.a. zuerst zu einer Aktivierung von extracellular signal-regulated kinase (ERK) und v-akt murine thymoma viral oncogene homolog (AKT) (Lennartsson et al. 2005, Roskoski 2005a). Die Aktivierung von ERK, die schließlich zur Phosphorylierung von Transkriptionsfaktoren im Zellkern führt, wird dabei durch SFKs (SRC family kinases) und das Adapterprotein growth factor receptor-bound protein 2 (Grb2) vermittelt. AKT wird durch die Phosphatidylinositol3-OH- (PI3-) Kinase, einer Lipid-Kinase, aktiviert (Abbildung 1.3/1).

Cellular homolog of the transforming protein of Rous sarcoma virus (SRC) und die nach diesem Gen benannte Familie von Tyrosin-Kinasen, SRC family kinases (SFK), spielen bei einer Reihe von Zellfunktionen wie Zellzyklus, Chemotaxis, Adhäsion, Überleben und Proteintransport eine Rolle (Thomas und Brugge 1997). Die Bindung von SCF an KIT führt zu einer schnellen Steigerung der Kinaseaktivität von SFK (Ware et al. 1997).

Aktiviertes ERK erhöht die für den Ablauf des Zellzyklus essentielle Cyclin-D1-m-RNAExpression (Lavoie et al. 1996, Albanese et al. 1995), während AKT Teil der Regulation der Cyclin-D1-m-RNA-Translation ist. Zwischen ERK und AKT liegt eine „Kreuzverbindung“ vor, die Zellwachstum und Zellteilung aufeinander abstimmt (Ruggero und Sonenberg 2005, Chambard et al. 2007). 


\subsection{Regulation des Zellzyklus}

Proliferierende Zellen durchlaufen einen Teilungszyklus, dessen Abläufe unter physiologischen Umständen streng reguliert sind. Der Zyklus wird in vier verschiedene Phasen (G1, S, G2 und M) und eine Ruhe- (G0-) Phase eingeteilt (Murray 1993). Störungen in der Zellzyklus-Regulation können zu unkontrolliertem Zellwachstum und so zur Tumorentstehung und -progression führen.

Der regelhafte Durchgang durch den Zellzyklus wird unter anderem durch eine Vielzahl verschiedener Proteinkomplexe aus Cyclinen und cyclinabhängigen Kinasen (cyclindependent kinase (CDK)), sowie ihren Gegenspielern, den cyclin-abhängigen KinasenInhibitoren, reguliert (Murray 1993). Diese Proteinkomplexe tragen dazu bei, dass letztendlich ein Eintritt der Zelle in die S-Phase des Zyklus möglich wird, in der DNA synthetisiert wird (Cordon-Cardo 1995).

Eine entscheidende Weiche wird gestellt, wenn Zellen den sog. Kontroll-/Begrenzungspunkt innerhalb der G1-Phase überschreiten, von dem ab sie ohne Rückkehrmöglichkeit in eine neue Runde der Zellteilung eintreten (Pardee 1989). Dieser Punkt dient der Aufrechterhaltung der geregelten Zellproliferation, um auf diese Weise hyper- bzw. neoplastisches Wachstum zu verhindern (Ortega et al. 2002).

Cyclin-D1 als Aktivatorprotein ist dabei essentiell für das Fortschreiten des Zellzyklus. Physiologischerweise ist die Menge an Cyclin-D1 für die Passage des Kontrollpunktes zu gering. Durch aktivierte Transkriptionsfaktoren, die an den Promoter des Cyclin-D1-Gens binden, kommt es zu einer verstärkten Ablesung des Gens und damit zu einer Hochregulation der m-RNA-Menge. Die Expression der Cyclin-D1-m-RNA wird dabei unter anderem durch ERK und AKT reguliert, welche durch KIT und PDGFRA aktiviert werden (Chambard et al. 2007). Anschließend erfolgt die Translation der Cyclin-D1-m-RNA in das entsprechende Protein. Dieser Vorgang wird ebenfalls entsprechend kontrolliert, u.a. durch AKT (Ruggero und Sonenberg 2005).

Die Cyclin-D1-Proteine binden schließlich an die Kinasen CDK4 und CDK6 und bilden mit diesen Cyclin-D1/CDK4- bzw. Cyclin-D1/CDK6-Komplexe. Die so aktivierten Kinasen können das Tumorsuppressorprotein retinoblastoma (RB) phosphorylieren. RB überwacht die Passage durch den Kontrollpunkt des Zellzyklus. Seine Interaktion mit dem 
Transkriptionsfaktor E2F1 (transcription factor 1) ist dabei von zentraler Bedeutung (Lundberg et al. 1998).

In der Ruhephase des Zellzyklus ist RB zunächst an E2F1 gebunden und E2F1 somit inhibiert. Durch die Phosphorylierung des RB wird dieses selbst inhibiert und E2F1 damit aus der blockierenden Verbindung herausgelöst (Weinberg 1995). Das freie E2F1 führt als Transkriptionsfaktor schließlich zur m-RNA-Synthese von zahlreichen Proteinen, die für die DNA-Synthese und das Fortschreiten des Zellzyklus notwendig sind (Lukas et al. 1996). Diese Vorgänge ebnen den Weg für den Übergang in die S-Phase des Zellzyklus (Müller et al. 2001). Frei vorliegendes E2F1 ist zudem in der Lage, seine eigene m-RNA-Expression über positives Feedback herauf zu regulieren, sowie die späten G1/S-Phase-Regulatoren Cyclin-E, Cyclin-B und CDK2 auf transkriptioneller Ebene positiv zu beeinflussen (Müller et al. 2001, Vernell et al. 2003). Es konnte gezeigt werden, dass eine höhere E2F1-Expression bei GIST mit höherer mitotischer Aktivität und höherer Proliferationsrate assoziiert ist (Haller et al. 2005).

Der Eintritt in die Mitose wird ebenfalls durch die Aktivierung eines Proteinkomplexes reguliert. Dieser besteht aus Cyclin-B1 und CDC2 (auch CDK1 genannt) und stellt einen essentiellen Regulator für den Eintritt der Zelle in die Mitose dar (Jin et al. 1998).

CDC2 liegt während der einzelnen Zellzyklusphasen relativ konstant vor, während die Expression von Cyclin-B1 am Ende der S-Phase ansteigt und am G2-M-Übergang ihren höchsten Wert erreicht. Cyclin-B1 ist für die Kontrolle dieses Proteinkomplexes verantwortlich und mit mitotischer Aktivität assoziiert (Pines und Hunter 1989).

Es wurde gezeigt, dass während der Mitose das Ki-67-Protein posttranslational modifiziert wird und dass diese Modifikation aus Phosphorylierungen resultiert, die vom CyclinB1/CDC2-Kinase-Weg reguliert werden (MacCallum und Hall 1999, Endl und Gerdes 2000a).

Ki-67 ist ein nukleäres und nukleoläres Protein, das sehr eng mit Zellproliferation assoziiert ist. 1983 erstmals durch einen Antiköper gefunden (Gerdes et al. 1983), deckten Zellzyklusanalysen ein Jahr später das entsprechende Antigen (Ki-67-Protein) auf. Dieses wird ausschließlich von Zellen in G1-, S-, G2- und M-Phase, nicht aber von Zellen in der G0Phase, exprimiert (Gerdes et al. 1984). Diese exklusive Ki-67-Expression von proliferierenden Zellen machen Antikörper gegen das Ki-67-Protein zu Proliferationsmarkern, 
die in der Tumordiagnostik einen hohen prognostischen Wert besitzen, da sie Aufschluss über die Zellteilungsrate eines Tumors geben können (Scholzen und Gerdes 2000). Es wird diskutiert, ob das Ki-67-Protein nicht nur mit dem regulierenden Protein-Netzwerk, das den Zellteilungszyklus betreibt, assoziiert, sondern in dieses integriert ist (Endl und Gerdes 2000b). Im Gegensatz zu anderen Methoden wie DNA-Untersuchungen oder der mikroskopischen Mitosen-Auszählung hat die Ki-67-Immunhistochemie Vorteile in Praktikabilität, Reproduzierbarkeit und Sensitivität. Der Ki-67 äquivalente monoklonale Antikörper Mib-1 ist paraffin-gängig und so bei verschiedenen zytologischen und histologischen Präparationen anwendbar (Scholzen und Gerdes 2000).

\subsection{Fragestellung}

In der vorliegenden Arbeit sollen die drei Tumorentitäten GIST, Leiomyom und Leiomyosarkom hinsichtlich klinisch-pathologischer Parameter und der Expression verschiedener Signaltransduktions- und Zellzyklus-Proteine untersucht werden.

Es lassen sich folgende Fragen formulieren:

1. Welche Gemeinsamkeiten bzw. Unterschiede lassen sich bei GIST, Leiomyomen und Leiomyosarkomen hinsichtlich der klinisch-pathologischen Parameter beobachten?

2. Wie geeignet sind KIT und PDGFRA als diagnostische Marker zur Unterscheidung von GIST, Leiomyom und Leiomyosarkom? Ist eine PDGFRA-Expression ein spezifisches Merkmal von GIST?

3. Existieren zwischen GIST, Leiomyomen und Leiomyosarkomen quantitative Unterschiede in der Expression der untersuchten Signaltransduktions-Proteine? Lassen sich damit Rückschlüsse auf die in den einzelnen Tumorentitäten relevanten Signalwege ziehen?

4. Bestehen zwischen GIST, Leiomyomen und Leiomyosarkomen Unterschiede in der Expression der untersuchten Zellzyklus-Proteine? Wie stark korreliert die Expression der einzelnen Gene mit der Mitosenzählung als Merkmal der biologischen Aggressivität? 


\section{Material und Methoden}

\subsection{Untersuchungsmaterial}

Für die vorliegende Dissertation wurden 163 Tumoren mit der histologischen Diagnose GIST, Leiomyom oder Leiomyosarkom aus dem pathologischen Archiv der Universitätsklinik Göttingen (Zeitraum 1993 bis 2006) ausgewählt.

Die histologische Diagnose erfolgte durch Prof. Dr. med. Füzesi (Abteilung Gastroenteropathologie, Universitätsklinikum Göttingen) und wurde durch PD Dr. Agaimy (Abteilung Pathologie, Universitätsklinikum Erlangen) bestätigt.

Die histologische Diagnose „GIST“ wurde ferner durch eine immunhistochemische KITPositivität und Desmin-Negativität abgesichert, im Einzelfall auch durch eine molekulargenetische Analyse der Gene KIT und PDGFRA. Die histologische Diagnose „Leiomyom“ bzw. „Leiomyosarkom“ wurde durch immunhistochemische KIT-Negativität und Desmin-Positivität abgesichert.

\subsection{Manueller Tissue Micro Arrayer (TMA)}

Durch die Anwendung der manuell zu bedienenden Geräte der Tissue Array-Technologie ist es möglich, eine große Anzahl von Gewebeproben in Form von 0,1 cm großen Stanzkernen in einem gemeinsamen Paraffinblock in Form einer Matrix neu zusammenzustellen, welche dann für immunhistochemische Untersuchungen zur Verfügung stehen (Abbildung 2.2/1). Die verschiedenen Gewebeproben lassen sich so sehr gut vergleichen. Zu dem Vorteil des Gewinns einer großen Anzahl von Gewebeproben unter gleichzeitiger Schonung des Ausgangsmaterials kommen Ersparnis von Arbeitszeit und Färbematerial, sowie eine bessere quantitative Vergleichbarkeit. 


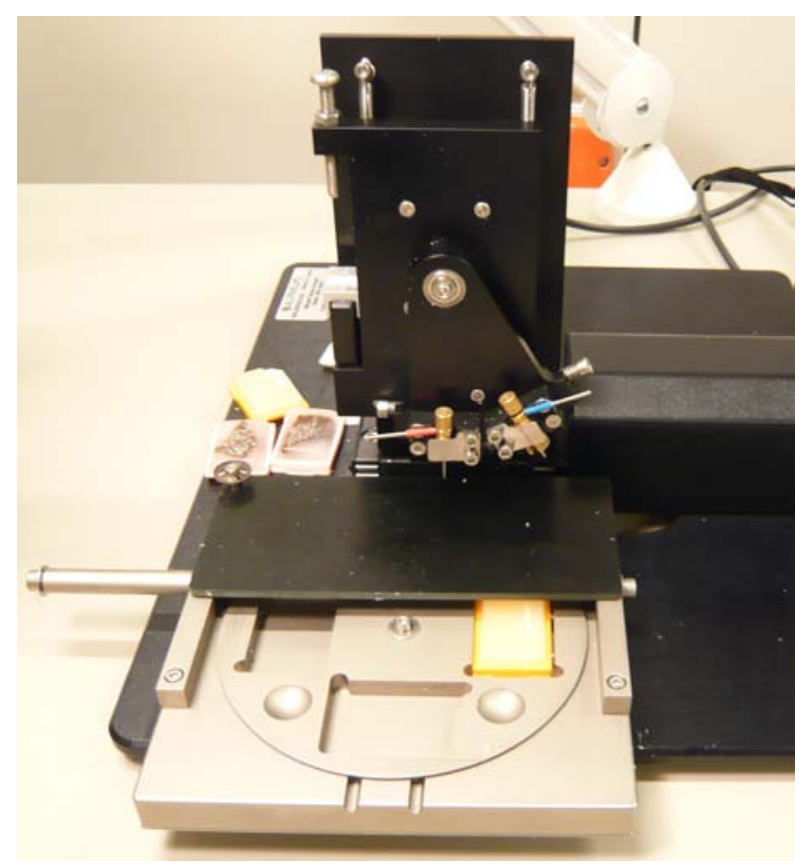

Abb. 2.2/1: Manueller Tissue Micro Arrayer

Der Vorgang des Gerätes beginnt mit einer von zwei verwendeten Hohlstanzen, die eine regelmäßige Matrix von Löchern in den Empfängerparaffinblock prägt. Die zweite Hohlstanze entnimmt präzise Stanzkerne aus selektierten Bereichen eines Spenderparaffinblocks und platziert diese in die präparierten Löcher des Empfängerparaffinblocks (Abbildung 2.2/2).

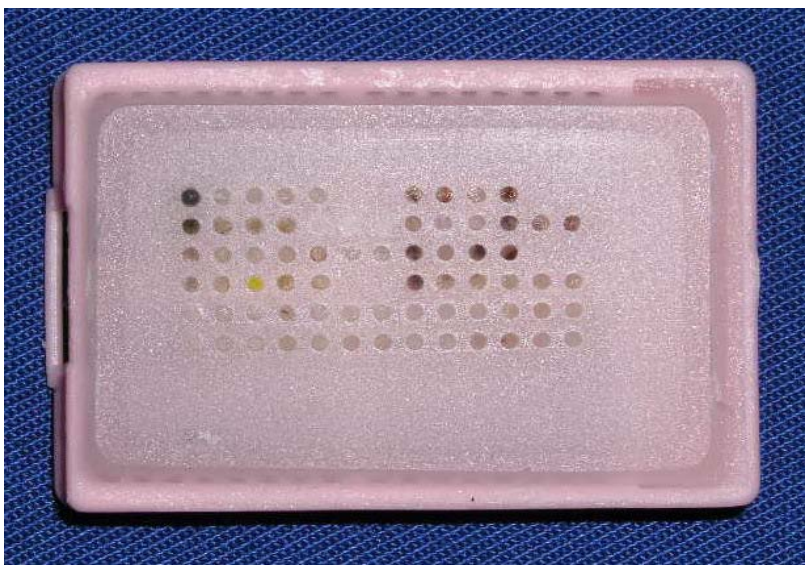

Abb. 2.2/2: Exemplarische Darstellung eines Paraffinblocks mit einer Matrix aus 0,1 cm großen Stanzkernen 
Nach einer halbstündigen Erwärmung des so gefertigten Tissue-Micro-Array-Paraffinblocks (TMAs) bei $37^{\circ} \mathrm{C}$ und anschließender manueller Kompression mittels eines Glasobjektträgers ist es dann möglich, gröbere Unregelmäßigkeiten in der Eindringtiefe der Stanzkerne im Empfängerparaffinblock auszugleichen. In einem weiteren Schritt wird der TMA für 15 min auf $60{ }^{\circ} \mathrm{C}$ erwärmt und dadurch das enthaltene Paraffin teilweise verflüssigt. Es entsteht ein optimaler Verbund zwischen den Stanzkernen und dem umgebenden Paraffin, der das präzise Schneiden des Paraffinblocks ermöglicht. Bei $-20^{\circ} \mathrm{C}$ werden die TMAs abgekühlt und anschließend $1 \mu \mathrm{m}$ dicke Schnitte mittels Mikrotom entnommen und auf einen Objektträger appliziert.

In der vorliegenden Arbeit wurde eine Matrix verwendet, auf der von 16 Patienten jeweils sechs Gewebeproben platziert waren (Abbildung 2.2/3 und Abbildung 2.2/4).

\begin{tabular}{|l|l|l|l|l|l|l|l|l|l|l|l|l|l|}
\hline TMA-1 & $\begin{array}{l}\text { Zeile I } \\
\text { Spalte }\end{array}$ & $\mathbf{1}$ & $\mathbf{2}$ & $\mathbf{3}$ & $\mathbf{4}$ & $\mathbf{5}$ & $\mathbf{6}$ & $\mathbf{7}$ & $\mathbf{8}$ & $\mathbf{9}$ & $\mathbf{1 0}$ & $\mathbf{1 1}$ & $\mathbf{1 2}$ \\
\hline & A & 1 & 1 & 1 & 1 & 1 & 1 & 2 & 2 & 2 & 2 & 2 & 2 \\
\hline & B & 3 & 3 & 3 & 3 & 3 & 3 & 4 & 4 & 4 & 4 & 4 & 4 \\
\hline & C & 5 & 5 & 5 & 5 & 5 & 5 & 6 & 6 & 6 & 6 & 6 & 6 \\
\hline & D & 7 & 7 & 7 & 7 & 7 & 7 & 8 & 8 & 8 & 8 & 8 & 8 \\
\hline & E & 9 & 9 & 9 & 9 & 9 & 9 & 10 & 10 & 10 & 10 & 10 & 10 \\
\hline & F & 11 & 11 & 11 & 11 & 11 & 11 & 12 & 12 & 12 & 12 & 12 & 12 \\
\hline & G & 13 & 13 & 13 & 13 & 13 & 13 & 14 & 14 & 14 & 14 & 14 & 14 \\
\hline & H & 15 & 15 & 15 & 15 & 15 & 15 & 16 & 16 & 16 & 16 & 16 & 16 \\
\hline
\end{tabular}

Abb.2.2/3: Beispiel einer Tissue-Mikroarray-Matrix mit 16 Patienten und je sechs Gewebeproben 


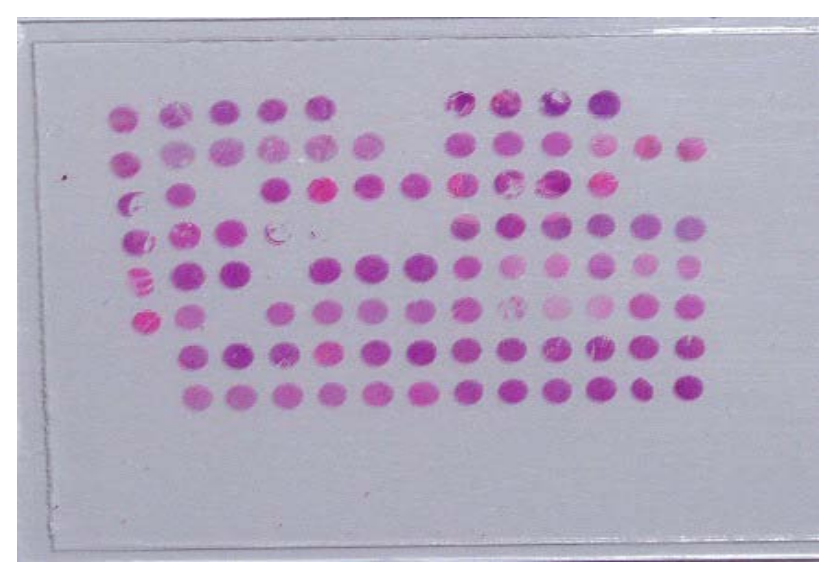

Abb.2.2/4: Beispiel einer Tissue-Mikroarray-Matrix auf einem Objektträger (H\&E gefärbt)

\subsection{Immunhistochmie}

Mit der Immunhistochemie (IHC) ist es möglich, mit Hilfe von Antikörpern Proteine in zu untersuchendem Gewebe sichtbar zu machen und somit Tumorzellen, die bestimmte Antigene exprimieren, zu identifizieren, zu klassifizieren und quantitativ auszuwerten. Diese Methode zeichnet sich durch gute Reproduzierbarkeit und Handhabung aus.

Die Identifizierung beruht auf der Affinität von Antikörpern zu einem bestimmten Epitop als Antigen-Antikörper-Reaktion. Ein spezifischer Primärantikörper bindet in einem ersten Schritt an das Epitop, in einem zweiten Schritt bindet ein Sekundärantikörper an den Primärantikörper. An den Sekundärantikörper ist ein Enzym gekoppelt, das durch eine Enzym-Substrat-Reaktion zur gewünschten Farbentstehung führt, die den Sekundärantikörper und somit das gesuchte Protein sichtbar macht.

Für die durchzuführende immunhistochemische Färbung waren eine Entparaffinierung der Schnitte und eine Vorbehandlung des jeweiligen Antikörpers notwendig.

Die verwendeten Antikörper mit zugehöriger Vorbehandlung und Verdünnung sind in Tabelle 2.3/1 aufgeführt.

Im ersten Schritt der Entparaffinierung wurden die auf silanbeschichteten Objektträgern fixierten Paraffinschnitte für 15 min in einer Xylol-Lösung inkubiert. Dies führte zur Lösung des Paraffins. Durch eine anschließende absteigende Alkoholreihe wurde das Paraffin 
herausgewaschen und Wasser eingelagert. Dies ist eine wichtige Voraussetzung für die immunhistochemische Färbung.

Die absteigende Alkoholreihe bestand aus drei unterschiedlich konzentrierten Alkohollösungen, in die die Schnitte pro Bad für 1-2 min gestellt wurden. Ein dreimaliges Bad mit 100\%igem Alkohol war der Beginn und wurde durch ein 96\%iges und ein anschließendes 75\%iges Alkoholbad abgewechselt.

Der Abschluss der Entparaffinierung bestand in der Spülung mit demineralisiertem Wasser. 
Tabelle 2.3/1: Übersicht über die verwendeten Antikörper

\begin{tabular}{|c|c|c|c|c|c|c|}
\hline Antikörper & Clone ID & $\begin{array}{l}\text { Bestell- } \\
\text { Nr. }\end{array}$ & $\begin{array}{l}\text { Firma (Stadt, } \\
\text { Land) }\end{array}$ & $\begin{array}{l}\text { verwendete } \\
\text { Verdünnung }\end{array}$ & $\begin{array}{l}\text { Vorbe- } \\
\text { handlung }\end{array}$ & $\begin{array}{l}\text { zelluläre } \\
\text { Lokalisation }\end{array}$ \\
\hline KIT & YR145 & $1522-1$ & $\begin{array}{l}\text { Epitomics, } \\
\text { (Burlingame, } \\
\text { CA, USA) }\end{array}$ & $1: 250$ & Citrat pH6 & zytoplasmatisch \\
\hline PDGFRA & $\begin{array}{l}\text { polyclonal } \\
\text { rabbit }\end{array}$ & $\begin{array}{l}\text { RB- } \\
\text { 9027-P }\end{array}$ & $\begin{array}{l}\text { NeoMarkers } \\
\text { (Fremont, CA, } \\
\text { USA) }\end{array}$ & $1: 200$ & Citrat pH 6 & zytoplasmatisch \\
\hline SRC & EG107 & $1587-1$ & $\begin{array}{l}\text { Epitomics, } \\
\text { (Burlingame, } \\
\text { CA, USA) }\end{array}$ & $1: 100$ & Citrat $\mathrm{pH} 9$ & zytoplasmatisch \\
\hline AKT1 & E45 & $1085-1$ & $\begin{array}{l}\text { Epitomics, } \\
\text { (Burlingame, } \\
\text { CA, USA) }\end{array}$ & $1: 1000$ & Citrat pH 6 & zytoplasmatisch \\
\hline ERK2 & E460 & $1586-1$ & $\begin{array}{l}\text { Epitomics, } \\
\text { (Burlingame, } \\
\text { CA, USA) }\end{array}$ & $1: 1000$ & Citrat pH 6 & nucleär \\
\hline Cyclin-D1 & SP4 & $\begin{array}{l}\text { RM- } \\
\text { 9104-R7 }\end{array}$ & $\begin{array}{l}\text { NeoMarkers } \\
\text { (Fremont, CA, } \\
\text { USA) }\end{array}$ & $1: 100$ & Citrat $\mathrm{pH} 6$ & nucleär \\
\hline E2F1 & КH 95 & $\begin{array}{l}\text { DLN- } \\
11363\end{array}$ & $\begin{array}{l}\text { Dianova } \\
\text { (Hamburg, } \\
\text { Deutschland) }\end{array}$ & $1: 200$ & Citrat pH 6 & nucleär \\
\hline $\begin{array}{l}\text { Mib-1- } \\
\text { Antigen }\end{array}$ & Mib-1 & M7240 & $\begin{array}{l}\text { Dako } \\
\text { (Hamburg, } \\
\text { Deutschland) }\end{array}$ & $1: 200$ & Citrat $\mathrm{pH} 6$ & nucleär \\
\hline Cyclin-B1 & Y106 & $1495-1$ & $\begin{array}{l}\text { Epitomics, } \\
\text { (Burlingame, } \\
\text { CA, USA) }\end{array}$ & $1: 100$ & Citrat $\mathrm{pH} 9$ & nucleär \\
\hline
\end{tabular}

Bei der immunhistochemischen Färbung fand das Dako REAL Detection System, Alkaline Phosphatase/RED, Rabbit/Mouse (Hamburg, Deutschland) Verwendung. Die Färbung beruht 
auf der Labelled (Strept-)Avidin-Biotin-Methode (LSAB, markiertes Streptavidin-Biotin) und wird in einem Drei-Schritte-Verfahren eingesetzt.

Zuerst wurde das Gewebe mit dem jeweiligen verdünnten Primärantikörper (Tabelle 2.3.1/1), danach mit einem Sekundärantikörper (Dako REAL TM Link, Biotinylated Secondary Antibodies (AB2)) und zuletzt mit Dako REAL Streptavidin Alkaline Phosphatase (AP) inkubiert. Abschließend wurde die Reaktion mit RED Chromogen sichtbar gemacht.

Im Folgenden werden die jeweiligen Einzelschritte der Färbung beschrieben.

Der erste Schritt des Färbevorgangs bestand aus einer fünfminütigen Waschung der Tissue Microarrays in einem neutralen TRIS-Puffer (12g TRIS + $18 \mathrm{~g} \mathrm{NaCl} / 2$ l bi-dest $\mathrm{H}_{2} 0$, pH: 7,4). Zum Blockieren des endogenen Biotins wurde mit der BSA-Fraktion-V (2g BSA / 100ml TRIS-Puffer) für 10 min inkubiert, worauf sich eine dreißigminütige Inkubation mit dem primären Antikörper bei Raumtemperatur anschloss.

Nach dreimaligem Waschen mit dem TRIS-Puffer wurde der sekundäre Antikörper (Dako REAL TM Detection System, Alkaline Phosphatase/RED, Link, Biotinylated Secondary Antibody) für 20 min hinzugegeben.

Nun wurde abermals mit dem TRIS-Puffer dreimal gewaschen und daraufhin das AP-EnzymKonjugat (Dako Real TM Detection, Alkaline Phophatase/RED Streptavidin Alkaline Phosphatase (AP)) für 20 min inkubiert, so dass abschließend nach erneuter dreimaliger Waschung mit TRIS-Puffer die Farbreaktion mit Chromogen (Dako REAL TM Detection System, Chromogen (RED)) vollzogen werden konnte. Die Einwirkzeit des Chromogens (Ansatz: $1 \mathrm{ml}$ Puffer $+40 \mu 1$ RED1 $+40 \mu 1$ RED2 $+40 \mu 1$ RED3 $+5 \mu 1$ Levamisol) betrug dabei 20 min.

Eine anschließende Spülung mit demineralisiertem Wasser trennte die nicht gebundenen Antikörper vom Gewebe.

Die nicht mit Antikörper besetzten Zellbestandteile wurden anschließend mittels Gegenfärbung mit Hämalaun nach Mayer gebläut, so dass später unter dem Mikroskop sowohl die positiv gefärbten, als auch die für den Antikörper negativen Anteile sichtbar waren.

Für die im nächsten Schritt folgende Eindeckung der TMAs auf dem Objektträger war es notwendig, das Wasser zu entfernen und Xylol einzuziehen. Dies wurde durch eine 
aufsteigende Alkoholreihe (ein Bad mit 75\%igem, ein Bad mit 96\%igem, drei Bäder mit 100\%igem Alkohol) und ein abschließendes dreimaliges Xylol-Bad gewährleistet.

\subsection{Quantitative Auswertung der immunhistochemischen Färbungen}

Mithilfe der fotographischen Auswertung war es möglich, quantitative und reproduzierbare Aussagen über die Ergebnisse zu machen.

Zur Auswertung der Ergebnisse wurden die immunhistochemisch gefärbten Tissue Microarrays lichtmikroskopisch untersucht und der aussagekräftigste Bildschnitt der Gewebeprobe mit einer Digital-Kamera (Olympus CAMEDIA C-5050 Zoom) und einer Auflösung von 5.0 Megapixel fotografiert. Die Fotos wurden anschließend entsprechend der verwendeten Matrix sortiert gespeichert und standen der computergestützten Auswertung mittels einer speziellen Software zur Verfügung (Cameron et al. 2008).

Bei nukleären Färbungen erfolgt die Markierung und Zählung aller auf dem Bildschnitt befindlichen Zellkerne, gefolgt von einem zweiten Durchlauf, bei dem nur die positiv gefärbten Zellkerne markiert und gezählt werden.

Die Relation der markierten positiv-gefärbten zu allen markierten Zellkernen in Prozent ergab schließlich eine quantitative Aussage über die Expressionsstärke der untersuchten Gene (Abbildung 2.4/1). 

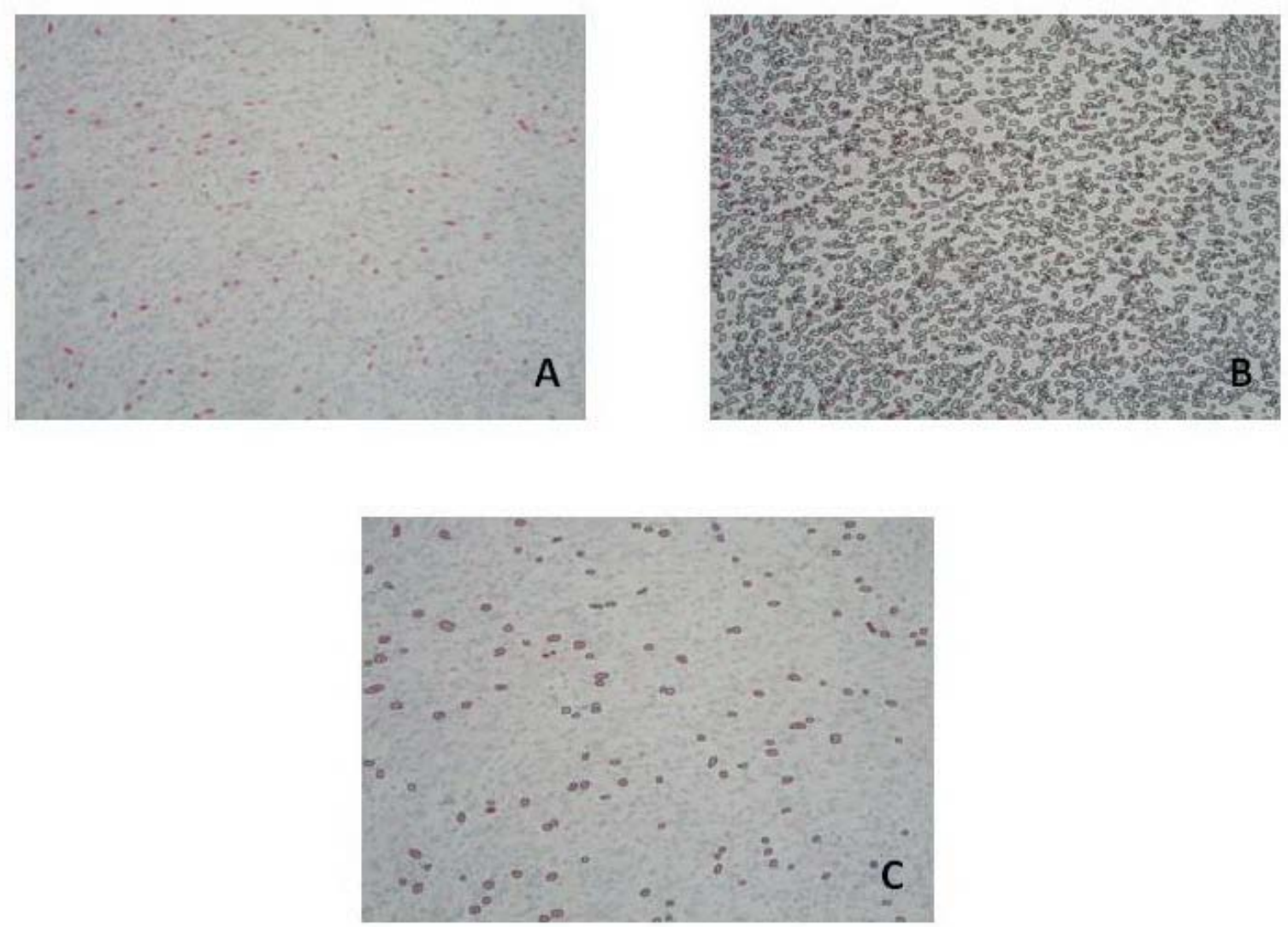

Abb.2.4/1: Beispiel einer computergestützten Foto-Auswertung (A: Ausgangsfoto, B: Markierung aller auf dem Bildschnitt befindlichen Zellkerne, C: Markierung der positiv gefärbten Zellkerne)

Bei zytoplasmatischen Färbungen hingegen wurde die Stärke der Expression als Färbeintensität gemittelt über alle Tumorzellen gemessen. Sie wurde daher ebenfalls als quantitative Expression, jedoch ohne Benennung einer Einheit, angegeben.

\subsection{Statistik}

Die statistische Auswertung der Daten und die Erstellung aller Tests und Graphiken erfolgten mit Statistica 8.0 (StatSoft, Hamburg, Germany). Die klinisch-pathologischen und immunhistochemischen Daten wurden dabei mit T-Tests für unabhängige Gruppen evaluiert und mittels Box-Plots graphisch dargestellt. Die nicht-nummerischen Daten wie die 
histologische Tumorentität bzw. die Verteilung der molekulargenetischen Untergruppen und ihre entsprechenden anatomischen Lokalisationen wurden mittels Vier-Felder-Tafeln erfasst und mit Kreisdiagrammen bzw. Tabellen veranschaulicht. 


\section{Ergebnisse}

\subsection{Darstellung des untersuchten Tumorkollektivs}

Bei 137 der 163 Patienten (84,0 \%) lag ein GIST vor, bei 15 (9,2 \%) ein Leiomyom, und bei 11 (6,8 \%) ein Leiomyosarkom (Abbildung 3.1.1/1).

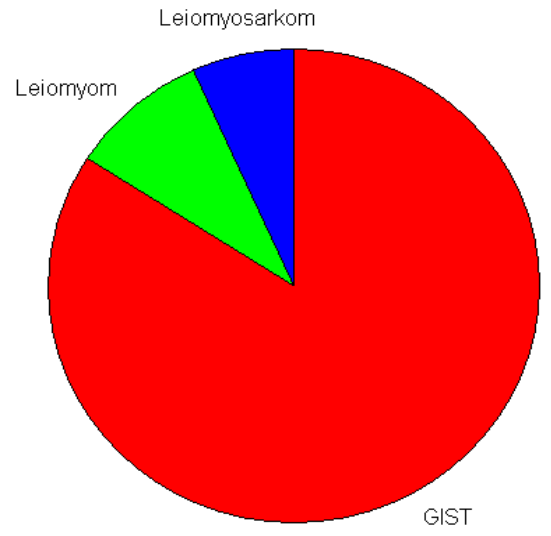

Abb.3.1.1/1: Verteilung der histologischen Tumorentitäten im untersuchten Kollektiv

\subsection{Klinisch-pathologische Parameter}

\subsubsection{Geschlechterverhältnis}

Bei den GIST waren 65 der 137 Patienten weiblich (47,4 \%), 72 waren männlich (52,6 \%), dies entsprach einem Geschlechterverhältnis von Frauen zu Männern von 1:1,1.

Bei den Leiomyomen waren 5 der 15 Patienten Frauen (33,3 \%), 10 waren Männer (66,7 \%), dies entsprach einem Geschlechterverhältnis von Frauen zu Männern von 1:2. 
Bei den Leiomyosarkomen waren 6 der 11 Patienten weiblich (54,5 \%), 5 waren männlich (45,5 \%), das Geschlechterverhältnis Frauen zu Männern betrug 1:0,8.

Innerhalb der histologischen Tumorentitäten bestand kein signifikanter Unterschied hinsichtlich der Geschlechterverteilung.

\subsubsection{Altersverteilung der Patienten}

Das Alter der Patienten mit GIST lag zwischen 33 und 91 Jahren und betrug im Mittel 67,4 Jahre ( \pm 11,2 Jahre).

Die Patienten mit Leiomyom waren zwischen 21 und 89 Jahren alt, das Alter betrug im Mittel 51,7 Jahre ( \pm 18,9 Jahre).

Das Alter der Patienten mit Leiomyosarkom variierte zwischen 46 und 80 Jahren und betrug im Mittel 60,2 Jahre ( \pm 11,6 Jahre).

Der Vergleich des Patientenalters zwischen den drei histologischen Tumorentitäten zeigte, dass Patienten mit GIST signifikant älter waren als Patienten mit Leiomyom $(p=0,000005)$ bzw. mit Leiomyosarkom ( $\mathrm{p}=0,04)$ (Abbildung 3.2.2/1).

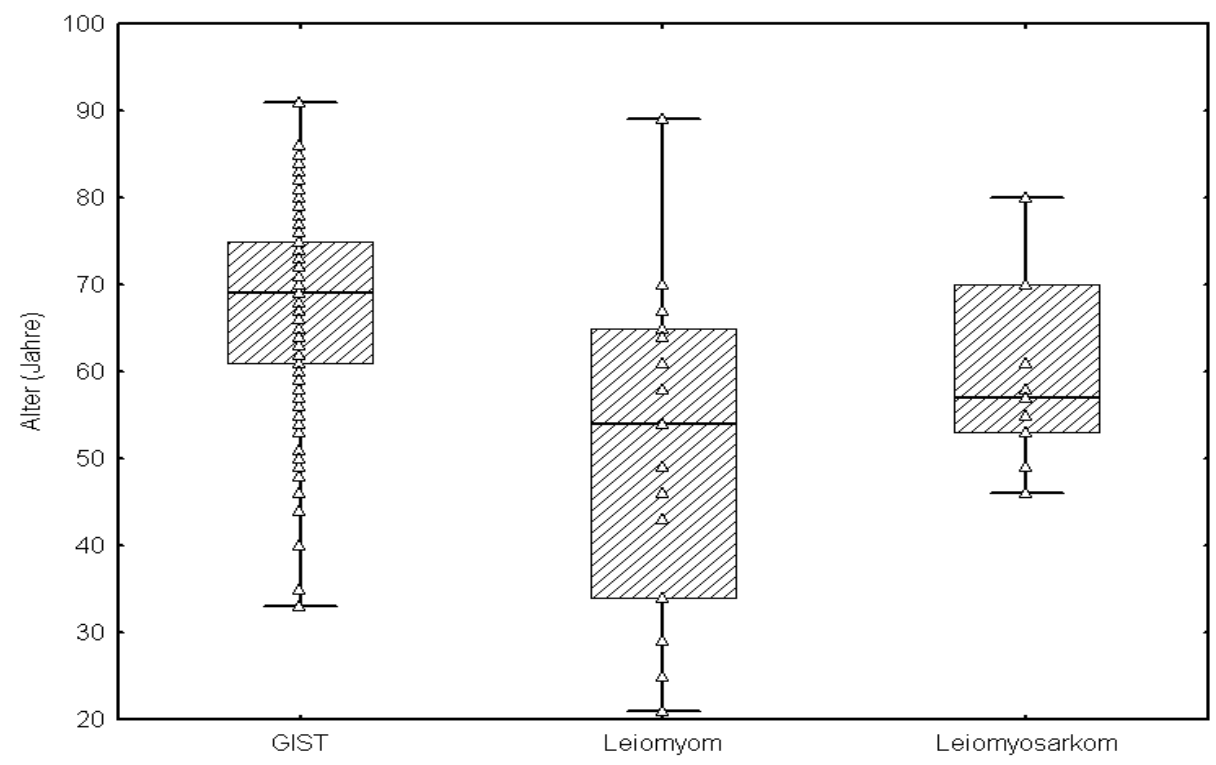

Abb. 3.2.2/1: Patientenalter (mittlere horizontale Linie: Median, innere Box: 25\% - 75\%-Intervall, Kreise: Ausreißer, äußere Begrenzungen: Minimum und Maximum) 


\subsubsection{Tumorgröße}

GIST besaßen eine maximale Tumorgröße, die zwischen 0,7 und $30 \mathrm{~cm}$ variierte und im Mittel 7,1 cm $( \pm 5,1 \mathrm{~cm})$ betrug.

Leiomyome waren zwischen 0,4 und $16 \mathrm{~cm}$ groß; im Mittel 4,6 cm $( \pm$ 4,5 cm).

Leiomyosarkome zeigten eine maximale Tumorgröße, die zwischen 2,5 und 29,0 cm lag und im Mittel 8,0 cm ( \pm 7,4 cm) betrug.

Zwischen GIST, Leiomyomen und Leiomyosarkomen bestand kein signifikanter Unterschied hinsichtlich der maximalen Tumorgröße, wobei Leiomyome tendenziell kleiner waren (Abbildung 3.2.3/1).

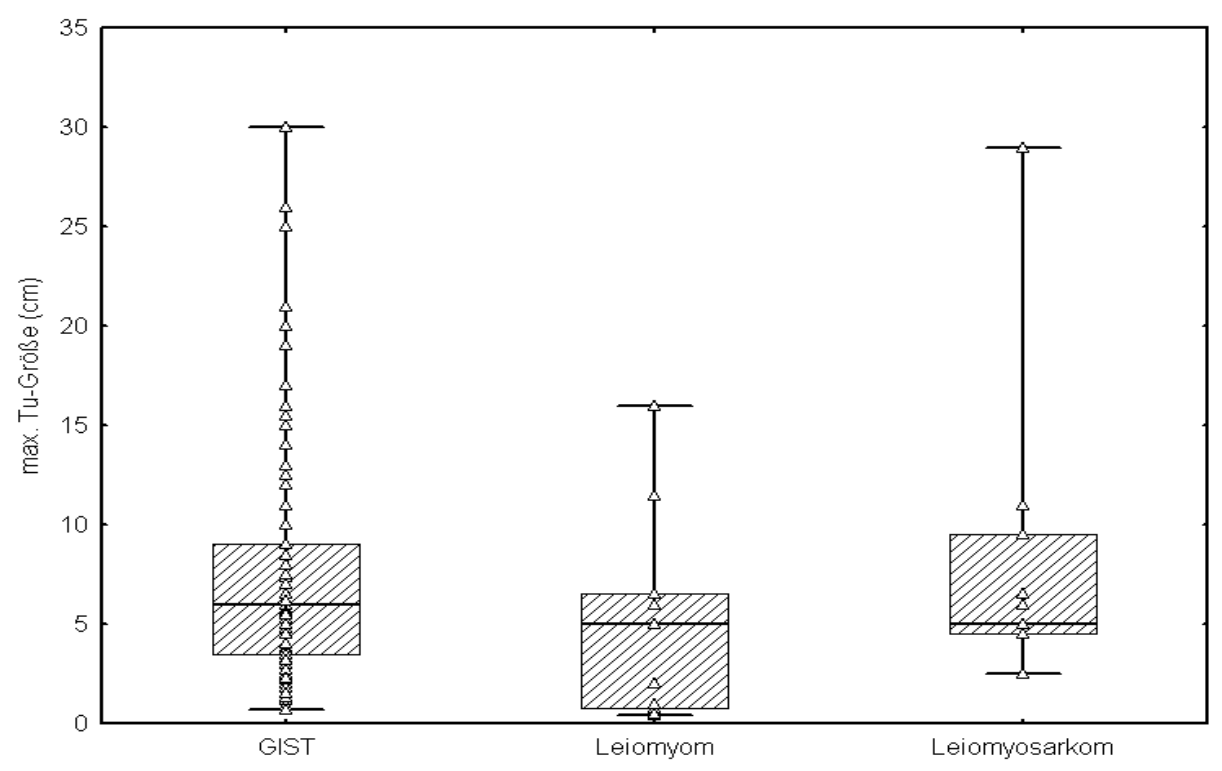

Abb. 3.2.3/1: Maximale Tumorgröße (mittlere horizontale Linie: Median, innere Box: 25\% - 75\%-Intervall, Kreise: Ausreißer, äußere Begrenzungen: Minimum und Maximum)

\subsubsection{Anatomische Lokalisation}

GIST, Leiomyome und Leiomyosarkome wiesen deutliche Unterschiede in der Verteilung der anatomischen Lokalisation auf. 
Die absoluten und relativen Anzahlen und entsprechende Signifikanz-Werte der untersuchten Vergleiche sind in Tabelle 3.2.4/1 dargestellt. Einen Überblick über die prozentuale Verteilung der drei Tumorentitäten zeigt Abbildung 3.2.4/2.

Bei den GIST kamen von 137 untersuchten Fällen 0 im Ösophagus (0 \%), 80 im Magen (58,4 \%), 42 im Dünndarm (30,6 \%), 9 im Dickdarm (6,6 \%) und 6 (4,4 \%) extraintestinal vor.

Bei den 15 Leiomyomen waren 3 (20 \%) im Ösophagus, 2 (13,3 \%) im Magen, 2 (13,3 \%) im Dünndarm, 8 im Dickdarm (53,4 \%) und 0 (0 \%) extraintestinal lokalisiert.

Bei den 11 untersuchten Leiomyosarkomen kamen 1 (9,1 \%) im Ösophagus, 0 (0 \%) im Magen, 1 (9,1 \%) im Dünndarm, 3 (27,3 \%) im Dickdarm und 6 (54,5 \%) extraintestinal vor.

GIST kamen damit im Vergleich zu Leiomyomen $(\mathrm{p}<0,0009)$ und Leiomyosarkomen $(p=0,0002)$ signifikant häufiger im Magen vor.

Im Gegensatz dazu traten Leiomyome und Leiomyosarkome im Vergleich zu GIST signifikant häufiger im Dickdarm $(\mathrm{p}<0,0001$ und $\mathrm{p}=0,01)$ und Ösophagus $(\mathrm{p}<0,0001$ und $\mathrm{p}=0,0004)$ auf.

Leiomyosarkome kamen im Vergleich zu GIST $(\mathrm{p}<0,0001)$ und Leiomyomen $(p=0,001)$ signifikant häufiger extraintestinal vor. 
Tab.3.2.4/1: Überblick und Vergleich der anatomischen Lokalisation der drei Tumorentitäten (der linke Teil der Tabelle zeigt die absoluten und relativen Anzahlen von GIST, LM, LMS, der linke Teil der Tabelle die Vergleiche zwischen den drei Tumorentitäten, fette Zahlen = signifikante p-Werte)

\begin{tabular}{|c|c|c|c|c|c|c|}
\hline \multirow[t]{4}{*}{ Lokalisation } & \multirow{2}{*}{ GIST } & \multirow{2}{*}{$\mathbf{L M}$} & \multirow{2}{*}{ LMS } & \multirow{2}{*}{$\begin{array}{l}\text { GIST vs. } \\
\text { LM }\end{array}$} & \multirow{2}{*}{$\begin{array}{l}\text { GIST vs. } \\
\text { LMS }\end{array}$} & \multirow{2}{*}{$\begin{array}{l}\text { LM vs. } \\
\text { LMS }\end{array}$} \\
\hline & & & & & & \\
\hline & Anzahl & Anzahl & Anzahl & p-Werte & p-Werte & p-Werte \\
\hline & (Prozent) & (Prozent) & (Prozent) & & & \\
\hline Ösophagus & $0(0 \%)$ & $3(20 \%)$ & $1(9,1 \%)$ & $p=0,0001$ & $p=0,0004$ & $\mathrm{p}=0,4$ \\
\hline Magen & $80(58,4 \%)$ & $2(13,3 \%)$ & $0(0 \%)$ & $p=0,0009$ & $p=0,0002$ & $\mathrm{p}=0,2$ \\
\hline Dünndarm & $42(30,6 \%)$ & $2(13,3 \%)$ & $1(9,1 \%)$ & $\mathrm{p}=0,2$ & $\mathrm{p}=0,1$ & $\mathrm{p}=0,7$ \\
\hline Dickdarm & $9(6,6 \%)$ & $8(53,4 \%)$ & $3(27,3 \%)$ & $p=0,0001$ & $p=0,01$ & $\mathrm{p}=0,2$ \\
\hline extraintestinal & $6(4,4 \%)$ & $0(0 \%)$ & $6(54,5 \%)$ & $\mathrm{p}=0,4$ & $p=0,0001$ & $p=0,001$ \\
\hline Gesamt & 137 (100\%) & 15 (100\%) & 11 (100\%) & & & \\
\hline
\end{tabular}




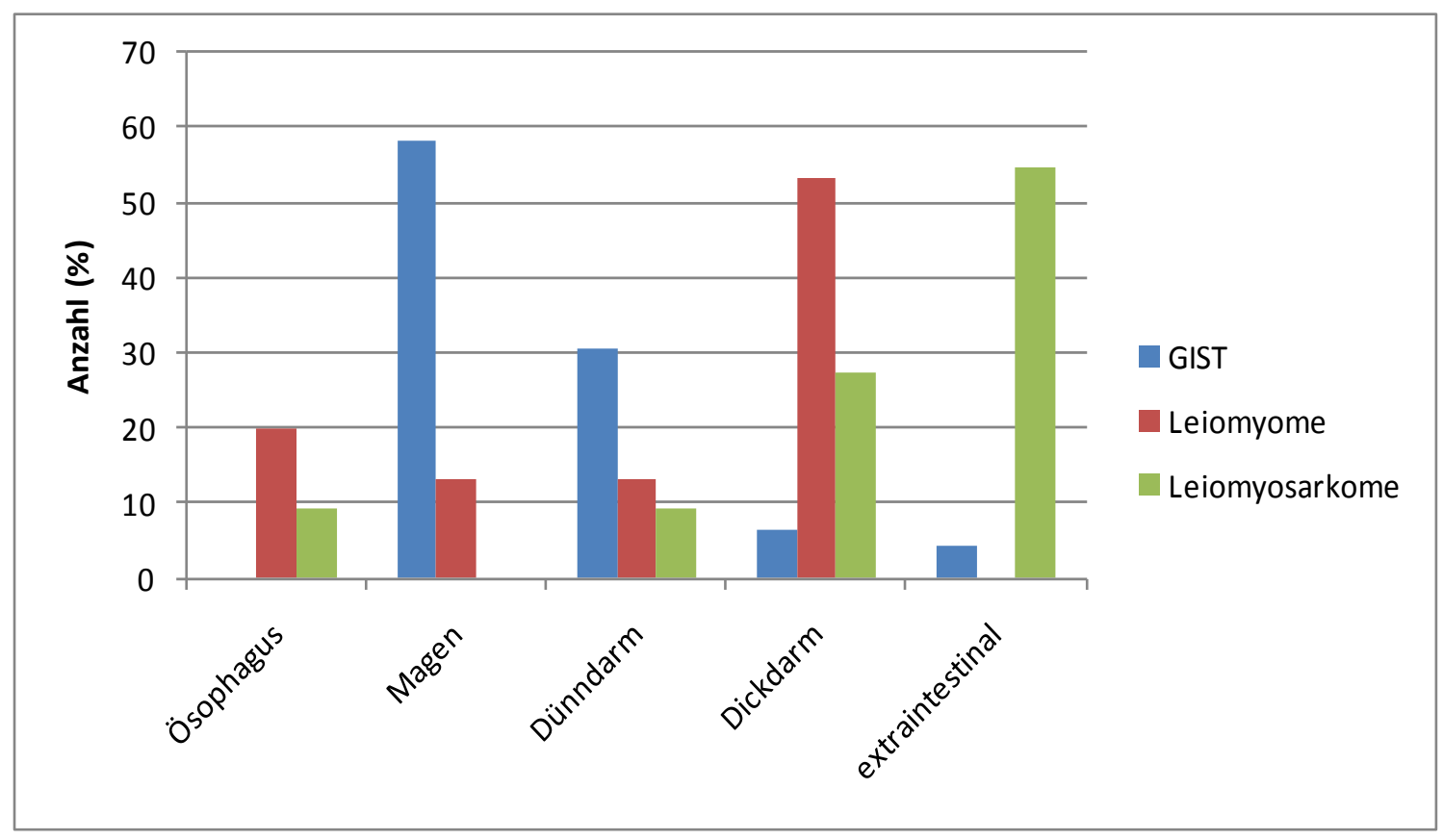

Abb. 3.2.4/2: anatomische Lokalisation

\subsubsection{Mitosenanzahl}

Die Mitosenanzahl der GIST variierte zwischen 0 und 245/50 HPFs und betrug im Mittel 17,6/50 HPFs ( \pm 36,7/50 HPFs).

Leiomyome besaßen eine Mitosenanzahl zwischen 0 und 3/50 HPFs, im Mittel 0,5/50 HPFs ( \pm 1,0/50 HPFs).

Leiomyosarkome wiesen eine Mitosenanzahl zwischen 22 und 165/50 HPFs auf, im Mittel 70,8/50 HPFs ( \pm 45,7/50 HPFs).

GIST wiesen im Vergleich zu den Leiomyomen mehr Mitosen auf, dieser Unterschied war allerdings nicht signifikant.

Leiomyosarkome wiesen sowohl im Vergleich zu GIST $(\mathrm{p}=0,00001)$ als auch zu Leiomyomen $(\mathrm{p}=0,000003)$ eine signifikant höhere Anzahl an Mitosen auf (Abbildung $3.2 .5 / 1)$. 


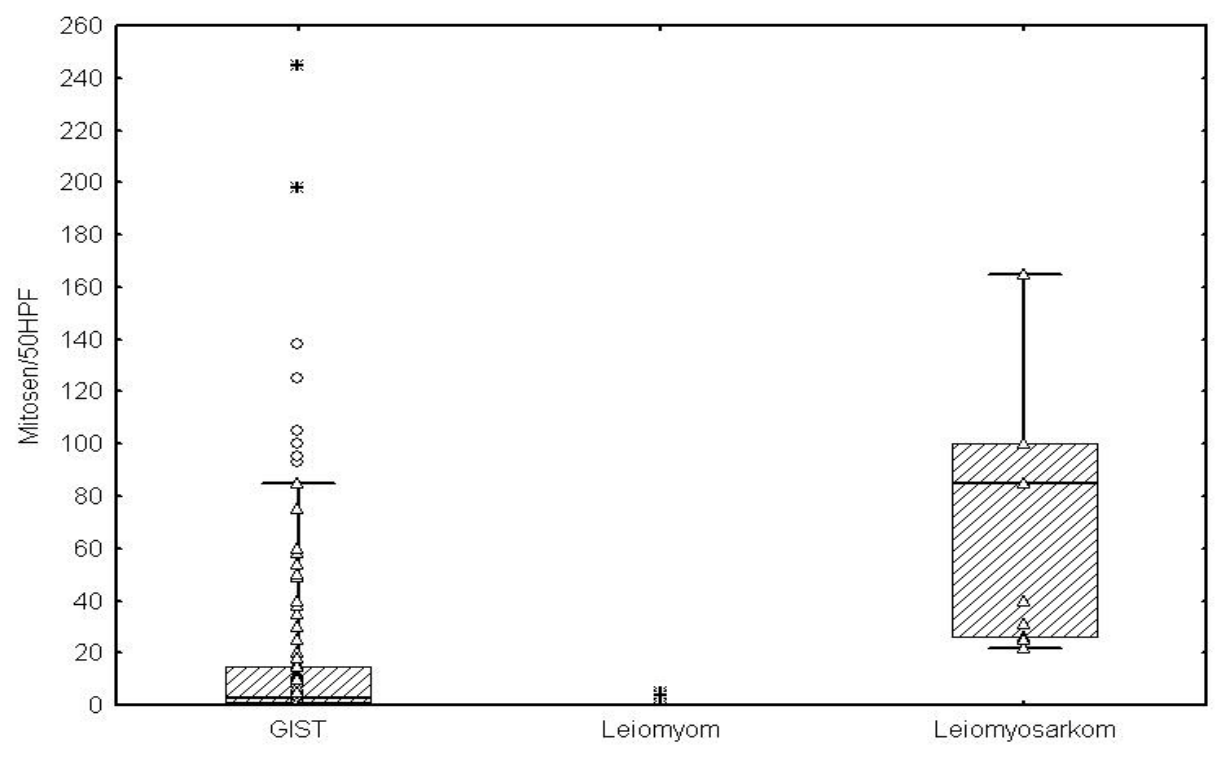

Abb. 3.2.5/1: Mitosenanzahl (mittlere horizontale Linie: Median, innere Box: 25\% - 75\%-Intervall, Kreise: Ausreißer, äußere Begrenzungen: Minimum und Maximum)

\subsection{Expression der Rezeptor-Tyrosin-Kinasen}

Die Stärke der Expression der untersuchten Signaltransduktionsproteine wurde als Färbeintensität gemittelt über alle Tumorzellen gemessen, und wird daher als Expression (ohne Benennung einer Einheit) bezeichnet.

\subsubsection{KIT}

GIST zeigten eine KIT-Expression, die im Mittel 27,1 ( \pm 16,5) betrug.

Leiomyome zeigten eine KIT-Expression, die im Mittel 0,4 $( \pm 0,8)$ betrug.

Leiomyosarkome zeigten eine KIT-Expression im Mittel von 0,2 $( \pm 0,1)$.

GIST hatten eine 67,8-fach höhere KIT-Expression als Leiomyome und eine 135,5-fach höhere als Leiomyosarkome. Es bestand damit ein signifikanter Unterschied zwischen GIST und Leiomyomen $(\mathrm{p}<0,000001)$ bzw. GIST und Leiomyosarkomen $(\mathrm{p}<0,000001)$ (Abbildung 3.3.1/1). 


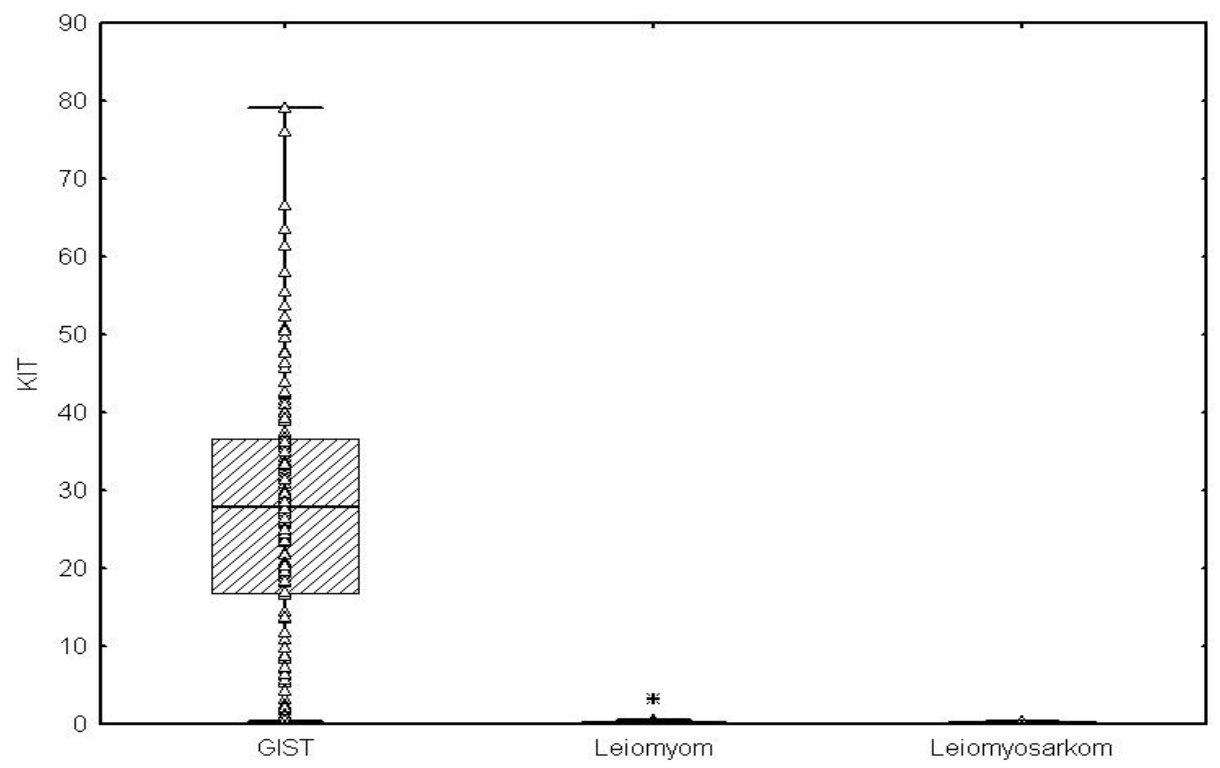

Abb. 3.3.1/1: Expression von KIT (mittlere horizontale Linie: Median, innere Box: 25\% - 75\%-Intervall, Kreise: Ausreißer, äußere Begrenzungen: Minimum und Maximum)

\subsubsection{PDGFRA}

GIST wiesen eine PDGFRA-Expression auf, die im Mittel 18,5 $( \pm 14,0)$ betrug.

Leiomyome wiesen eine PDGRFA-Expression auf, die im Mittel 1,0 ( $\pm 1,0)$ betrug.

Leiomyosarkome zeigten eine PDGFRA-Expression, die im Mittel 11,0 ( $\pm 11,3)$ betrug.

GIST hatten im Vergleich zu Leiomyomen eine 18,5-fach höhere PDGFRA-Expression, dieser Unterschied war signifikant $(\mathrm{p}=0,00001)$.

Einerseits bestand kein signifikanter Unterschied in der PDGFRA-Expression zwischen GIST und Leiomyosarkomen, andererseits wiesen die Leiomyosarkome eine 11-fach höhere PDGFRA-Expression als die Leiomyome auf $(p=0,004)$ (Abbildung 3.3.2/1). 


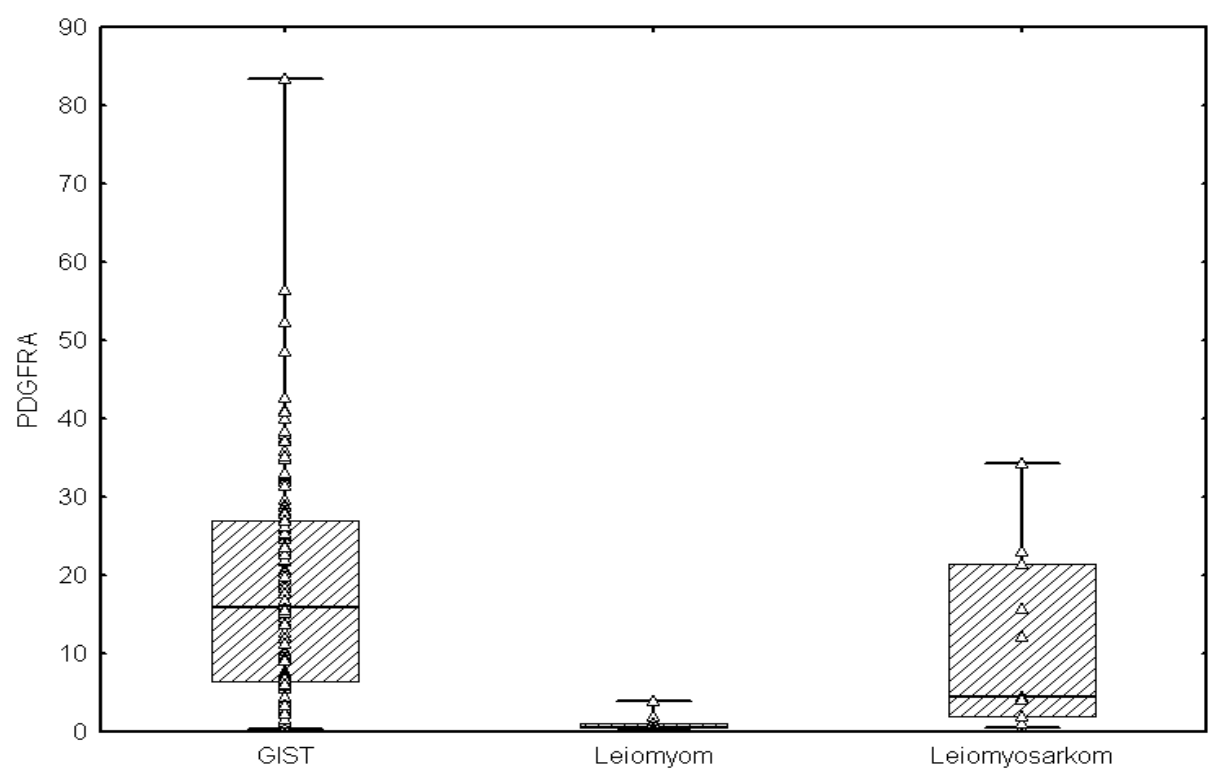

Abb.3.3.2/1: Expression von PDGFRA (mittlere horizontale Linie: Median, innere Box: 25\% - 75\%-Intervall, Kreise: Ausreißer, äußere Begrenzungen: Minimum und Maximum)

Eine Zusammenfassung über die Vergleiche hinsichtlich der KIT- und PDGFRA-Expression bei GIST, Leiomyomen und Leiomyosarkomen zeigt Tabelle 3.3.2/2.

Tab. 3.3.2/2: Zusammenfassung der Vergleiche hinsichtlich KIT- und PDGFRA-Expression (fette Zahlen = signifikante p-Werte)

\begin{tabular}{lll}
\hline & KIT & PDGFRA \\
& ratio (p-Wert) & ratio (p-Wert) \\
\hline GIST vs. LM & $67,8(\mathrm{p}=\mathbf{0 , 0 0 0 0 0 1})$ & $18,5(\mathrm{p}=\mathbf{0 , 0 0 0 0 1})$ \\
GIST vs. LMS & $135,5(\mathrm{p}=\mathbf{0 , 0 0 0 0 0 1})$ & $1,7(\mathrm{p}=\mathbf{0 , 0 9})$ \\
& & $11,0(\mathrm{p}=0,004)$ \\
\hline
\end{tabular}




\subsection{Expression der Signaltransduktions-Proteine}

\subsubsection{SRC}

GIST besaßen eine SRC-Expression, die im Mittel 12,3 $( \pm 8,6)$ betrug.

Leiomyome zeigten eine SRC-Expression, die im Mittel 5,3 $( \pm 4,1)$ betrug.

Leiomyosarkome wiesen eine SRC-Expression auf, die im Mittel 1,3 $( \pm 0,9)$ betrug.

GIST zeigten eine 9,5-fach höhere Expression von SRC im Vergleich zu Leiomyosarkomen und exprimierten damit signifikant mehr SRC $(\mathrm{p}=0,01)$ (Abbildung 3.4.1/1).

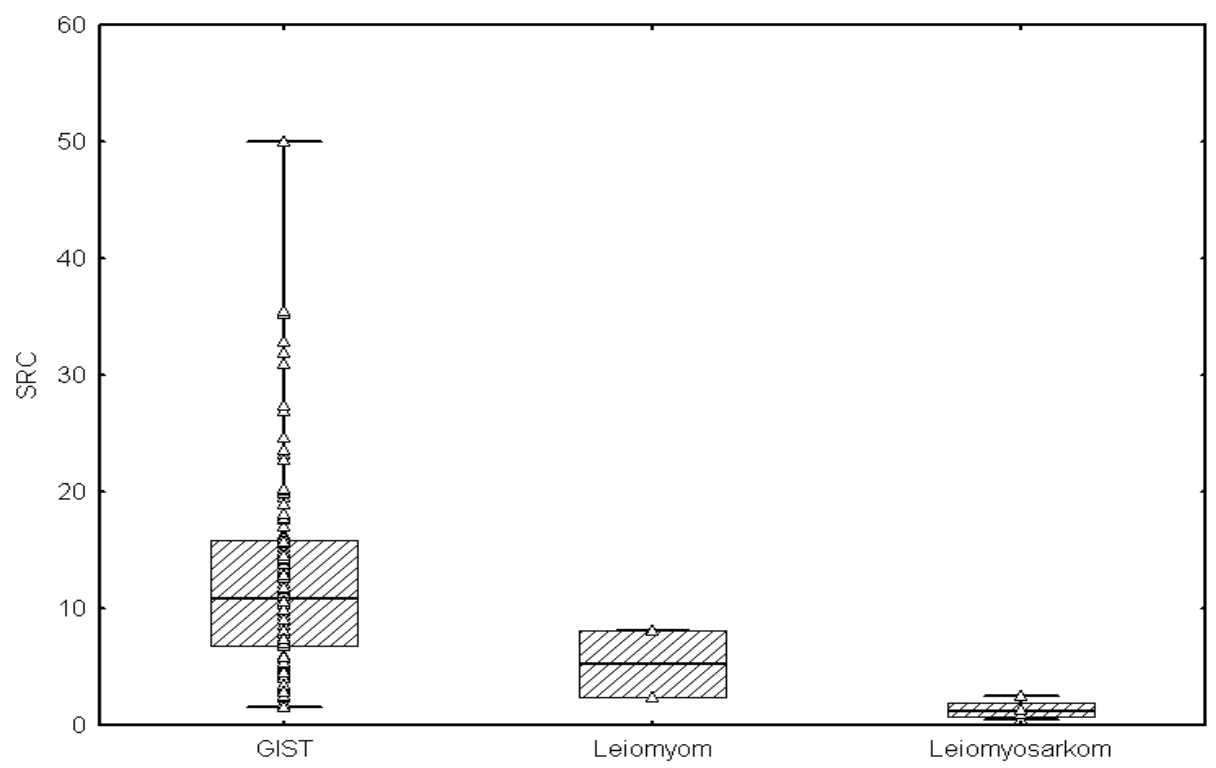

Abb. 3.4.1/1: Expression von SRC (mittlere horizontale Linie: Median, innere Box: 25\% - 75\%-Intervall, Kreise: Ausreißer, äußere Begrenzungen: Minimum und Maximum)

\subsubsection{AKT1}

GIST zeigten eine AKT1-Expression, die im Mittel bei 7,3 ( $\pm 5,1)$ lag.

Leiomyome wiesen eine AKT1-Expression auf, die im Mittel 2,1 $( \pm 2,6)$ betrug. 
Leiomyosarkome besaßen eine AKT1-Expression, die im Mittel bei 3,5 $( \pm 2,7)$ lag.

GIST wiesen eine Expression von AKT1 auf, die 3,5-fach höher war als die der Leiomyome und 2,1-fach höher als die der Leiomyosarkome.

Sowohl der Unterschied zwischen GIST und Leiomyomen $(\mathrm{p}=0,0005)$ als auch der zwischen GIST und Leiomyosarkomen ( $\mathrm{p}=0,03$ ) war signifikant (Abbildung 3.4.2/1).

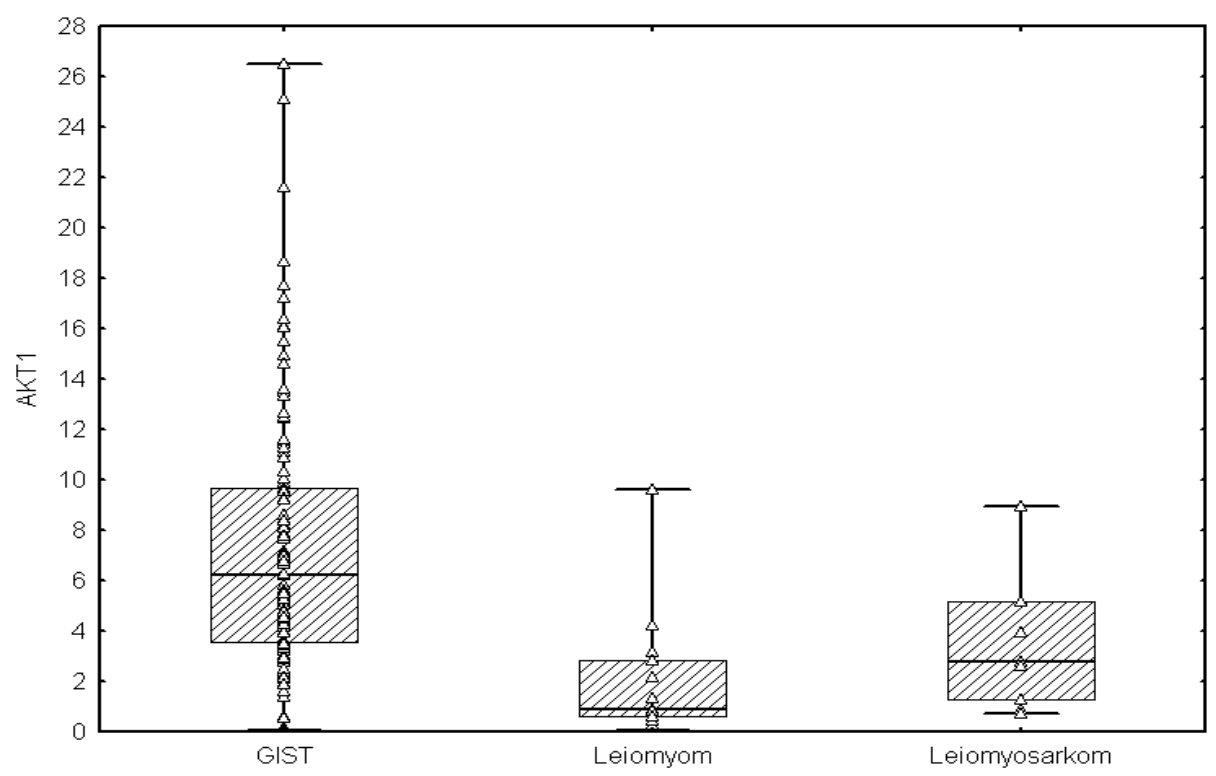

Abb. 3.4.2/1: Expression von AKT1 (mittlere horizontale Linie: Median, innere Box: 25\% - 75\%-Intervall, Kreise: Ausreißer, äußere Begrenzungen: Minimum und Maximum)

\subsubsection{ERK2}

GIST zeigten eine ERK2-Expression von im Mittel 11,7 $( \pm 9,2)$.

Leiomyome wiesen eine ERK2-Expression auf, die im Mittel 5,0 ( \pm 2,5) betrug.

Leiomyosarkome wiesen eine ERK2-Expression auf, die im Mittel 6,7 $( \pm 4,7)$ betrug.

GIST wiesen im Vergleich zu Leiomyomen eine 2,3-fach und damit signifikant höhere ERK2-Expression auf ( $\mathrm{p}=0,008)$ (Abbildung 3.4.3/1). 


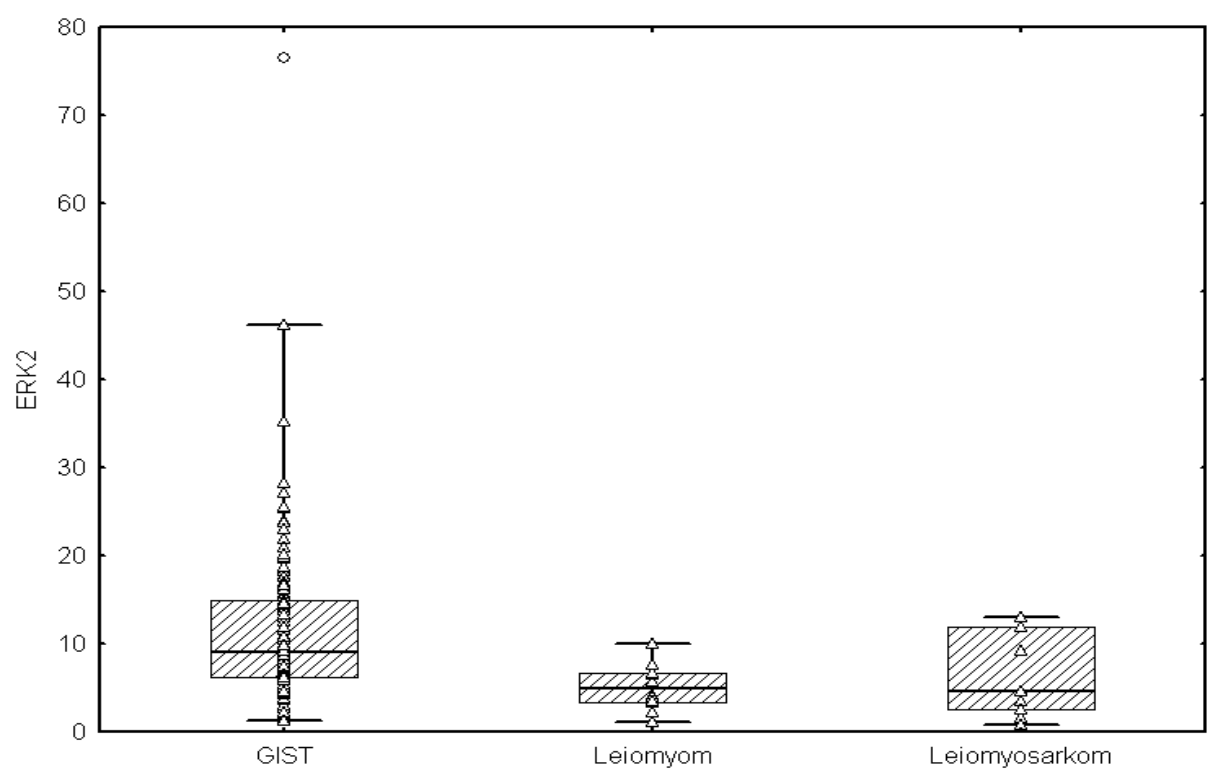

Abb. 3.4.3/1: Expression von ERK2 (mittlere horizontale Linie: Median, innere Box: 25\% - 75\%-Intervall, Kreise: Ausreißer, äußere Begrenzungen: Minimum und Maximum)

Eine Zusammenfassung über die Vergleiche hinsichtlich der Expression der untersuchten Signaltransduktions-Proteine bei GIST, Leiomyomen und Leiomyosarkomen zeigt Tabelle 3.4.3/2.

Tab. 3.4.3/2: Zusammenfassung Vergleiche hinsichtlich der Expression der untersuchten SignaltransduktionsProteine (fette Zahlen = signifikante $\mathrm{p}$-Werte)

\begin{tabular}{llll}
\hline & SRC & AKT1 & ERK2 \\
& ratio (p-Wert) & ratio (p-Wert) & ratio (p-Wert) \\
\hline GIST vs. $\mathbf{L M}$ & $2,3(\mathrm{p}=0,3)$ & $3,5(\mathrm{p}=\mathbf{0 , 0 0 0 5})$ & $2,3(\mathrm{p}=\mathbf{0 , 0 0 8})$ \\
GIST vs. $\mathbf{L M S}$ & $9,5(\mathrm{p}=\mathbf{0 , 0 1})$ & $2,1(\mathrm{p}=\mathbf{0 , 0 3})$ & $1,7(\mathrm{p}=0,08)$ \\
& & & $1,3(\mathrm{p}=0,3)$ \\
\hline
\end{tabular}




\subsection{Expression der Zellzyklus-Proteine}

Da sich Zellzyklus-Proteine durch eine starke Kernfärbung auszeichneten, wurde die Anzahl der positiven Tumorzellkerne durch die Gesamtanzahl der Tumorzellkerne ermittelt, und die Expressionsstärke in Prozent angegeben.

\subsubsection{Cyclin-D1}

GIST wiesen eine Cyclin-D1-Expression auf, die im Mittel 3,6 \% ( \pm 7,1\%) betrug.

Leiomyome besaßen eine Cyclin-D1-Expression von im Mittel 0,1 \% ( \pm 0,2.

Leiomyosarkomen wiesen eine Cyclin-D1-Expression auf, die im Mittel 1,4 \% $( \pm$ 3,5 \%) betrug.

GIST wiesen eine höhere Cyclin-D1-Expression als die leiomyogenen Tumoren auf, dieser Unterschied war allerdings nicht signifikant (Abbildung 3.5.1/1).

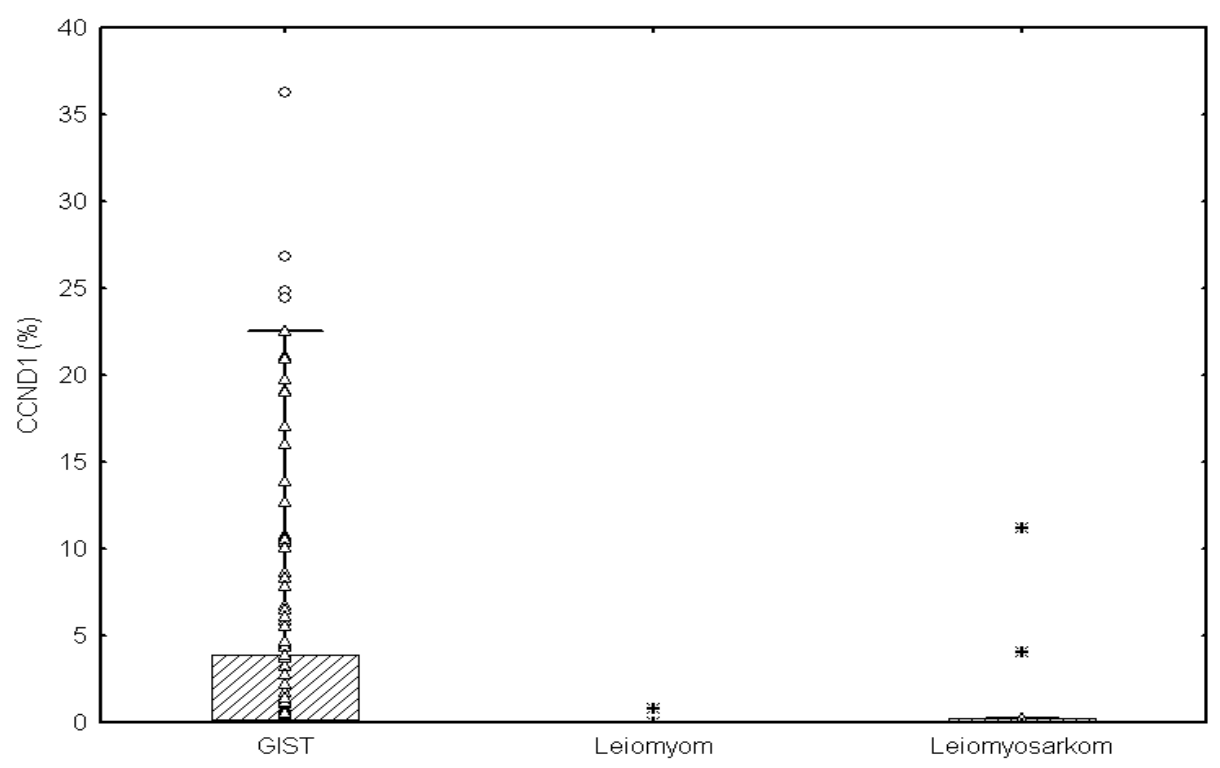

Abb. 3.5.1/1: Expressionsstärke von Cyclin-D1 (mittlere horizontale Linie: Median, innere Box: 25\% - 75\%Intervall, Kreise: Ausreißer, äußere Begrenzungen: Minimum und Maximum) 


\subsubsection{E2F1}

Die GIST als Gruppe wiesen im Mittel 3,4 \% ( \pm 3,8 \%) E2F1-positive Kerne auf.

Leiomyome zeigten im Mittel 0,7 \% ( \pm 0,7 \%) E2F1-positive Kerne.

Leiomyosarkomen wiesen im Mittel 7,9 \% ( \pm 7,0 \%) E2F1-positive Kerne auf.

Leiomyosarkome zeigten im Vergleich zu GIST eine um den Faktor 2,5 höhere Prozentzahl an E2F1-positiven Kernen und im Vergleich zu Leiomyomen eine 11,3-fach höhere.

Damit wiesen Leiomyosarkome signifikant mehr E2F1-positive Kerne als GIST ( $p=0,001)$ und Leiomyome ( $\mathrm{p}=0,03)$ auf (Abbildung 3.5.2/1).

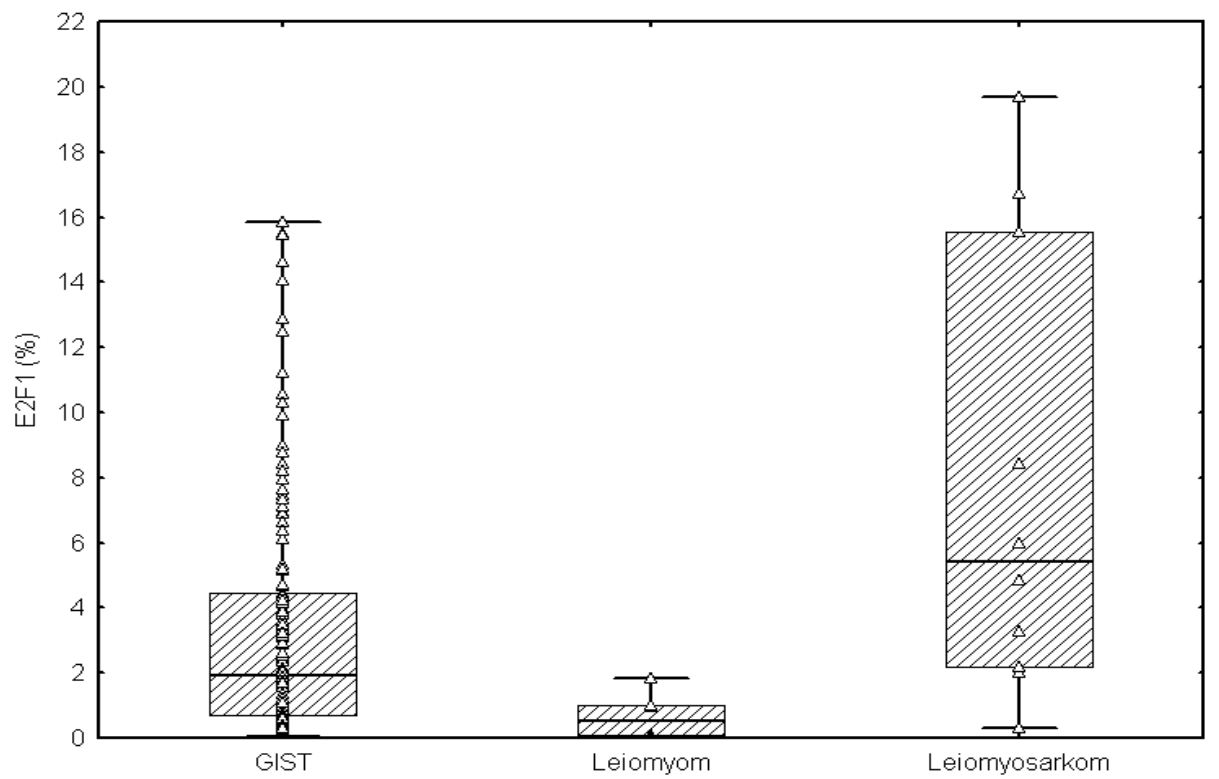

Abb. 3.5.2/1: Expressionsstärke von E2F1 (mittlere horizontale Linie: Median, innere Box: 25\% - 75\%Intervall, Kreise: Ausreißer, äußere Begrenzungen: Minimum und Maximum)

\subsubsection{Cyclin-B1}

GIST wiesen im Mittel 6,2 \% ( \pm 7,9 \%) Cyclin-B1-positive Kerne auf.

Leiomyome besaßen im Mittel 2,5 \% ( \pm 3,8 \%) Cyclin-B1-positive Kerne.

Leiomyosarkomen wiesen im Mittel 8,0 \% ( \pm 6,3 \%) Cyclin-B1-positive Kerne auf. 
Leiomyosarkome wiesen im Vergleich zu Leiomyomen eine 3,2-fach höhere Anzahl an Cyclin-B1-positiven Kernen auf. Damit zeigten Leiomyosarkome signifikant mehr CyclinB1-positive Kerne als Leiomyome $(p=0,02)$ (Abbildung 3.5.3/1).

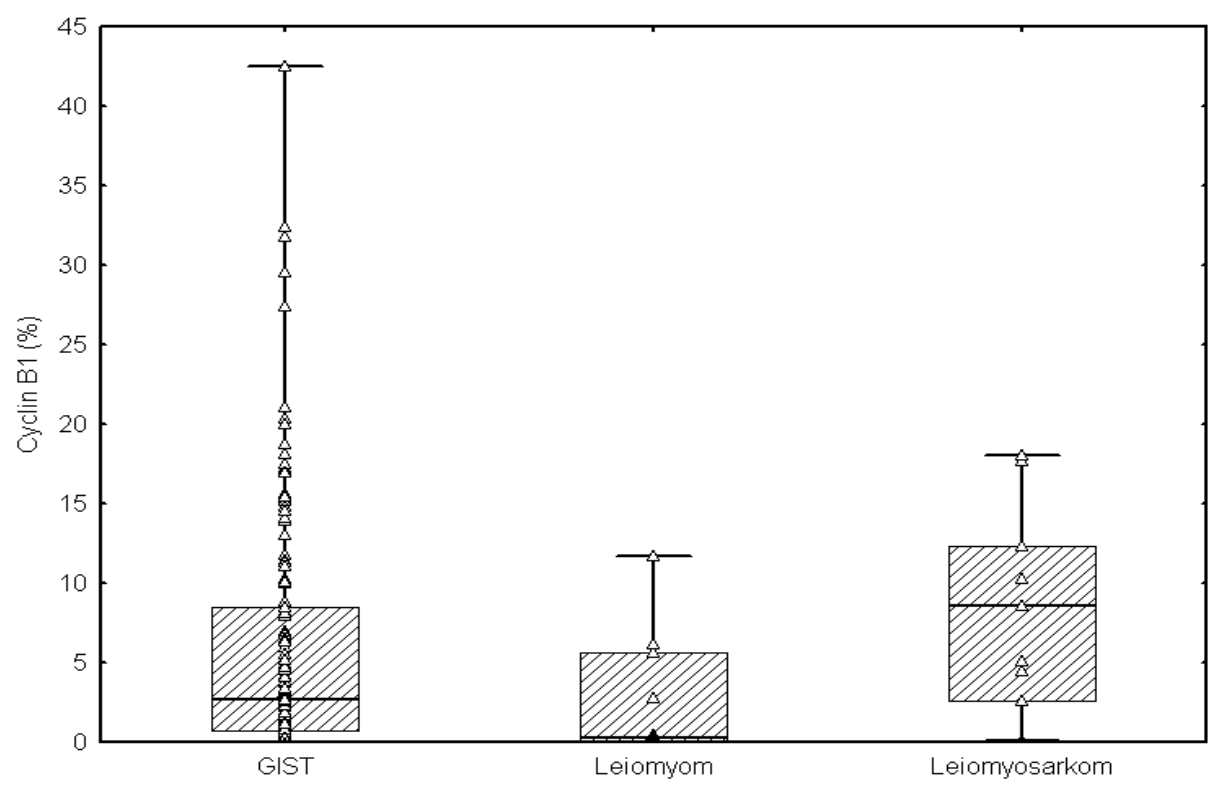

Abb. 3.5.3/1: Expressionsstärke von Cyclin-B1 (mittlere horizontale Linie: Median, innere Box: 25\% - 75\%Intervall, Kreise: Ausreißer, äußere Begrenzungen: Minimum und Maximum)

\subsubsection{Mib1-Antigen}

GIST zeigten im Mittel 2,4 \% ( \pm 3,8 \%) positive Mib1-Kerne.

Leiomyome wiesen eine Anzahl an Mib1-positiven Kernen auf, die im Mittel 0,2 \% ( \pm 0,3 \%) betrug.

Leiomyosarkome besaßen im Mittel 5,6 \% ( \pm 6,8 \%) Mib1-positive Kerne.

Der Vergleich der Mib1-positiven Kerne von GIST, Leiomyomen und Leiomyosarkomen zeigte, dass GIST im Vergleich zu Leiomyomen 12-fach mehr und damit signifikant mehr Mib1-positive Kerne ( $p=0,04)$ besaßen. 
Die Anzahl der Mib1-positiven Kerne der Leiomyosarkome war im Vergleich zu GIST um den Faktor 2,5 höher und im Vergleich zu Leiomyomen 28-fach höher.

Leiomyosarkome zeigten damit sowohl im Vergleich zu GIST $(p=0,02)$ als auch zu Leiomyomen ( $\mathrm{p}=0,005)$ signifikant mehr Mib-1-positiven Kerne (Abbildung 3.5.4/1).

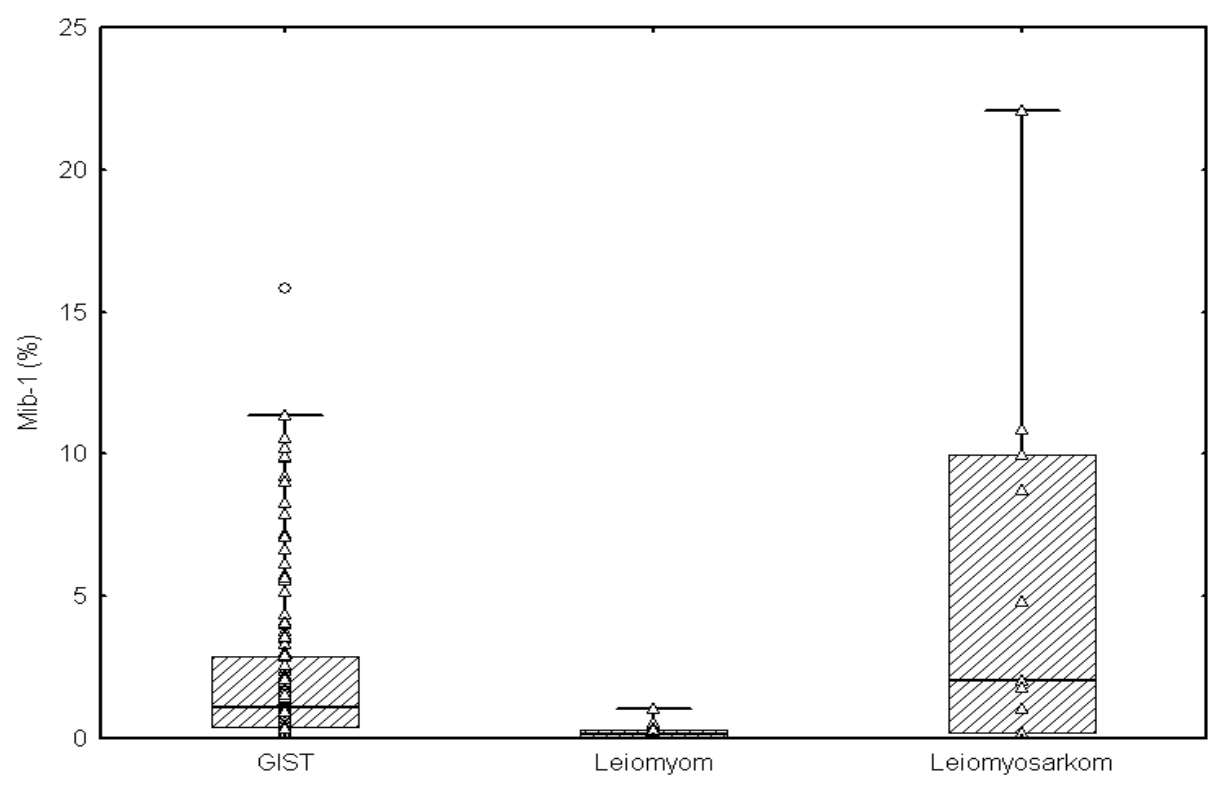

Abb. 3.5.4/1: Expressionsstärke von Mib1 (mittlere horizontale Linie: Median, innere Box: 25\% - 75\%Intervall, Kreise: Ausreißer, äußere Begrenzungen: Minimum und Maximum)

Eine Zusammenfassung über die Vergleiche hinsichtlich der Expression der untersuchten Zellzyklus-Proteine von GIST, Leiomyomen und Leiomyosarkomen zeigt Tabelle 3.5.4/2. 
Tab. 3.5.4/2: Zusammenfassung der Vergleiche hinsichtlich der Expression der untersuchten ZellzyklusProteine (fette Zahlen = signifikante p-Werte)

\begin{tabular}{lllll}
\hline & Cyclin-D1 & E2F1 & Cyclin-B1 & Mib1-Antigen \\
& ratio (p-Wert) & ratio (p-Wert) & ratio (p-Wert) & ratio (p-Wert) \\
\hline GIST vs. LM & $36(\mathrm{p}=0,1)$ & $4,9(\mathrm{p}=0,08)$ & $2,5(\mathrm{p}=0,1)$ & $12,0(\mathrm{p}=\mathbf{0 , 0 4})$ \\
GIST vs. LMS & $2,6(\mathrm{p}=0,3)$ & $0,4(\mathrm{p}=\mathbf{0 , 0 0 1})$ & $0,8(\mathrm{p}=0,5)$ & $0,4(\mathrm{p}=\mathbf{0 , 0 2})$ \\
LMS vs. LM & $14(\mathrm{p}=0,2)$ & $11,3(\mathrm{p}=\mathbf{0 , 0 3})$ & $3,2(\mathrm{p}=\mathbf{0 , 0 2})$ & $28,0(\mathrm{p}=\mathbf{0 , 0 0 5})$ \\
\hline
\end{tabular}




\section{Diskussion}

In der vorliegenden Arbeit wurde ein Kollektiv aus 137 GIST, 15 Leiomyomen und 11 Leiomyosarkomen untersucht. Diese mesenchymalen Tumoren wurden sowohl hinsichtlich klinisch-pathologischer Parameter als auch hinsichtlich ausgewählter Signaltransduktions-und Zellzyklus-Proteine analysiert und miteinander verglichen. Eine computergestützte Auswertung machte es hierbei erstmalig möglich, quantitative Unterschiede in der Proteinexpression festzustellen und somit die unterschiedlichen aktivierten Signalwege in GIST, Leiomyomen und Leiomyosarkomen auf immunhistochemischer Ebene durch Gegenüberstellung weiter zu charakterisieren.

\subsection{Vergleich der klinisch-pathologischen Parameter}

GIST, Leiomyome und Leiomyosarkome wurden zunächst hinsichtlich der klinischpathologischen Faktoren Geschlechter- und Altersverteilung, Tumorgröße, anatomische Lokalisation und Mitosenanzahl verglichen.

Der Vergleich bezüglich der Geschlechterverteilung der drei Tumorentitäten zeigte, dass GIST, Leiomyome und Leiomyosarkome keinen signifikanten Unterschied aufwiesen. Leiomyome besaßen tendenziell eine höhere Prävalenz bei Männern, Leiomyosarkome kamen hingegen in leichter Tendenz häufiger bei Frauen vor. Das Verhältnis von Frauen zu Männern betrug bei GIST 1:1,1, bei Leiomyomen 1:2 und bei Leiomyosarkomen 1:0,8. In der Literatur finden sich für GIST sowohl Angaben über eine höhere Prävalenz beim männlichen Geschlecht (vorwiegend bei malignen GIST) als auch über eine gleichgeschlechtliche Verteilung (Miettinen und Lasota 2006, Miettinen et al. 1999, Miettinen et al. 2000c, Lerma et al. 1994); letztere konnte in der vorliegenden Dissertation bestätigt werden. Für Leiomyome konnte am vorliegenden Tumorkollektiv die ebenfalls bereits bekannte höhere Prävalenz bei Männern (Miettinen und Lasota (2001)) nachvollzogen werden. Für Leiomyosarkome wird in der Literatur selten eine Geschlechterprävalenz angegeben; es finden sich vereinzelt Angaben über eine eher geringfügig höhere Prävalenz beim weiblichen Geschlecht (Miettinen et al. 2001c). In leichter Tendenz konnte diese höhere Prävalenz bei Frauen für Leiomyosarkome nachvollzogen werden. 
Die Untersuchung hinsichtlich des $\underline{\text { Alters }}$ der Patienten zeigte, dass Patienten mit GIST im Vergleich zu Patienten mit Leiomyom bzw. mit Leiomyosarkom ein signifikant höheres Alter aufwiesen. Patienten mit GIST waren im Mittel 67,4 Jahre, Patienten mit Leiomyom 51,7 Jahre und Patienten mit Leiomyosarkom 60,2 Jahre alt. In der Literatur wird für Patienten mit GIST ein mittleres Alter von 55 - 65 Jahren beschrieben (Corless et al. 2004). Leiomyosarkome finden sich ebenfalls häufiger bei Patienten höheren Alters (Miettinen et al. 2003), wohingegen ein Teil der Leiomyome auch bei jüngeren Patienten (30 - 35 Jahre) auftritt (Miettinen und Fetsch 2006). In der vorliegenden Dissertation lag das mittlere Alter der Patienten mit GIST höher als das in der Literatur beschriebene, unterstrich damit jedoch die Differenz zu den Patienten mit leiomyogenen Tumoren, deren niedrigeres mittleres Alter im vorliegenden Kollektiv nachvollzogen werden konnte.

Bezüglich der Tumorgröße wurde beim Vergleich der drei Tumorentitäten für GIST eine mittlere Tumorgröße von 7,1 cm, für Leiomyome von 4,6 cm und für Leiomyosarkome von 8,0 cm gefunden. Die in der Literatur formulierte starke Varianz der Tumorgröße für GIST (2 - $30 \mathrm{~cm}$, Corless et al. 2004), für Leiomyome (1 - über $10 \mathrm{~cm}$, (Miettinen et al 2000b, Seremetis et al. 1976) und für Leiomyosarkome (3 - über 19 cm, Miettinen et al. 2000c) konnte anhand des vorliegenden Kollektivs bestätigt werden. Für Leiomyome ist bereits mit Ausnahme der Leiomyome des Ösophagus, die in einigen Fällen auch sehr groß in Erscheinung treten können (Abraham 2007, Cheng et al. 2005), beschrieben, dass diese benigne leiomyogene Tumorentität meist geringe Größen aufweist Die drei Tumoren zeigten in der vorliegenden Dissertation hinsichtlich der maximalen Größe keinen signifikanten Unterschied, jedoch konnte für die im Allgemeinen klein bleibenden Leiomyome eine Tendenz zu geringerer Größe nachvollzogen werden.

Hinsichtlich der anatomischen Lokalisation zeigten die drei Tumorentitäten stark unterschiedliche Verteilungen. GIST kamen am häufigsten im Magen und nicht im Ösophagus vor. Leiomyome hingegen waren am häufigsten im Dickdarm und im Ösophagus, jedoch nicht extraintestinal lokalisiert. Leiomyosarkome wiederum waren am häufigsten extraintestinal, jedoch nicht im Magen zu finden. Damit wiesen die drei Tumorentitäten wesentliche Unterschiede hinsichtlich der anatomischen Lokalisation auf und waren in 
gewissem Maße gegensätzlich lokalisiert. Der Vergleich zwischen GIST und den zwei leiomyogenen Tumorentitäten zeigte einerseits, dass im Magen, der die häufigste Lokalisation der GIST darstellte, keine Leiomyosarkome beobachtet werden konnten. Andererseits fiel auf, dass im Ösophagus, wo keine der GIST lokalisiert waren, sich die zweithäufigste Lokalisation der Leiomyome befand. In ähnlicher Weise kontrastierten sich die leiomyogenen Tumoren hinsichtlich der extraintestinalen Lokalisation. Dort waren von den untersuchten Leiomyomen keine zu finden, bei den Leiomyosarkomen war dies jedoch die häufigste Lokalisation. Diese Beobachtungen bezüglich der anatomischen Lokalisation entsprechen sowohl den bereits beschriebenen Kontrasten zwischen leiomyogenen Tumoren und GIST als auch den bekannten Unterschieden zwischen Leiomyomen und Leiomyosarkomen (Agaimy und Wünsch 2007).

Bis auf die häufigste Lokalisation der Leiomyosarkome im Kolorektum (Miettinen und Fetsch 2006) stimmten die in der Literatur beschriebenen häufigsten Lokalisationen von GIST im Magen (Miettinen und Lasota 2006) und von Leiomyomen im Ösophagus (Miettinen und Lasota 2001) mit denen des vorliegenden Kollektivs überein.

Zusammenfassend kann damit gesagt werden, dass bei GIST, Leiomyomen und Leiomyosarkomen starke Unterschiede in der Verteilung der anatomischen Lokalisation vorhanden sind, die in der Literatur bereits beschrieben wurden und am vorliegenden Kollektiv klar nachvollzogen werden konnten.

Bei der Untersuchung der mitotischen Aktivität der Tumorentitäten wurde für GIST eine Mitosenanzahl von im Mittel 17,6/50 HPFs, für Leiomyome von im Mittel 0,5/50 HPFs und für Leiomyosarkome von im Mittel 70,8/50 HPFs gefunden. Diese Beobachtungen für die drei Tumorentitäten entsprechen den in der Literatur beschriebenen Zahlen (Miettinen und Fetsch 2006, Singer et al. 2002). Innerhalb der leiomyogenen Tumoren ist eine hohe mitotische Aktivität ein klares diagnostisches Kriterium bei der Abgrenzung eines Leiomyosarkoms von einem Leiomyom, wobei die Unterschiede in der Anzahl der Mitosen zwischen diesen beiden Entitäten insgesamt sehr stark ausgeprägt sind. Im Gegensatz dazu weisen GIST ein Kontinuum in der Mitosenanzahl auf, wobei Fälle mit keinen, wenigen bis hin zu vielen Mitosen vorkommen. Im Gegensatz zu den leiomyogenen Tumoren kann bei GIST im Einzelfall nicht sicher unterschieden werden, ob es sich um einen benignen oder 
malignen Tumor handelt. Diese Problematik ist zum Teil auf die beschriebene kontinuierliche Verteilung der Mitosenanzahl zurückzuführen, die eine klare Einordnung verhindert.

In der vorliegenden Dissertation sollte daher weiter untersucht werden, welche Signaltransduktionswege zur Zellproliferation in den drei Tumorentitäten aktiviert sind, und wie stark die Expression der Proteine in den einzelnen Phasen des Zellzyklus ist.

\subsection{Vergleich der KIT- und PDGFRA-Expression}

In der vorliegenden Arbeit zeigten GIST sowohl im Vergleich zu Leiomyomen als auch zu Leiomyosarkomen eine signifikant höhere KIT-Expression (67,8-fach bzw. 135,5-fach höher). Für Leiomyome bzw. Leiomyosarkome ergab sich eine KIT-Expression von im Mittel 0,4 bzw. 0,2; diese Tumoren waren damit im Prinzip KIT-negativ. Die für die leiomyogenen Tumoren gefundenen Ergebnisse sehr geringer quantitativer Ausprägung sind auf die in der vorliegenden Arbeit verwendete Messmethode zurückzuführen, bei der die Stärke der Expression zunächst in Grauwerte umgerechnet und dann als Färbeintensität gemittelt über alle Tumorzellen gemessen wurde. Damit stellen die Werte der leiomyogenen Tumoren keine echte KIT-Expression, sondern lediglich die stets geringfügig vorhandenen Hintergrundgrauwerte dar.

Leiomyome und Leiomyosarkome werden in der Literatur als KIT-negativ geführt (Miettinen et al. 2000b). In einer erst kürzlich veröffentlichen Studie über leiomyogene Tumoren des Dünndarms konnte weder bei 6 untersuchten Leiomyomen, noch bei 11 untersuchten Leiomyosarkomen eine KIT-Positivität festgestellt werden (Miettinen et al. 2009a). Betrachtet man die in der Gesamtheit sehr hohen Fallzahlen an leiomyogenen Tumoren von Miettinen et. al ( $n=187)$, bei denen alle untersuchten leiomyogenen Tumoren des Gastrointestinaltrakts KIT-negativ waren, können die Beobachtungen als repräsentativ angesehen werden (Miettinen et al. 2000b, Miettinen et al. 2000c, Miettinen et al. 2001c, Miettinen et al. 2003, Miettinen et al. 2009a und b). Zwei weitere veröffentliche Studien anderer Autoren, die ebenfalls leiomyogene Tumoren ( $n=20$ bzw. n=16) auf KIT-Positivität untersuchten, decken sich mit den Ergebnissen der Vergleichsarbeiten (Rossi et al. 2005, Peterson et al. 2006) 
Im Gegensatz zu den leiomyogenen Tumorentitäten wird für GIST hingegen in der Literatur angeben, dass diese in > 95 \% der Fälle KIT-Positivität zeigen (Lasota und Miettinen. 2008).

Da in der vorliegenden Arbeit ebenfalls nur GIST eine echte KIT-Expression aufwiesen, stehen diese Beobachtungen mit der Literatur im Einklang. Ferner lässt sich bekräftigen, dass sich mithilfe von KIT-Expression GIST gegenüber den leiomyogenen Tumorentitäten abgrenzen lassen und sich die Diagnose GIST unterstützen lässt.

Die Untersuchung der PDGFRA-Expression der drei Tumorentitäten zeigte, dass GIST im Vergleich zu den leiomyogenen Tumorentitäten eine höhere PDGFRA-Expression aufwiesen. Im Gegensatz zu Leiomyomen, die keine PDGFRA-Expression besaßen, konnte bei Leiomyosarkomen jedoch durchaus eine echte PDGFRA-Expression nachgewiesen werden. Die PDGFRA-Expression der Leiomyosarkome war zwar geringer als die der GIST, stellte jedoch einen signifikanten Unterschied zu den Leiomyomen dar.

Diese Beobachtungen bestätigen auf der einen Seite die schon bekannte PDGFRA-Expression der GIST (Heinrich et al. 2003b, Peterson et al. 2006), zeigen jedoch erstmalig eine PDGFRA-Expression in Leiomyosarkomen, die bisher in der Literatur noch nicht beschrieben war.

In einer Studie von Wasag et al. konnte weder bei 8 der untersuchten Leiomyosarkome noch bei 12 der untersuchten Leiomyome eine PDGFRA-Positivität gefunden werden (Wasag et al. 2004). Analoge Beobachtungen machten Rossi et al. an einem Kollektiv aus insgesamt 167 mesenchymalen Tumoren des Gastrointestinaltrakts. 6,2 \% der untersuchten GIST und damit alle (100 \%) der KIT-negativen GIST waren PDGFRA-positiv, während alle untersuchten Leiomyome und Leiomyosarkome PDGFRA-negativ waren (Rossi et al. 2005).

In einer weiteren, semiquantitativen Arbeit von Peterson et al., in der 39 GIST und 20 andere mesenchymale Tumoren auf PDGFRA-Positivität untersucht wurden, zeigten zwar $25 \%$ der Nicht-GIST ebenfalls PDGFRA-Positivität, diese war jedoch nur schwach bis moderat (Peterson et al. 2006). Diese PDGFRA-Positivität wurde im Gegensatz zur vorliegenden Arbeit nicht bei Leiomyosarkomen, sondern bei 4 der 12 untersuchten Leiomyome gefunden. Alle 4 untersuchten Leiomyosarkome der Studie von Peterson et al. zeigten keine PDGFRAPositivität. 
Starke PDGFRA-Positivität, die sich im Vergleich quantitativ deutlich abgrenzt, wurde in der Untersuchung von Peterson et al. nur bei GIST gefunden. Diese Ergebnisse decken sich mit denen der vorliegenden Arbeit, bei der die höchste PDGFRA-Expression bei GIST gefunden wurde.

Zusammenfassend konnte in der vorliegenden Arbeit erstmalig bei Leiomyosarkomen eine PDGFRA-Expression gefunden werden, die quantitativ zwar niedriger ausgeprägt war als bei GIST, aber klar von der nicht vorhandenen PDGFRA-Expression der Leiomyome abgegrenzt werden konnte. Die Relevanz dieser Beobachtung besteht zum einen darin, dass eine PDGFRA-Expression als differenzialdiagnostischer Marker bei KIT-negativen GIST vorsichtig gewertet muss, da es sich bei KIT-negativen und PDGFRA-positiven Tumoren nicht nur um PDGFRA-mutierte GIST, sondern eben auch um ein Leiomyosarkom handeln kann. Zum anderen könnte die PDGFRA-Expression in den Leiomyosarkomen im Gegensatz $\mathrm{zu}$ den Leiomyomen einen besonderen pathogenetischen Unterschied darstellen, der die unterschiedlich starke mitotische Aktivität und damit eventuell auch das biologische Verhalten teilweise mit erklären könnte.

\subsection{Vergleich der Expression ausgewählter Signaltransduktions-Proteine}

Um Rückschlüsse auf die weiteren, vermutlich different beschrittenen, Signalwege von GIST, Leiomyomen und Leiomyosarkomen ziehen zu können, wurden die drei Tumorentitäten auf quantitative Unterschiede in der Expression ausgewählter Signaltransduktions-Proteine untersucht. In der Literatur finden sich nur sehr wenige spezifische Angaben über die Expression dieser Signal-Proteine in GIST, Leiomyomen und Leiomyosarkomen.

Im Folgenden werden die Signaltransduktions-Proteine entsprechend der in Abbildung 1.2/1 aufgeführten Signalwege fortlaufend dargestellt.

Hinsichtlich der SRC-Expression zeigten GIST im Vergleich zu den leiomyogenen Tumorentitäten eine höhere SRC-Expression. Leiomyosarkome wiesen bei diesem Vergleich die geringste Expression von SRC auf, dieser Unterschied zu GIST war signifikant. Bei der 
Untersuchung der SRC-Expression konnte zwischen Leiomyomen und Leiomyosarkomen kein signifikanter Unterschied gefunden werden. Leiomyome wiesen im Vergleich zu Leiomyosarkomen jedoch tendenziell eine stärkere SRC-Expression auf.

SRC und SFKs, die wichtige Rollen in Zelldifferenzierung, -motilität, -proliferation und überleben spielen (Thomas und Brugge 1997), sind streng reguliert und während der G2/MPhase des Zellzyklus aktiv (Roskoski 2005c). Erhöhte SRC-Kinase-Aktivität ist bereits für verschiedene Tumoren -darunter Neoplasien der Lunge, des Kolons, des Magens, des Pankreas etc.- beschrieben (Roskoski 2004, Frame 2002, Levin 2004, Irby und Yeatman 2000).

Es wird vermutet, dass SRC über mehrere Mechanismen aktiviert werden kann; darunter auch PDGFRA (Stover et al. 1996, Gould und Hunter 1988). In Hinblick auf diesen Aspekt scheint sich die im Vergleich zu den zwei leiomyogenen Tumorentitäten gefundene höchste SRCExpression der GIST erklären zu lassen, da GIST in der vorliegenden Dissertation ebenfalls die höchste PDGFRA-Expression aufzeigten. So könnte SRC in GIST durch KIT bzw. PDGFRA aktiviert werden.

SRC wird in der Literatur außerdem eine entscheidende Position in den Signaltransduktionskaskaden, die Zellwachstum kontrollieren, zugesprochen (Irby und Yeatman 2000). Für Leiomyosarkome, die hohe Proliferationsraten besitzen, ist in diesem Kontext die geringe SRC-Expression der vorliegenden Untersuchung im Vergleich zu Leiomyomen wahrscheinlich dadurch bedingt, dass SRC in den leiomyogenen Tumoren keine bedeutende Rolle in der Aktivierung der Zellproliferation spielt.

Die höchste Expression von $\underline{\text { AKT1 }}$ und ERK2 wurden in der vorliegenden Dissertation bei GIST gefunden Mit Ausnahme der ERK2-Expression im Vergleich zwischen GIST und Leiomyosarkomen, besaßen GIST in jedem Vergleich zu den leiomyogenen Tumorentitäten eine signifikant höhere AKT1- und ERK2-Expression. Zwischen den leiomyogenen Tumorentitäten konnten hinsichtlich der AKT1- und ERK2-Expression keine signifikanten Unterschiede gefunden werden, wobei Leiomyosarkome tendenziell eine höhere AKT1- und ERK2-Expression zeigten. 
Die bereits bekannte AKT1-Positivität der GIST (Fletcher et al. 2002, Miettinen und Lasota. 2006) und der leiomyogenen Tumoren (Miettinen et al. 2000a) konnte bestätigt und durch einen quantitativen Vergleich ergänzt werden. Da AKT1 die Translation und ERK2 die mRNA-Expression von Cyclin-D1 reguliert (Lavoie et al. 1996, Albanese et al. 1995), werden diese Proteine den stimulierenden Regulatoren der Zellproliferation zugeordnet.

Da die höchsten AKT1- und ERK2-Expression in der vorliegenden Arbeit bei GIST gefunden wurden, kann für GIST damit ein zentraler Weg von KIT bzw. PDGFRA zur Zellproliferation nachvollzogen werden. AKT1 und ERK2 werden in GIST wahrscheinlich durch KIT bzw. PDGFRA aktiviert. Ferner können diese Beobachtungen bestätigen, dass der Signalweg, der von aktiviertem KIT-Rezeptor zu Zellproliferation führt, in GIST u.a. über AKT1 und ERK2 führt (Haller et al. 2008b, Tuveson et al. 2001, Duensing et al. 2004, Bauer et al. 2007, Sommer et al. 2003, Rubin et al. 2005, Nakai et al. 2008).

Die stark proliferierenden Leiomyosarkome zeigten nur eine geringfügig höhere AKT1- und ERK2-Expression als Leiomyome. Somit scheinen auch AKT1/ERK2 und SRC bei den leiomyogenen Tumoren keine bedeutende Rolle in der Aktivierung der Zellproliferation zu spielen.

\subsection{Vergleich der Expression ausgewählter Zellzyklus-Proteine}

Die Untersuchung der Cyclin-D1-Expression zeigte, dass GIST im Vergleich die höchste Cyclin-D1-Expression besaßen, gefolgt von Leiomyosarkomen und Leiomyomen.

Quantitative Veränderungen der Expression von Cyclinen sind wichtige regulatorische Ereignisse, die die Passage durch den Zellzyklus kontrollieren (Rosenwald et al. 1993, Draetta 1990). Heraufregulation der Cyclin-D1-Expression stellt ein starkes Signal für den Eintritt in die G1-Phase des Zellzyklus dar (Wang et al. 2004).und spielt vermutlich eine entscheidende 
Rolle bei der Zellwachstumsregulation. In der Literatur ist eine erhöhte Cyclin-D1-Expression bereits in einigen Tumoren - wie beispielsweise in Parathyroid- und Brustkrebs- identifiziert worden (Rosenwald et al. 1993, Lammie et al. 1991, Motokura et al. 1991, Withers et al. 1991). Außerdem konnte bei Sarkomen der Extremitäten eine Assoziation zwischen CyclinD1-Expression und einer eher schlechten Prognose gefunden werden (Sabah et al. 2006, Kim et al. 1998).

Da in der vorliegenden Dissertation GIST die höchste Cyclin-D1-Expression besaßen, lässt sich für GIST der zentrale Weg von KIT zur Zellproliferation um einen weiteren Schritt verfolgen. An eine erhöhte KIT-Expression mit erhöhter AKT1- und ERK2-Expression schließt sich bei GIST eine erhöhte Cyclin-D1-Expression an.

Zwischen Leiomyomen und Leiomyosarkomen war hinsichtlich der Cyclin-D1-Expression kein signifikanter Unterschied zu finden. Dieses Ergebnis ist insofern unerwartet, als man bei den hochproliferierenden Leiomyosarkomen eine hohe Expression von Cyclin-D1 als stimulierendes Signal für den Eintritt in die G1-Phase des Zellzyklus erwarten könnte. Diese Beobachtung lässt vermuten, dass sowohl bei Leiomyomen als auch bei Leiomyosarkomen die Stimulierung der Zellproliferation ohne vorherige Steigerung der Cyclin-D1-Expression erfolgt.

Die Untersuchung der E2F1-positiven Kerne ergab, dass sich die höchste Anzahl an E2F1positiven Kernen bei Leiomyosarkomen zeigte. Sowohl im Vergleich zu Leiomyomen als auch zu GIST besaßen Leiomyosarkome signifikant mehr E2F1-positive Kerne.

Für GIST ist in der Literatur bereits beschrieben, dass die Regulation des ZellzyklusKontrollgens E2F1 für Zellproliferation und Prognose eine zentrale Bedeutung einnimmt (Haller et al. 2005, Sabah et al. 2006). In der vorliegenden Dissertation konnte bei GIST die Aktivierung des Zellzyklus weiter nachvollzogen werden. Von der KIT-Expression führt bei GIST der Weg über AKT1-, ERK2- und Cyclin-D1-Expression bis zur E2F1-Expression. 
Bei den leiomyogenen Tumoren entspricht die E2F1-Expression der Erwartung, dass die hochproliferativen Leiomyosarkome eine deutlich höhere Expression als die mitotisch kaum aktiven Leiomyome zeigen.

Im Gegensatz zu GIST ließ sich in der vorliegenden Dissertation jedoch für Leiomyosarkome keine sequenzielle Aktivierung der untersuchten Signalwege finden, die zur E2F1Aktivierung führt. Die hohe Anzahl an E2F1-postiven Kernen der Leiomyosarkome lässt sich somit nicht anhand des AKT1-/ERK2-/Cyclin-D1-Signalwegs nachvollziehen. Möglicherweise sind bei Leiomyosarkomen andere Signalwege angeschaltet, die wahrscheinlich ohne eine vorherige Cyclin-D1-Zunahme direkt eine E2F1-Aktivierung bewirken.

Die höchste Anzahl an Cyclin-B1-positiven Kernen wurde in der vorliegenden Arbeit ebenfalls bei Leiomyosarkomen gefunden. Leiomyosarkome zeigten signifikant mehr CyclinB1-positive Kerne als Leiomyome. Zwischen GIST und den zwei leiomyogenen Tumoren konnten in der vorliegenden Dissertation keine signifikanten Unterschiede bezüglich der Anzahl an Cyclin-B1-positiven Kernen gefunden werden. Tendenziell besaßen Leiomyosarkome im Vergleich zu GIST und GIST im Vergleich zu Leiomyomen mehr Cyclin-B1-positive Kerne.

Cyclin-B1 wird in der Literatur als ein nützlicher Marker für Zellproliferation von GIST geführt und neben bereits bekannten Prognose- und Risikofaktoren misst man einer erhöhten Cyclin-B1-Expression aufgrund einiger Studien ebenfalls prognostischen Wert bei (Nakamura et al. 2005). Koon et al. konnten bereits zeigen, dass die Cyclin-B1-Expression in malignen GIST höher ist als in benignen GIST und dass eine relativ hohe Cyclin-B1-Expression mit hoher Mib1-Expression korreliert (Koon et al. 2004). Bei GIST konnte die Aktivierung des Zellzyklus weiter nachvollzogen werden. Von KIT-Expression führt bei GIST der Weg über AKT1-, ERK2-, Cyclin-D1- und E2F1-Expression bis Cyclin-B1-Expression.

Die benignen Leiomyome besaßen im Vergleich zu den malignen Leiomyosarkomen signifikant weniger Cyclin-B1-positive Kerne, was der biologischen Aggressivität entspricht.

Die höchste Anzahl an Mib1-positiven Kernen wurde in der vorliegenden Arbeit erneut bei Leiomyosarkomen gefunden. Damit zeigte sich für Leiomyosarkome ein weiterer 
signifikanter Unterschied zu Leiomyomen und ebenfalls zu GIST. GIST besaßen wiederum im Vergleich zu Leiomyomen signifikant mehr Mib1-positive Kerne. Zusammenfassend kann damit Mib1 als Marker der Proliferationsaktivität bei GIST, Leiomyomen und Leiomyosarkomen bestätigt werden (Miettinen et al. 2002).

Zusammenfassend konnte hinsichtlich der Expression der untersuchten Zellzyklus-Proteine gezeigt werden, dass sich zum einen bei GIST ein klarer Weg der Aktivierung der Zellproliferation vom mutierten Gen (KIT) über die intrazelluläre Signalaktivierung (AKT1, ERK2) bis hin zur sequenziellen Aktivierung des Zellzyklus (Cyclin-D1, E2F1, Cyclin-B1) nachvollziehen lässt. Im Gegensatz zu den GIST konnte bei den leiomyogenen Tumoren ein völlig anderes Muster identifiziert werden: Leiomyosarkome und Leiomyome wiesen eine niedrige Expression der Rezeptortyrosinkinasen (KIT/PDGFRA), der intrazellulären Signaltransduktoren (AKT1/ERK2, SRC), sowie des ersten Effektors dieser Signalwege, Cyclin-D1, auf. Diese Beobachtungen sind soweit gut nachvollziehbar, als dass bei den leiomyogenen Tumoren keine Mutationen dieser Signalwege bekannt sind. Unerwartet ist jedoch die niedrige Expression von Cyclin-D1 in den Leiomyosarkomen, was vermuten lässt, dass die Stimulierung der Zellproliferation bei den leiomyogenen Tumoren einen anderen Weg nimmt. Leiomyosarkome wiesen dann die höchste Expression von E2F1 und Cyclin-B1 auf. Es liegt also nahe, dass molekulargenetische Ereignisse, die zu einer erhöhten Expression von E2F1 führen, bei den leiomyogenen Tumoren zur Zellproliferation führen.

Da bis heute sehr wenig über die tumorinitiierenden Ereignisse bei leiomyogenen Tumoren des Gastrointestinaltrakts bekannt ist, sollten Untersuchungen über eventuell aktivierte Signaltransduktionswege, die zu einer erhöhten E2F1-Aktivierung bei Leiomyosarkomen führen, Gegenstand fortführender Studien sein. Signalmoleküle, die zur Steigerung von E2F1 führen können, wie beispielsweise v-myc myelocytomatosis viral oncogene homolog (MYC), könnten ein Ansatz für nachfolgende Arbeiten sein. So sind entsprechende Untersuchungen mit größeren Fallzahlen -auch auf molekulargenetischer Ebene- notwendig, um die Bedeutung der erhöhten E2F1-Expression für die Tumorprogression der Leiomyosarkome herauszuarbeiten. 


\section{Zusammenfassung}

In der vorliegenden Arbeit wurden 137 GIST, 15 Leiomyome und 11 Leiomyosarkome sowohl hinsichtlich der Ausprägung klinisch-pathologischer Parameter als auch bezüglich der Aktivierung und Expression von Rezeptor-Tyrosin-Kinasen, intrazellulären Signalwegen und Regulatoren der Zellproliferation mittels immunhistochemischer Färbungen untersucht und miteinander verglichen.

Bis Anfang der 90er Jahre war es aufgrund fehlender spezifischer Marker schwierig, GIST von leiomyogenen Tumoren differentialdiagnostisch $\mathrm{zu}$ trennen. Heute ist mithilfe der Immunhistochemie fast immer eine eindeutige Zuordnung möglich. Viele Studien zeigen, dass eine KIT-Expression einen besonderen differentialdiagnostischen Wert für die Unterscheidung von GIST und leiomyogenen Tumoren besitzt, da Leiomyome und Leiomyosarkome im Gegensatz zu GIST keine KIT-Expression aufweisen.

Aktivierende Mutationen des KIT-Gens, und seltener auch des PDGFRA-Gens, sind als tumorinitiierende Ereignisse bei GIST bekannt. Man weiß jedoch bis heute noch wenig über die Tumorigenese der leiomyogenen Tumoren. Zusätzlich existieren so gut wie keine Angaben über die Eignung von PDGFRA als immunhistochemischen Marker für die Differentialdiagnostik zwischen GIST und leiomyogenen Tumoren. In der vorliegenden Arbeit wurde erstmalig eine PDGFRA-Expression in Leiomyosarkomen nachgewiesen. Diese neue Beobachtung grenzt zum einen den differentialdiagnostischen Nutzen einer PDGFRAExpression für die Unterscheidung zwischen KIT-negativen GIST und Leiomyosarkomen ein. Da jedoch nur Leiomyosarkome PDGFRA-Expression aufwiesen, während Leiomyome keine PDGFRA-Expression zeigten, könnte dies zum anderen einen wichtigen biologischen Unterschied innerhalb der leiomyogenen Tumoren darstellen.

Die Untersuchung der Mitosenanzahl zeigte den bereits bekannten ausgeprägten Unterschied zwischen den mitotisch inaktiven Leiomyomen und den mitotisch stark aktiven Leiomyosarkomen. Dieser eindeutige Unterschied spiegelt das jeweilige biologische Verhalten wider und stellt damit ein wichtiges differentialdiagnostisches Kriterium für die Unterteilung innerhalb der leiomyogenen Tumoren als Leiomyom oder Leiomyosarkom dar. Im Gegensatz dazu zeigten GIST insgesamt ein Kontinuum in der Mitosenanzahl. Es existierten sowohl Fälle mit keiner, mit wenig als auch mit sehr starker mitotischer Aktivität. Diese bekannte kontinuierliche Verteilung der Mitosenanzahl trägt zu der Problematik bei, 
dass im Gegensatz zu den leiomyogenen Tumoren im Einzelfall nicht sicher zwischen einem benignen und einem malignen GIST unterschieden werden kann.

Um die vermutlich different beschrittenen Signaltransduktionswege von GIST, Leiomyomen und Leiomyosarkomen zu analysieren, wurden die drei Tumorentitäten dann auf quantitative Unterschiede in der Expression ausgewählter Signaltransduktions- und Zellzyklus-Proteine untersucht. Dabei konnte für GIST ein zentraler Weg vom mutierten Gen (KIT bzw. PDGFRA) über die intrazelluläre Signalaktivierung (AKT1/EKR2) zur Aktivierung des Zellzyklus (Cyclin-D1, E2F1, Cyclin-B1) eindeutig nachvollzogen werden. Die Beobachtungen an den Leiomyomen und Leiomyosarkomen hingegen lassen vermuten, dass AKT1/ERK2 und SRC bei leiomyogenen Tumoren keine entscheidende Rolle in der intrazellulären Signalaktivierung spielen. Da bei den leiomyogenen Tumoren bis heute keine Mutationen dieser Signaltransduktionswege bekannt sind, lassen sich diese Beobachtungen für Leiomyome und Leiomyosarkome gut nachvollziehen.

Unerwartet ist die beobachtete niedrige Expression des G1-Phase-Cyclins Cyclin-D1 in den Leiomyosarkomen. Da eine Steigerung der Expression von Cyclin-D1 ein zentrales Signal für den Eintritt in die G1-Phase des Zellzyklus darstellt, hätte man bei den hochproliferierenden Leiomyosarkomen eine entsprechend hohe Expression von Cyclin-D1 vermutet. Die höchste Expression von Cyclin-D1 wurde jedoch bei GIST gefunden. Sowohl bei Leiomyomen als auch bei Leiomyosarkomen scheint die Zellproliferation ohne starken Anstieg der Cyclin-D1Expression zu erfolgen. Im Gegensatz zu der unerwartet niedrigen Expression von Cyclin-D1 zeigten Leiomyosarkome dann im Vergleich die höchste Expression des für den Übergang von der G1- in die S-Phase wichtigen Transkriptionsfaktors E2F1 und auch des G2-PhaseCyclins Cyclin-B1. Dies deckt ein völlig anderes Muster der Aktivierung des Zellzyklus auf und lässt vermuten, dass in Leiomyosarkomen möglicherweise unbekannte molekulargenetische Ereignisse ohne vorherige Steigerung der Cyclin-D1-Expression zu einer erhöhten E2F1-Expression führen und damit eine entscheidende Rolle in der Tumorprogression spielen. Es sind daher weiterführende Studien denkbar, welche die noch unbekannten Signale untersuchen, die zu einer E2F1-Expression bei Leiomyosarkomen führen. Ein solches Signalmolekül könnte beispielsweise der Transkriptionsfaktor MYC sein, welcher bei verschiedenen anderen Tumorentitäten eine wichtige Rolle für die Aktivierung der Zellproliferation spielt. 


\section{Abbildungs- und Tabellenverzeichnis}

Abbildung

$1.1 .1 / 1$

1.1.2.1/1

1.1.2.2/1

$1.2 / 1$

$1.2 / 2$

$2.2 / 1$

$2.2 / 2$

$2.2 / 3$

$2.2 / 4$

$2.4 / 1$

3.1.1/1

3.2.2/1

3.2.3/1

$3.2 .4 / 2$

$3.2 .5 / 1$

3.3.1/1

3.3.2/1

3.4.1/1

3.4.2/1

3.4.3/1

3.5.1/1

3.5.2/1

3.5.3/1

3.5.4/1
Seite

5

7

8

12

14

20

20

21

22

27

29

30

31

34

35

36

37

38

39

40

41

42

43

44

21

2

27

9

31

34

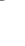

\section{7}

8

9

40

\section{1}

43

44

Tabelle

Seite

1.1/1

2

2.3/1

24

3.2.4/1

33

3.3.2/2

37

3.4.3/2

40

3.5.4/2

45 


\section{Literaturverzeichnis}

Abraham SC (2007): Distinguishing gastrointestinal stromal tumors from their mimics: an update. Adv Anat Pathol 14, 178-188

Agaimy A, Wünsch PH (2007): True smooth muscle neoplasms of the gastrointestinal tract: morphological spectrum and classification in a series of 85 cases from a single institute. Langenbecks Arch Surg $\underline{392}$, 75-81

Agaimy A, Terracciano LM, Dirnhofer S, Tornillo L, Foerster A, Hartmann A, Bihl MP (2009): V600E BRAF mutations are alternative early molecular events in a subset of KIT/PDGFRA wild-type gastrointestinal stromal tumours. J Clin Pathol $\underline{62}$, 613-61

Albanese C, Johnson J, Watanabe G, Eklund N, Vu D, Arnold A, Pestell RG (1995): Transforming p21ras mutants and c-Ets-2 activate the cyclin D1 promoter through distinguishable regions. J Biol Chem 270, 23589-23597

Appelman HD (1986): Smooth muscle tumors of the gastrointestinal tract. What we know now that Stout didn't know. Am J Surg Pathol 10 Suppl 1, 83-99

Bauer S, Duensing A, Demetri GD, Fletcher JA (2007): KIT oncogenic signaling mechanisms in imatinib-resistant gastrointestinal stromal tumor: PI3-kinase/AKT is a crucial survival pathway. Oncogene 26, 7560-7568

Blume-Jensen P, Claesson-Welsh L, Siegbahn A, Zsebo KM, Westermark B, Heldin CH (1991): Activation of the human c-kit product by ligand-induced dimerization mediates circular actin reorganization and chemotaxis, EMBO J 10, 4121-4128

Cameron S, Haller F, Dudas J, Moriconi F, Gunawan B, Armbrust T, Langer C, Füzesi L, Ramadori G (2008): Immune cells in primary gastrointestinal stromal tumors. Eur J Gastroenterol Hepatol 4, 327-334 
Carlson JW, Fletcher CD (2007): Immunohistochemistry for b-catenin in the differential diagnosis of spindle cell lesions: analysis of a series and review of the literature. Histopathology 51, 509-514

Chambard JC, Lefloch R, Pouyssegur J, Lenormand P (2007): ERK implication in cell cycle regulation. Biochim Biophys Acta 1773, 1299-1310

Chandu de Silva MV, Reid R (2003): Gastrointestinal stromal tumors (GIST): C-kit mutations, CD117 Expression, differential diagnosis and targeted cancer therapy with Imatinib. Pathol Oncol Res $\underline{9}, 13-19$

Cheng BC, Chang S, Mao ZF, Li MJ, Huang J, Wang ZW, Wang TS. (2005): Surgical treatment of giant esophageal leiomyoma. World J Gastroenterol 11, 4258-4260

Cook JR, Dehner LP, Collins MH, Ma Z, Morris SW, Coffin CM, Hill DA (2001): Anaplastic lymphoma kinase (ALK) expression in the inflammatory myofibroblastic tumor. A comparative immunohistochemical study. Am J Surg Pathol 25, 1364-1371

Cordon-Cardo C (1995): Mutation of Cell Cycle Regulators Biological and Clinical Implications for Human Neoplasia. Am J Pathol $\underline{3}$, 545-560

Corless CL, Fletcher JA, Heinrich MC (2004): Biology of gastrointestinal stromal tumors. J Clin Oncol 22, 3813-3825

Debiec-Rychter M, Dumez H, Judson I, Wasag B, Verweij J, Brown M, Dimitrijevic S, Sciot R, Stul M, Vranck H, Scurr M, Hagemeijer A, van Glabbeke M, van Oosterom AT. (2004): Use of c-KIT/PDGFRA mutational analysis to predict the clinical response to imatinib in patients with advanced gastrointestinal stromal tumours entered on phase I and II studies of the EORTC Soft Tissue and Bone Sarcoma Group. Eur J Cancer 40, 689-695

Dei Tos AP (2003): The reappraisal of gastrointestinal stromal tumors: from Stout to the KIT revolution. Virchows Arch 442, 421-428 
DeMatteo RP, Lewis JJ, Leung D, Mudan SS, Woodruff JM, Brennan MF (2000): Two hundred gastrointestinal stromal tumors: recurrence patterns and prognostic factors for survival. Ann Surg 231, 51-58

De Parrot M, Kurt AM, Robert JH, Borisch B, Spiliopoulos A (1999): Clinical behavior of solitary fibrous tumors of the pleura. Ann Thorac Surg 67, 1456-1459

Draetta G (1990): Cell cycle control in eukaryotes: molecular mechanisms of cdc2 activation. Trends Biochem Sci 15, 378-383

Duensing A, Medeiros F, McConarty B, Joseph NE, Panigrahy D, Singer S, et al. (2004): Mechanisms of oncogenic KIT signal transduction in primary gastrointestinal stromal tumors (GISTs). Oncogene 23, 3999-4006

Endl E, Gerdes J (2000a): Post-translational modifications of the Ki-67 protein coincide with two major check points during mitosis. J Cell Physiol 182, 371- 380

Endl E, Gerdes J (2000b): The Ki-67 Protein: fascinating forms and an unknown function. Exp Cell Res 257, 231-237

Eriksson A, Siegbahn A, Wetsermark B, Heldin C, Claesson-Welsh L (1992): PDGF alpha- and beta-receptors activate unique and common signal transduction pathways. EMBO J $\underline{11,}$ 543-550

Fletcher CD, Berman JJ, Corless C, Gorstein F, Lasota J, Longley BJ, Miettinen M, O'Leary TJ, Remotti H, Rubin BP, Shmookler B, Sobin LH, Weiss SW (2002): Diagnosis of gastrointestinal stromal tumors: A consensus approach. Hum Pathol $\underline{33}, 459-465$

Frame MC (2002): Src in cancer: deregulation and consequences for cell behavior. Biochim Biophys Acta 1602, 114-130 
Fredriksson L, Li H, Eriksson U (2004): The PDGF family: four gene products form five dimeric isoforms. Cytokine Growth Factor Rev $\underline{15}$, 197-204

Fukunaga M, Naganuma H, Ushigome S, Endo Y, Ishikawa E (1996): Malignant solitary ibrous tumour of the peritoneum. Histopathology $\underline{28}$, 463-466

Gerdes J, Schwab U, Lemke H, Stein H. (1983): Production of a mouse monoclonal antibody reactive with a human nuclear antigen associated with cell proliferation. Int $\mathrm{J}$ Cancer 31, 13-20

Gerdes J, Lemke H, Baisch H, Wacher H-H, Schwab U, Stein H (1984): Cell cycle analysis of a cell proliferationassociated human nuclear antigen defined by the monoclonal antibody Ki-67. J Immunol 133, 1710-1715

Gould KL, Hunter T (1988): Platelet-derived growth factor induces multisite phosphorylation of pp60c-src and increases its proteintyrosine kinase activity. Mol Cell Biol 8, 3345-3356

Graadt van Roggen J F, van Velthuysen M L F, Hogendoorn P C W (2001): The histopathological differential diagnosis of gastrointestinal stromal tumours. J Clin Pathol $\underline{54}$, 96-102

Griffin CA, Hawkins AL, Dvorak C, Henkle C, Ellingham T, Perlman EJ (1999): Recurrent involvement of 2p23 in inflammatory myofibroblastic tumors. Cancer Res 59, 2776-2780

Haller F: Molekularbiologische Evaluation prognostischer Parameter in Gastrointestinalen Stromatumoren (GIST). Med. Habil.-Schr. Göttingen 2008

Haller F, Gunawan B, von Heydebreck A, Schwager S, Schulten H-J, Wolf-Salgo J, Langer C, Ramadori G, Sültmann H, Füzesi L (2005): Prognostic role of E2F1 and members of the CDKN2A network in gastrointestinal stromal tumors. Clin Cancer Res 18, 6589-6597 
Haller F, Happel N, Schulten HJ, von Heydebreck A, Schwager S, Armbrust T, Langer C, Gunawan B, Doenecke D, Füzesi L (2007): Site-dependent differential KIT and PDGFRA expression in gastric and intestinal gastrointestinal stromal tumors. Mod Pathol 20, 1103-1111

Haller F, Löbke C , Ruschhaupt M, Cameron S, Schulten H-J, Schwager S, von Heydebreck A, Gunawan B, Langer C, Ramadori G, Sültmann H, Poustka A, Korf U, Füzesi L (2008a): Loss of 9p leads to p16INK4A down-regulation and enables RB/E2F1dependent cell cycle promotion in gastrointestinal stromal tumours (GISTs). J Pathol $\underline{215}, 253-262$

Haller F, Löbke C, Ruschhaupt M, Schulten H-J, Schwager S, Gunawan B, Armbrust T, Langer C, Ramadori G, Sültmann H, Poustka A, Korf U, Füzesi L (2008b): Increased KIT signalling with up-regulation of cyclin D correlates to accelerated proliferation and shorter disease-free survival in gastrointestinal stromal tumours (GISTs) with KIT exon 11 deletions. J Pathol 216, 225-235

Hanau CA, Miettinen M (1995): Solitary fibrous tumor: Histological and immunohistochemical spectrum of benign and malignant variants presenting at different sites. Hum Pathol 26, 440-449

Heinrich MC, Corless CL, Demetri GD, Blanke CD, von Mehren M, Joensuu H, McGreevey LS, Chen CJ, Van den Abbeele AD, Druker BJ, Kiese B, Eisenberg B, Roberts PJ, Singer S, Fletcher CD, Silberman S, Dimitrijevic S, Fletcher JA (2003a): Kinase mutations and imatinib response in patients with metastatic gastrointestinal stromal tumor. J Clin Oncol 21, 4342-4349

Heinrich MC, Corless CL, Duensing A, McGreevey L, Chen CJ, Joseph N, Singer S, Griffith DJ, Haley A, Town A, Demetri GD, Fletcher CD, Fletcher JA (2003b): PDGFRA activating mutations in gastrointestinal stromal tumors. Science 299, 708710

Hirota S, Isozaki K, Moriyama Y, Hashimoto K, Nishida T, Ishiguro S, Kawano K, Hanada M, Kurata A, Takeda M, Muhammad Tunio G, Matsuzawa Y, Kanakura Y, 
Shinomura Y, Kitamura Y (1998): Gain-of-function mutations of c-kit in human gastrointestinal stromal tumors. Science $\underline{279}, 577-580$

Hirota S, Ohashi A, Nishida T, Isozaki K, Kinoshita K, Shinomura Y, Kitamura Y (2003): Gain-of-function mutations of platelet-derived growth factor receptor $\alpha$ Gene in gastrointestinal stromal tumors. Gastroenterology 125, 660-667

Irby RB, Yeatman TJ (2000): Role of Src expression and activation in human cancer, Oncogene 19, 5636-5642

Jin P, Hardy S, Morgan DO (1998): Nuclear localization of cyclin B controls mitotic entry after DNA damage. J Cell Biol 141, 875-885.

Kim SH, Lewis JJ, Brennan MF, Woodruff JM, Dudas M, Cordon-Cardo C (1998): Overexpression of cyclin D1 is associated with poor prognosis in extremity soft-tissue sarcomas. Clin Cancer Res ㄴ, 2377-2382

Kindblom LG, Remotti HE, Aldenborg F, Meis-Kindblom JM (1998): Gastrointestinal pacemaker cell tumor (GIPACT): gastrointestinal stromal tumors show phenotypic characteristics of the interstitial cells of Cajal. Am J Pathol 152, 1259-1269

Koon N, Schneider-Stock R, Sarlomo-Rikala M, Lasota J, Smolkin M, Petroni G, Zaika A, Boltze C, Meyer F, Andersson L, Knuutila S, Miettinen M, El-Rifai W (2004): Molecular targets for tumour progression in gastrointestinal stromal tumours. Gut $\underline{2}$ : $235-240$

Lammie GA, Fanti V, Smith R, Schuuring E, Brookes S, Michalides R, Dickson C, Arnold A, Peters G (1991): D11S287, a putative oncogene on chromosome 11q13, is amplified and expressed in squamous cell and mammary carcinomas and linked to BCL-1. Oncogene 6 , 439-444

Lasota J, Miettinen M (2008): Clinical significance of oncogenic KIT and PDGFRA mutations in gastrointestinal stromal tumours. Histopathology $\underline{53}, 245-266$ 
Lasota J, Dansonka-Mieszkowska A, Sobin LH, Miettinen M (2004): A great majority of GISTs with PDGFRA mutations represent gastric tumors of low or no malignant potential. Lab Invest $\underline{84}$, 874-883

Lasota J, Wang ZF, Sobin LH, Miettinen M (2009): Gain-of-function PDGFRA mutations, earlier reported in gastrointestinal stromal tumors, are common in small intestinal inflammatory fibroid polyps. A study of 60 cases. Mod Pathol $\underline{8}, 1049-1056$

Lavoie JN, L’Allemain G, Brunet A, Muller R, Pouyssegur J (1996): Cyclin D1 expression is regulated positively by the p42/p44MAPK and negatively by the p38/HOGMAPK pathway. J Biol Chem 271, 20608-20616

Lawrence B, Perez-Atayde A, Hibbard MK, Rubin BP, Dal Cin P, Pinkus JL, Pinkus GS, Xiao S, Yi ES,. Fletcher CDM, Fletcher JA (2000): TPM3-ALK and TPM4-ALK oncogenes in inflammatory myofibroblastic tumors. Am J Pathol 2, 377-384

Lazar AJ, Tuvin D, Hajibashi S, Habeeb S, Bolshakov S, Mayordomo-Aranda E, Warneke CL, Lopez-Terrada D, Pollock RE, Lev D (2008): Specific mutations in the beta-catenin gene (CTNNB1) correlate with local recurrence in sporadic desmoid tumors. Am J Pathol $\underline{5}, 1518-1527$

Leithner A, Gapp M, Radl R, Pascher A, Krippl P, Leithner K, Windhager R, Beham A (2005): Immunohistochemical analysis of desmoid tumours. J Clin Pathol $\underline{58}, 1152-$ 1156

Lennartsson J, Jelacic T, Linnekin D, Shivakrupa R (2005): Normal and oncogenic forms of the receptor tyrosine kinase kit. Stem Cells $\underline{23}$, 16-43

Lerma E, Oliva E, Tugues D, Prat J (1994): Stromal tumours of the gastrointestinal tract: a clinicopathological and ploidy analysis of 33 cases. Virchows Arch 424, 19-24

Levin VA (2004): Basis and importance of Src as a target in cancer. Cancer Treat Res $\underline{119}$, 89-119 
Lewis JJ, Brennan MR (1996): Soft tissue sarcomas. Curr Probl Surg 33, 817-872

Liegl B, Leithner A, Bauernhofer T, Windhager R, Guelly C, Regauer S, Beham A (2006): Immunohistochemical and mutational analysis of PDGF and PDGFR in desmoid tumours: is there a role for tyrosine kinase inhibitors in c-kit-negative desmoid tumours? Histopathology $\underline{49}$, 576-581

Lukas J, Petersen BO, Holm K, Bartek J, Helin K (1996): Deregulated expression of E2F family members induces S-phase entry and overcomes p16INK4Amediated growth suppression. Mol Cell Biol 16, 1047-1057

Lundberg AS, Weinberg RA (1998): Functional inactivation of the retinoblastoma protein requires sequential modification by at least two distinct cyclin-cdk complexes. Mol Cell Biol 18, 753-761

Lyman SD, Jacobsen SE (1998): C-kit ligand and Flt3 ligand: stem/ progenitor cell factors with overlapping yet distinct activities, Blood 91, 1101-1134

MacCallum DE, Hall PA (1999): Biochemical characterization of pKi67 with the identification of a mitotic-specific form associated with hyperphosphorylation and altered DNA binding. Exp Cell Res 252, 186-198

Mechtersheimer G, Lehnert T, Penzel R, Joos S, Egerer G, Otto HF (2003): Gastrointestinal stromal tumors. A morphologic and molecular genetic independent tumor entity with new therapeutic perspectives. Pathologe 24, 182-191

Mentzel T, Bainbridge TC, Katenkamp D (1997): Solitary fibrous tumour: clinicopathological, immunohistochemical and ultrastructural analysis of 12 cases arising in soft tissues, nasal cavity and nasopharynx, urinary bladder and prostate. Virchows Arch 430, 445-453

Miettinen M, Lasota J (2001): Gastrointestinal stromal tumors--definition, clinical, histological, immunohistochemical, and molecular genetic features and differential diagnosis. Virchows Arch 438, 1-12 
Miettinen M, Fetsch J F (2006): Evaluation of biological potential of smooth muscle tumours. Histopathology $\underline{48}, 97-105$

Miettinen M, Lasota J (2006): Gastrointestinal stromal tumors: review on morphology, molecular pathology, prognosis, and differential diagnosis. Arch Pathol Lab Med 130, $1466-1478$

Miettinen M, Sarlomo-Rikala J, Lasota J (1999): Gastrointestinal stromal tumors - new findings on their biology. A review. Hum Pathol 23, 1209-1220

Miettinen M, Sobin LH, Sarlomo-Rikala M (2000a): Immunohistochemical spectrum of GISTs at different sites and their differential diagnosis with a reference to CD117 (KIT). Mod Pathol 10, 1134-1142

Miettinen M, Sarlomo-Rikala M, Sobin LH, Lasota J (2000b): Esophageal stromal tumors - a clinicopathologic, immunohistochemical and molecular genetic study of seventeen cases and comparison with esophageal leiomyomas and leiomyosarcomas. Am J Surg Pathol 23, 121-132

Miettinen M, Sarlomo-Rikala M, Sobin LH, Lasota J (2000c): Gastrointestinal stromal tumors and leiomyosarcomas in the colon. A clinicopathologic, immunhistochemical, and molecular genetic study of 44 cases. Am J Surg Pathol 24, 1339-1352

Miettinen M, Sarlomo-Rikala M, Sobin LH (2001a): Mesenchymal tumors oft he muscularis mucosae of colon and rectum are benign leiomyomas that should be separated from gastrointestinal stromal tumors - a clinicopathologic and immunhistochemical study of eighty-eight cases. Mod Pathol 14, 950-956

Miettinen M, Shekitka KM, Sobin LH (2001b): Schwannomas in the colon and rectum, A clinicopathologic and immunohistochemical study of 20 cases. Am J Surg Pathol 7, 846-855 
Miettinen M, Furlong M, Sarlomo-Rikala M, Burke A, Sobin LH, Lasota J (2001c): Intramural leiomyomas, and leiomyosarcomas in the rectum and anus. A clinicopathologic, immunohistochemical and molecular genetic study of 144 cases. Am J Surg Pathol $\underline{9}, 1121-1133$

Miettinen M, El-Rifai W, Sobin LH, Lasota J (2002): Evaluation of malignancy and prognosis of gastrointestinal stromal tumors: a review. Hum Pathol $\underline{33}$, 478-483

Miettinen M, Kopczynski J, Makhlouf HR, Sarlomo-Rikala M, Gyorffy H, Burke A, Sobin LH, Lasota J (2003): Gastrointestinal stromal tumors, intramural leiomyomas, and leiomyosarcomas in the duodenum, A clinicopathologic, immunohistochemical, and molecular genetic study of 167 cases. Am J Surg Pathol $\underline{5}$, 625-641

Miettinen M, Leslie H, Sobin LH, Lasota J (2009a): True smooth muscle tumors of the small intestine. A clinicopathologic, immunhistochemical, and molecular genetic study of 25 cases, Am J Surg Pathol 33, 430-436

Miettinen M, Wang Z-F, Lasota J (2009b): DOG1 Antibody in the differential diagnosis of gastrointestinal stromal tumors. A study of 1840 cases. Am J Surg Pathol 33, 14011408

Monihan JM, Carr NJ, Sobin LH (1994): CD34 immunoexpression in stromal tumours of the gastrointestinal tract and in mesenteric fibromatoses. Histopathology $\underline{25}$, 469-473

Motokura, T, Bloom T, Kim HG, Juppner H, Ruderman JV, Kronenberg HM, Arnold A (1991): A novel cyclin encoded by a bcl 1-linked candidate oncogene. Nature (London) 350, 512-515

Müller H, Bracken AP, Vernell R, Moroni MC, Christians F, Grassilli E, Prosperini E, Vigo E, Oliner JD, Helin K (2001): E2Fs regulate the expression of genes involved in differentiation, development, proliferation, and apoptosis. Genes Dev $\underline{15}$, 267-285

Murray AW (1993): Cell-cycle control: turning on mitosis. Curr Biol $\underline{5}$, 291-293 
Nakai N, Ishikawa T, Nishitani A, Liu NN, Shincho M, Hao H, Isozaki K, Kanda T, Nishida T, Fujimoto J, Hirota S (2008): A mouse model of a human multiple GIST family with KITAsp820Tyr mutation generated by a knock-in strategy. J Pathol 214, 302-311

Nakamura N, Yamamoto H, Yao T, Oda Y, Nishiyama K, Imamura M, Yamada T, Nawata H, Tsuneyoshi M (2005): Prognostic significance of expressions of cell-cycle regulatory proteins in gastrointestinal stromal tumor and the relevance of the risk grade. Hum Pathol 36, 828-837

Ortega S, Malumbres M, Barbacid M (2002): Cyclin D-dependent kinases, INK4 inhibitors and cancer. Biochim Biophys Acta 1602, 73-87

Pantanowitz L, Antoniol DA, Pinkus GS, Shahsafaei A, Odze R (2004): Inflammatory fibroid polyps of the gastrointestinal tract evidence for a dendritic cell origin, Am $\mathrm{J}$ Surg Pathol 28, 107-114

Pardee AB (1989): G1 events and regulation of cell proliferation. Science 246, 603-608

Pauls K, Merkelbach-Bruse S, Thal D, Buttner R,Wardelmann E (2005): PDGFRA- and c-kitmutated gastrointestinal stromal tumours (GISTs) are characterized by distinctive histological and immunohistochemical features. Histopathology 46, 166-175

Pawson T (2002): Regulation and targets of receptor tyrosine kinases. Eur J Cancer 38; 3-10

Penzel R, Aulmann S, Moock M, Schwarzbach M, Rieker RJ, Mechtersheimer G (2005): The location of KIT and PDGFRA gene mutations in gastrointestinal stromal tumours is site and phenotype associated. J Clin Pathol 58, 634-639

Peterson MR, Piao Z, Weidner N, Yi ES (2006): Strong PDGFRA positivity is seen in GISTs but not in other intra-abdominal mesenchymal tumors: immunhistochemical and mutational analyses. Appl Immunhistochem Mol Morphol 4, 390-396 
Pines J, Hunter T (1989): Isolation of a human cyclin cDNA: evidence for cyclin mRNA and protein regulation in the cell cycle and for interaction with p34cdc2. Cell 58, 833-846

Prevot S, Bienvenu L, Vaillant JC, de Saint-Maur PP (1999): Benign schwannoma of the digestive tract: a clinicopathologic and immunhistochemical study of five case, including a case of esophageal tumor. Am J Surg Pathol 23, 431-436

Rizeq MN, van de Rijn M, Hendrickson MR, Rouse RV (1994): A comparative immunohistochemical study of uterine smooth muscle neoplasms with emphasis on the epithelioid variant. Hum Pathol 25, 671-677

Rodriguez JA, Guarda LA, Rosai J (2004): Mesenteric fibromatosis with involvement of the gastrointestinal tract .A GIST simulator: a study of 25 cases. Am J Clin Pathol $\underline{121}$, 93-98

Rönnstrand L (2004): Signal transduction via the stem cell factor receptor/c-Kit. Cell Mol Life Sci $\underline{61}$, 2535-2548

Rosenwald IB, Lazaris-Karatzas A, Sonenberg N, V. Schmidt E (1993): Elevated levels of Cyclin D1 protein in response to increased expression of eukaryotic initiation factor 4E. Mol Cell Biol 12, 7358-7363

Roskoski R Jr (2004): Src protein-tyrosine kinase structure and regulation. Biochem Biophys Res Commun 324, 1155-1164

Roskoski R Jr (2005a): Signaling by Kit protein-tyrosine kinase--the stem cell factor receptor. Biochem Biophys Res Commun $\underline{337}$, 1-13

Roskoski R Jr (2005b): Structure and regulation of Kit protein-tyrosine kinase--the stem cell factor receptor. Biochem Biophys Res Commun $\underline{338}, 1307-1315$

Roskoski R Jr (2005c): Src kinase regulation by phosphorylation and dephosphorylation. Biochem Biophys Res Commun $\underline{331}, 1-14$ 
Rossi G, Valli R, Bertolini F, Marchioni A, Cavazza A, Mucciarini C, Migaldi M, Federico M, Trentini BP, Sgambato A (2005): PDGFR expression in differential diagnosis between KIT-negative gastrointestinal stromal tumours and other primary soft-tissue tumours of the gastrointestinal tract. Histopathology 46, 522-531

Rubin BP, Singer S, Tsao C, Duensing A, Lux ML, Ruiz R, Hibbard MK, Chen CJ, Xiao S, Tuveson DA,Demetri GD, Fletcher CD, Fletcher JA (2001): KIT activation is a ubiquitous feature of gastrointestinal stromal tumors. Cancer Res 61, 8118 - 8121

Rubin BP, Antonescu CR, Scott-Browne JP, Comstock ML, Gu Y, Tanas MR, Ware CB, Woodell J (2005): A knock-in mouse model of gastrointestinal stromal tumor harboring kit K641E. Cancer Res 65, 6631-6639

Ruggero D, Sonenberg N (2005): The Akt of translational control. Oncogene $\underline{24}$, 7426-7434

Sabah M, Cummins R, Leader M, Kay E (2006): Altered expression of cell cycle regulatory proteins in gastrointestinal stromal tumors: markers with potential prognostic implications. Hum Pathol 37, 648-655

Schildhaus H-U, Cavlar T, Binot E, Büttner R, Wardelmann E, Merkelbach-Bruse S (2008): Inflammatory fibroid polyps harbour mutations in the platelet-derived growth factor receptor alpha (PDGFRA) gene, J Pathol 216, 176-182

Scholzen T, Gerdes J (2000): The Ki-67 protein: from the known and the unknown. J Cell Physiol 182, 311-322

Seremetis MG, Lyons WS, deGuzman VC, Peabody JW (1976): Leiomyomata of the esophagus. An analysis of 838 cases. Cancer $\underline{38}$, 2166-2177

Shidham VB, Chivukula M, Gubta D, Rao RN, Komorowski R (2002): Immunhistochemical comparison of gastrointestinal stromal tumors and solitary fibrous tumor. Arch Pathol Lab Med 126, 1189-1192 
Singer S, Rubin BP, Lux ML, Chen C-J, Demetri GD, Fletcher CDM, Fletcher JA (2002): Prognostic value of KIT mutation type, mitotic activity, and histologic subtype in Gastrointestinal Stromal Tumors. J Clin Oncol 18, 3898-3905

Sommer G, Agosti V, Ehlers I, Rossi F, Corbacioglu S, Farkas J, Moore M, Manova K, Antonescu CR, Besmer P (2003): Gastrointestinal stromal tumors in a mouse model by targeted mutation of the Kit receptor tyrosine kinase. Proc Natl Acad Sci USA $\underline{100}$, 6706-6711

Soriano P (1997): The PDGFR alpha receptor is required for neural crest cell survival and for normal patterning of the somites. Development $\underline{124}$, 2691-2700

Stover DR, Furet P, Lydon NB (1996): Modulation of the SH2 binding specificity and kinase activity of Src by tyrosine phosphorylation within its SH2 domain. J Biol Chem 271, 12481-12487

Thomas SM, Brugge JS (1997): Cellular functions regulated by Src family kinases. Annu Rev Cell Dev Biol 13, 513-609

Tuveson DA, Willis NA, Jacks T, Griffin JD, Singer S, Fletcher CD, Fletcher JA, Demetri GD (2001): STI571 inactivation of the gastrointestinal stromal tumor c-KIT oncoprotein: biological and clinical implications. Oncogene 20, 5054-5058

Vernell R, Helin K, Müller H (2003): Identification of target genes of the p16INK4A-pRBE2F pathway. J Biol Chem 278, 46124-46137

Wang C, Li Z, Fu M, Bouras T, Pestell RG (2004): Signal transduction mediated by cyclin D1: from mitogens to cell proliferation: a molecular target with therapeutic potential. Cancer Treat Res 119, 217-237

Wardelmann E, Hrychyk A, Merkelbach-Bruse S, Pauls K, Goldstein J, Hohenberger P, Losen I, Manegold C, Büttner R, Pietsch T (2004): Association of platelet-derived 
growth factor receptor alpha mutations with gastric primary site and epithelioid or mixed cell morphology in gastrointestinal stromal tumors. J Mol Diagn $\underline{6}$, 197-204

Ware MF, Tice DA, Parsons SJ, Lauffenburger DA (1997): Overexpression of cellular Src in fibroblasts enhances endocytic internalization of epidermal growth factor receptor. $\mathrm{J}$ Biol Chem 272, 30185-30190

Wasag B, Debiec-Rychter M, Pauwels P, Stul M, Vranckx H, Van Oosterom A, Hagemeijer A, Sciot R (2004): Differential expression of KIT/PDGFRA mutant isoforms in epithelioid and mixed variants of gastrointestinal stromal tumors depends predominantly on the tumor site. Mod Pathol 17, 889-894

Weinberg RA (1995): The retinoblastoma protein and cell cycle control. Cell $\underline{81}$, 323-330

Williams DE, Eisenman J, Baird A, Rauch C, Van Ness K, March CJ, Park LS, Martin U, Mochizuki DY, Boswell HS, Burgess GS, Cosman D, Lyman SD (1990): Identification of a ligand for the c-kit proto-oncogene. Cell $\underline{63}, 167-174$

Withers DA, Harvey RC, Faust JB, Melnyk O, Carey K, Meeker TC (1991): Characterization of a candidate bcl-1 gene. Mol Cell Biol 11, 4846-4853

Yamaguchi U, Hasegawa T, Hirose T, Chuman H, Kawai A, Ito Y, Beppu Y (2003): Low grade malignant peripheral nerve sheath tumour: varied cytological and histological patterns. J Clin Pathol 트, 826-830

Yamaguchi U, Hasegawa T, Masuda T, Sekine S, Kawai A, Chuman H, Shimoda T (2004): Differential diagnosis of gastrointestinal stromal tumor and other spindle cell tumors in the gastrointestinal tract based on immunohistochemical analysis. Virchows Arch $\underline{445}, 142-150$

Yantiss RK, Spiro IJ, Compton CC, Rosenberg AE (2000): Gastrointestinal stromal tumors versus intra-abdominal fibromatosis of the bowel wall. A clinically important differential diagnosis. Am J Surg Pathol 24, 947-957 


\section{Danksagung:}

An erster Stelle danke ich Herrn Prof. Dr. med. László Füzesi, Leiter der Abteilung Gastroenteropathologie, für die Überlassung des Themas, für sein Mitwirken und seine fachlichen Anregungen.

Ich bedanke mich bei Herrn PD Dr. med. Florian Haller für seine vorbildliche Betreuung und stete Hilfsbereitschaft. Mein besonderer Dank gilt dabei seiner tatkräftigen Unterstützung sowohl als Betreuer als auch später als Doktorvater, mit der er maßgeblich zum Gelingen dieser Arbeit beigetragen hat.

Ich möchte mich ebenso bei Frau Dr. med. Silke Cameron und Herrn Dr. rer. nat. Robert Cameron sowie Frau Melanie Gebhardt für ihren Beitrag bei der Herstellung und Auswertung der immunhistochemischen Färbungen und ihre geduldige Hilfe bei allen praktischen Arbeiten bedanken.

Des Weiteren gilt mein Dank Herrn PD. Dr. med. Bastian Gunawan und Frau Judith WolfSálgó, die als Mitarbeiter der Abteilung Gastroenteropathologie einen Beitrag zu der vorliegenden Arbeit geleistet haben. 


\section{Lebenslauf:}

Am 23.11.1981 wurde ich in Göttingen als zweites Kind des Zahnarztes Dr. Werner Köhler und der medizinisch-technischen Assistentin Annegret Köhler geb. Hammerlik geboren.

Von 1988 bis 1992 besuchte ich die Grundschule Simmershausen und anschließend die Orientierungsstufe Gimte (OS II) in Hann. Münden.

Nach dem Wechsel auf das Grotefend-Gymnasium Münden im Jahre 1994 bestand ich dort im Juni 2001 die allgemeine Hochschulreife.

Im Oktober 2001 begann ich das Studium der Zahnheilkunde in Göttingen und legte dort Ende 2006 mein Staatsexamen ab und erhielt somit die Approbation als Zahnärztin.

Anfang des Jahres 2007 begann ich meine Doktorarbeit in der Abteilung Gastroenteropathologie im Zentrum Pathologie der Universitätsmedizin Göttingen unter Betreuung von Prof. Dr. med. László Füzesi und später PD Dr. med. Florian Haller.

Von Januar 2007 bis Januar 2009 arbeitete ich als zahnärztliche Ausbildungsassistentin in der Praxis meines Vaters in Hann. Münden.

Seit April 2009 bin ich als selbstständige Zahnärztin in Hann. Münden niedergelassen und arbeite mit meinem Vater in einer zahnärztlichen Berufsausübungsgemeinschaft. 